\title{
Concrete-filled twin-layer steel-sheet CWs system: A systematic review of the literature
}

\author{
Mustafa M. Ali ${ }^{a, b *}$ (D) S.A. Osman ${ }^{a *}$ (D) Al Zand AW ${ }^{a}$ (D), M.Y.M. Yatim ${ }^{a}$, Faesal Alatshana ${ }^{a, c}$ (D), Salam J. Hilo \\ a Department of Civil Engineering, Faculty of Engineering and Built Environment, Universiti Kebangsaan Malaysia (UKM), 43600 Bangi, \\ Selangor, Malaysia.E-mail:mma1416@yahoo.com, p86577@siswa.ukm.edu.my,saminah@ukm.edu.my, ahmedzand@ukm.edu.my, \\ ahmedzand70@gmail.com,mymy@ukm.edu.my, p94378@siswa.ukm.edu.my \\ ${ }^{\mathrm{b}}$ Department of Civil Engineering, University of Technology- Iraq. E-mail: eng.salamjh@gmail.com \\ c Department of Civil Engineering, College of Engineering Technology, Houn, Libya \\ *Corresponding author
}

https://doi.org/10.1590/1679-78256622

\begin{abstract}
Recently, the concrete-filled twin-layer steel-sheet composite wall systems (TSCWs) have become recommended by the engineers in the modern structures, since it has high energy absorption, ductility, and capacity compared to the corresponding conventional wall systems. Therefore, this paper presents and discusses the literature of researches particularly concerning this type of composite wall system. The review includes 80 papers that investigated the performance of TSCWs. These investigations classified TSCWs into two types: twin-layer flat steel sheet composite wall systems (TFSCWs) and twin-layer profiled steel-sheet composite wall systems (TPSCWs). The classification of these two types of TSCWs was based on the form of the sheeting as well as on the type of applied load. This classification introduced comprehensive mapping tables on the study details, loading, infill material, and interaction concept. Furthermore, the findings from this literature review are discussed, and the research gaps are summarized for each TSCW type, including the impact of providing an opening on the TSCWs performance.
\end{abstract}

\section{Keywords}

composite wall; twin-layer; concrete-filled steel plate; effect of opening; review paper; state of the art.

\section{Graphical Abstract}

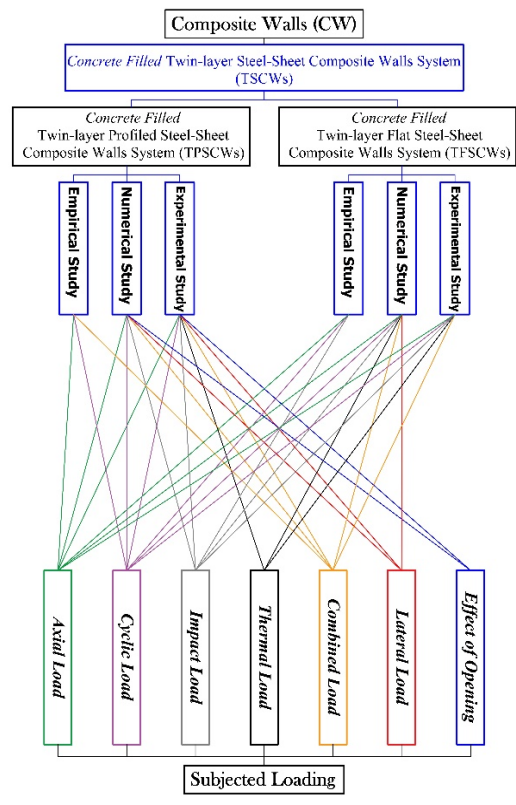




\section{Introduction}

Steel plate shear walls (SPSWs) and reinforced concrete (RC) walls are commonly used as axial, cyclic, and impact resistance members in buildings, for instance, in mid-rise and high-rise structures. Therefore, studies have been widely carried out over the last few years on several elements made of steel combined with reinforced concrete components acting together as a composite, including composite slabs, composite beams, composite columns, and composite shear walls. Also, a composite shear wall can mitigate plenty of the weaknesses of both reinforced concrete and steel shear walls, and take advantage of key features these two materials, have to offer. Generally, a steel-concrete (SC) shear wall usually consists of an RC shear wall, one or more steel plates, boundary beams and columns, and mechanical steel connectors. For instance, Figure 1 presents several compositions of the composite shear wall system, includes a combination of the steel plate and reinforced or normal concrete, which has been used in numerous buildings in the past few years Dean, Canon, and Poland (1977), for instance, the Tower of China World Trade Centre and the major hospital of San Francisco, USA.

In recent years, an extremely efficient composite wall known as a twin-layer steel composite wall system (TSCW) has been introduced and incorporated in building construction. The idea of the TSCW was initially developed from a wellknown and currently used composite flooring system that originated in the late 1990s Rafiei et al. (2013). TSCWs are beneficial as axial (bearing) and lateral (retaining) walls as well as safety-shield walls in nuclear power plants due to the exceptional materials of TSCWs and the way that the materials interact Varma, Malushte, et al. (2011). A conceptional illustration of TSCWs applications in structures is exhibited in Figure 2.

TSCWs have become favored in countless structures that require seismic resistance, which is attributed to the presence of steel plate sheeting, offering relatively high ductility resistance and shear load capacity for overload cycles Ji, Jiang, and Qian (2013) and limiting concrete fragmentation Qian, Jiang, and Ji (2012). Additionally, the TSCWs are considered an economic structure element since they can be fabricated and cast outside the site and then erected in the designed place in the structure, commonly known as an industrial building system (IBS).

TSCWs' applications include bearing walls, lateral retaining walls, and earthquake-resistant members in regular and high-rise buildings, as depicted in Figure 2. The uncomplicated assembly of TSCWs due to their convenient components, which include an external twin layer of the steel plate and mechanical connectors filled with concrete, with or without a boundary frame, is an additional motivation for using these composites in more applications.

This paper presents a systematic review, highlighting the significant information on the characteristics, performance, and responses of two different types of TSCWs under various loadings. Detailed findings from the results of previous studies are discussed and analyzed, and research gaps are identified. Further research on openings in TSCWs is also proposed. The overall research taxonomy is exhibited in Figure 3.

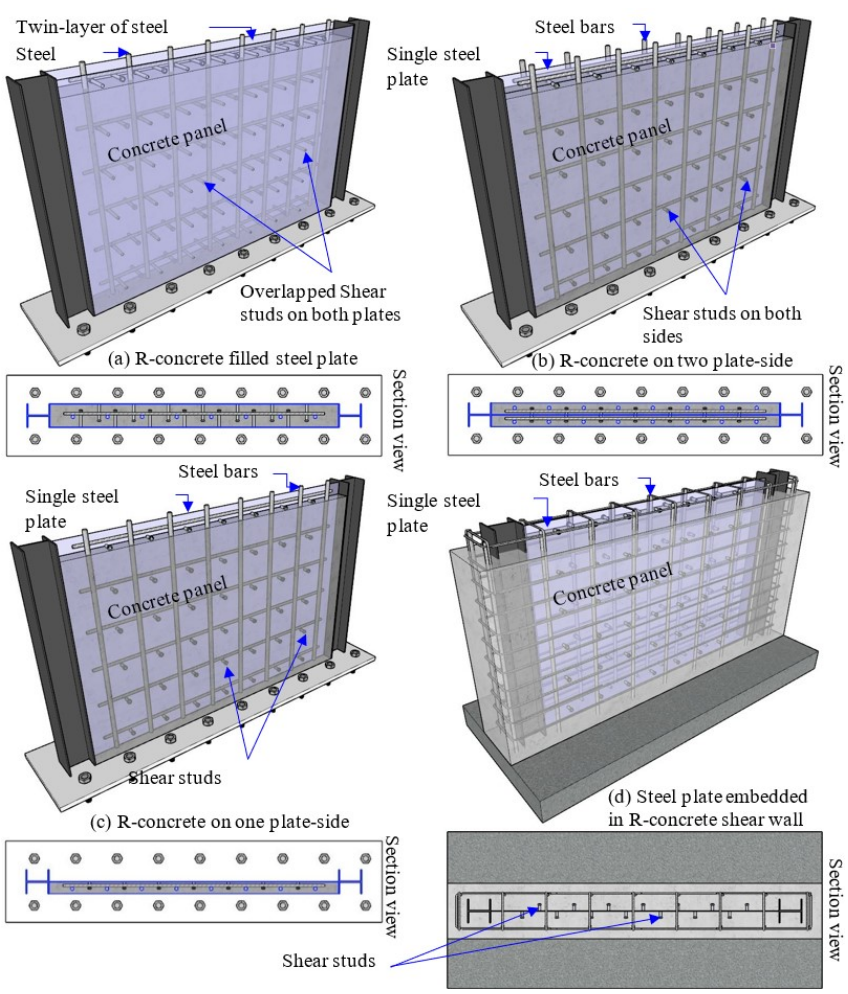

Figure 1. Traditional composition of composite shear walls 


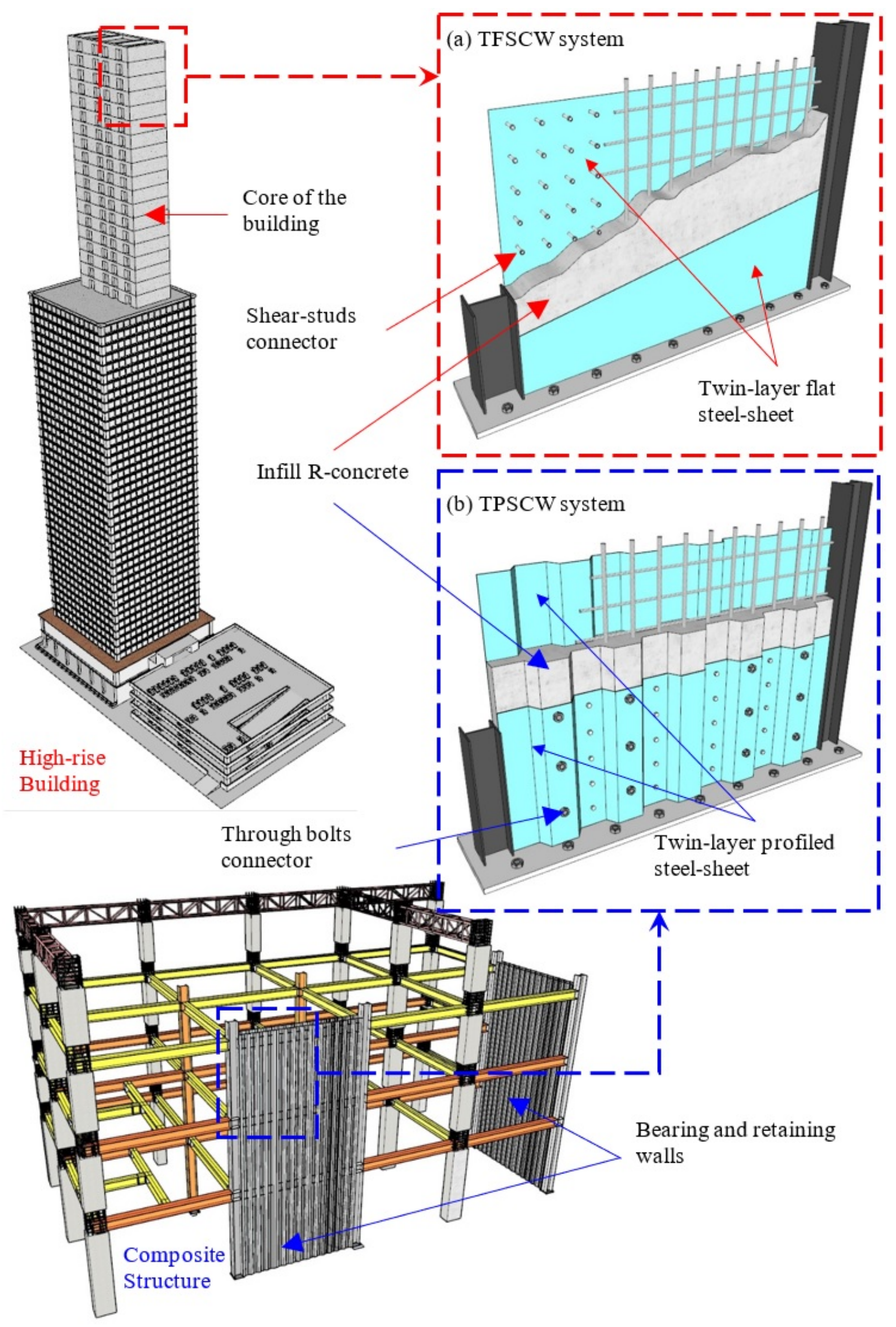

Figure 2. Conceptional application of TSCWs 


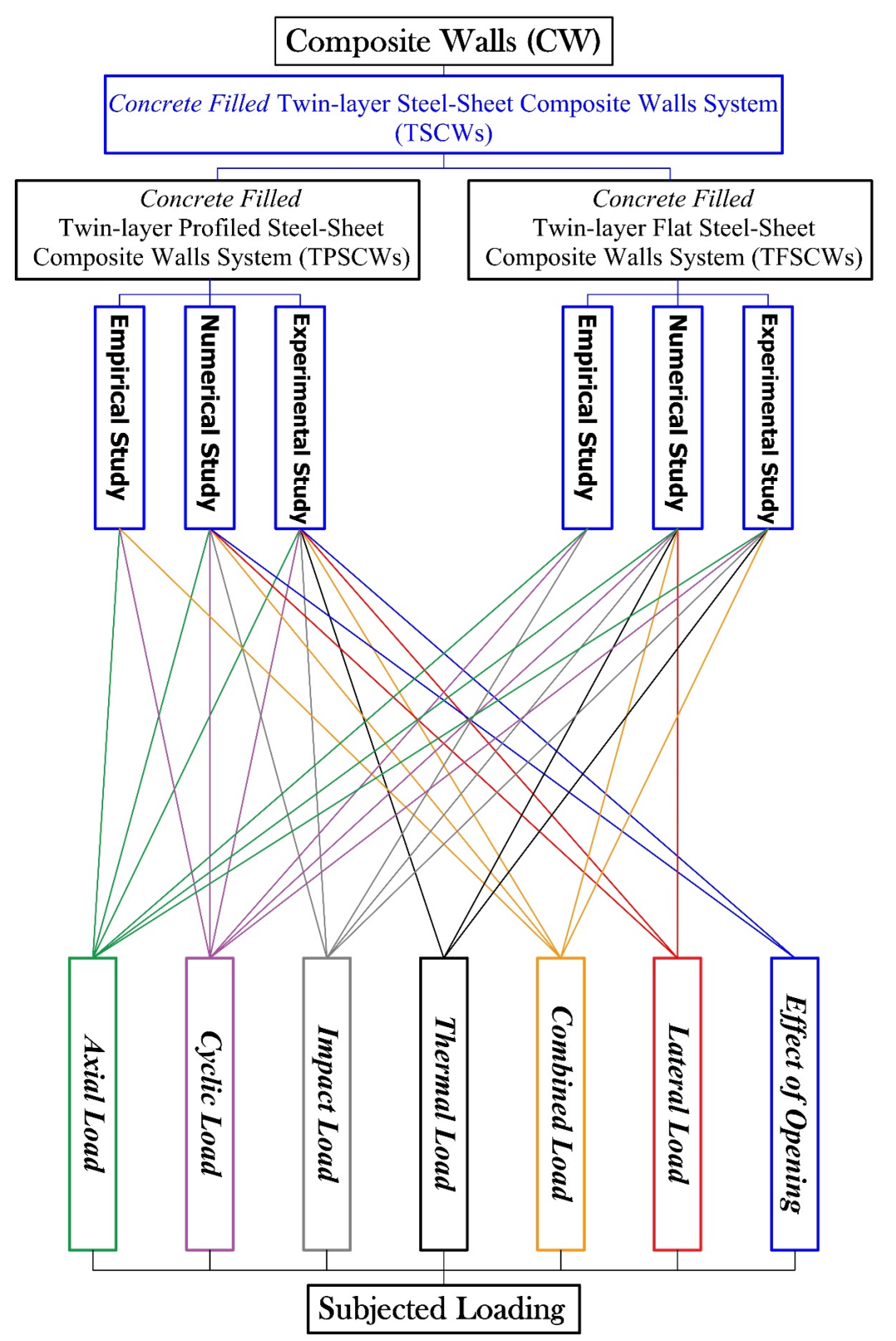

Figure 3. Taxonomy of research literature on Twin-layer composite walls

\section{Data Collection Methodology}

Extensive research has been conducted to collect relevant journal research papers and conference articles in the field of composite panels and/or walls. To this end, several online databases, subscribed by the library of UKM University, were used to collect the required data, such as Science Direct, WoS, Scopus, and ASCE exhibited in Figure 4. The search method for the studies was based on certain keywords, as stated in Figure 4. Some of these keywords were addressed to find the studies investigating composite walls' behavior in general, and others focused on the concrete-filled twinlayer of plate shear walls. Additionally, several additional criteria were adopted during collecting the data, which were (1) the language used in study writing is only English, (2) only the peer-reviewed journals and conferences articles, which are indexed in Scopus or Wos, were included in the search process, (3) studies contained a significant finding based on laboratory test, extensive analysis, and important theoretical outcomes. Some of the relevant references were excluded for inaccessibility reasons. 


\section{Research results}

The collected studies were 1769 articles/research papers conducted in between 1990 and 2020. These studies went through two phases of scanning and evaluating process, title and abstract reading, and then full reading, 1642 and 47 articles were excluded, respectively, thereby achieving 80 studies for the final review.

The collected research papers were used to produce the taxonomy shown earlier in Figure 3, which demonstrates the overall landscape of the current knowledge of TSCW systems. As presented in the resulted taxonomy, significant research efforts have been conducted to examine the behavior of TSCWs using different investigation approaches and under several loading conditions. Overall, only two main types of TSCWs were studied, namely, TSCW and TFSCW schemes. In addition, to identify the existing research gaps, Table 1 to 4 provide more detailed classification in terms of study methodology, loading nature, filling material, interaction concept, as well as the advantageous and disadvantageous of each type of TSCW system. All parts of the taxonomic system will be addressed and discussed in the subsequent sections.

\section{Data collection methodology}

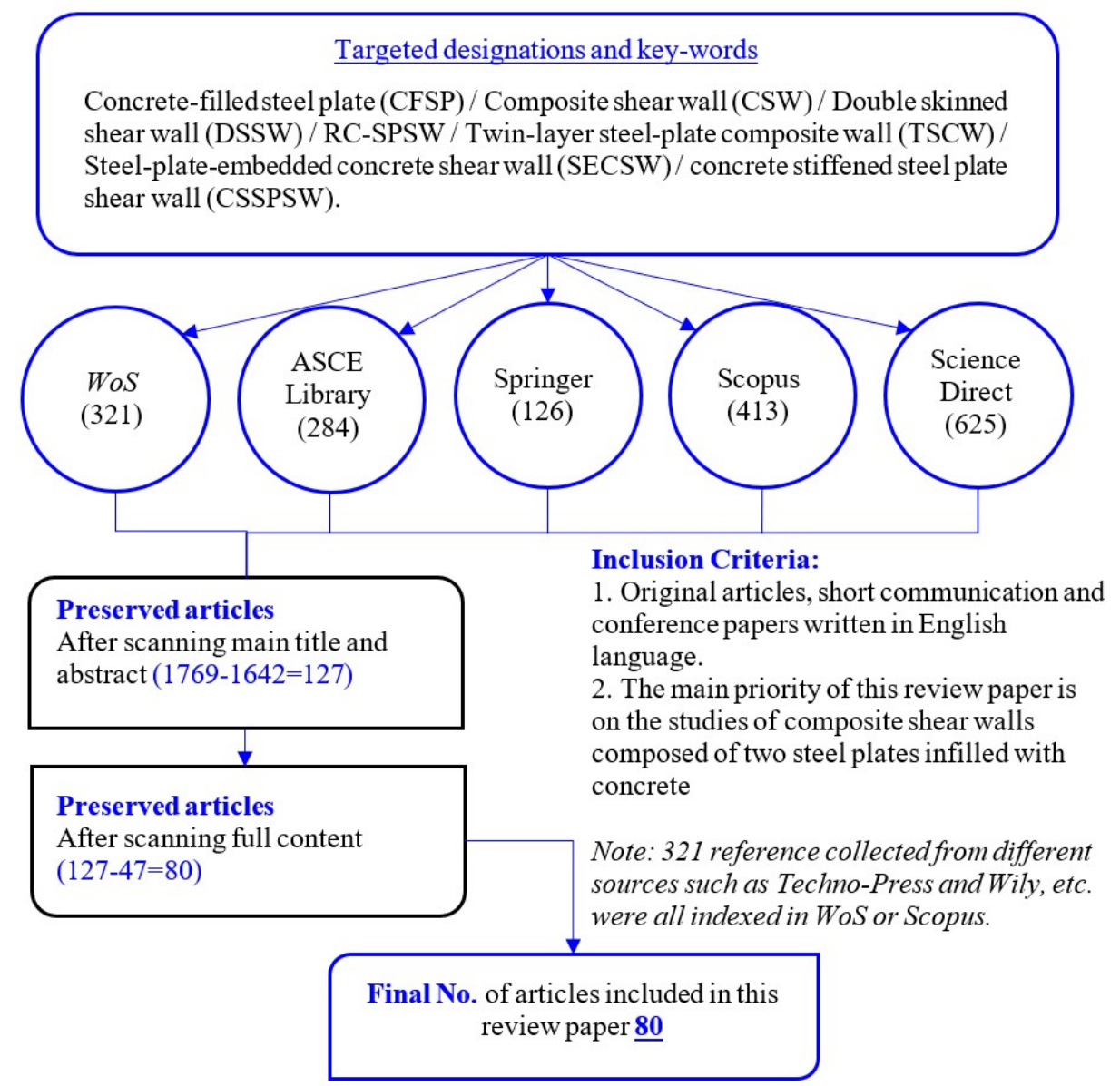

Figure 4. The process of the systematic review data collection

\subsection{Twin-Layer Steel-sheet Composite Walls (TSCWs)}

The design of TSCWs is a combination of twin layers of steel sheets (profiled or flat), filled in-between with concrete Fukumoto et al. (1987) and linked together by mechanical connectors. Previous studies proposed several types of connections to achieve the best composite behavior possible, such as headed steel shear studs, tie roads, throughthrough bolts, post-tension anchor bolts, fastener screws, hooks, batten plates, stiffeners, and normal stud connectors, to bond the steel plates and core concrete. For instance, Figure 5 exhibits some of the steel-concrete connectors used in prior research. Both the steel plate stability and loading resistance capacity were related directly by steel-concrete interaction, which restricts the steel sheet plate buckling, which is also considered concrete core reinforcement steel Wu, Kang, and Yang (2016); Petkune et al. (2016). 


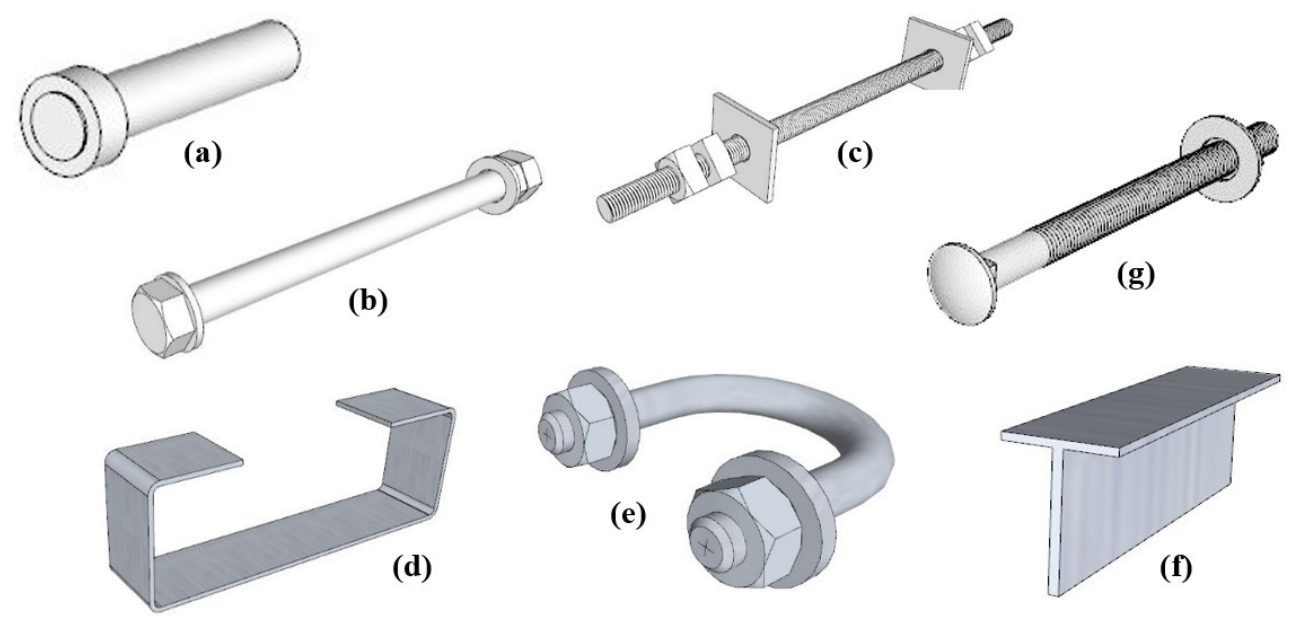

Figure 5. Steel-concrete connectors (a) Headed studs (b) Through bolt (c) Through rod (d) C-shape connector (e) U-hook (f) T-stiffener (g) Fasteners

\subsubsection{Twin-Layer Profiled Steel-Sheets Composite Walls System (TPSCW)}

The development of TPSCWs was derived from the commonly used composite flooring system Hossain and Wright (2005) and Hossain and Wright (2004d). This system was a wide range used due to its comprising both profiled steel sheets panels (SSPs) and infilled concrete making Similarly, a new type of composite walls (CWs) is the TPSCWs, containing two corrugated SSPs infilled with concrete, as shown in Figure 6, which was developed to resist axial, lateral, and cyclic loading loads. In other words, there is a potential for the TPSCW to be employed as a bearing wall, retaining wall, and shear wall. To this end, validating the load resistance of TPSCWs is the main deliberation in designing buildings' structural systems. Moreover, Table 1 exhibits the pros and cons of the TPSCWs. Considering the diversity of the prior research, current review proposed a comprehensive taxonomy to simplify the presentation and provide a deep understanding. Table 2 exhibits a summary of this section.

Table 1 - Advantages and disadvantages of TPSCW wall system

\begin{tabular}{|c|c|}
\hline \multicolumn{2}{|c|}{ TPSCW wall system } \\
\hline Advantages & Disadvantages \\
\hline $\begin{array}{l}\text { Short construction period compared with other CWs which } \\
\text { required formwork }\end{array}$ & $\begin{array}{l}\text { It has a corrugated outside shape which makes it } \\
\text { architecturally challenging especially at open spaces }\end{array}$ \\
\hline $\begin{array}{l}\text { - Significantly function as a bearing wall as it resists the } \\
\text { vertical profiled sheet local buckling }\end{array}$ & - Relatively insufficient to resist lateral and/or cyclic loads \\
\hline - It is moderately accepted in terms of construction cost & $\begin{array}{c}\cdot \text { Thin TPSCWs might requires self consolidating or high } \\
\text { workability concrete with smaller coarse aggregate size to prevent } \\
\text { the segregation phenomenon }\end{array}$ \\
\hline $\begin{array}{l}\text { - Simple construction and implementation as a partition wall } \\
\text { and/or shear wall }\end{array}$ & $\begin{array}{l}\text { Compared with the embedded steel sheet CWs, TPSCWs are } \\
\text { less thermal resistance as the profiled steel sheet will be exposed } \\
\text { to the thermal load directly }\end{array}$ \\
\hline $\begin{array}{l}\text { - It can be assembled under an industrial building system } \\
\text { (IBM) }\end{array}$ & $\begin{array}{l}\text {-As a bearing wall, TPSCW system mostly failed when the } \\
\text { twin-layer of profiled sheets start to buckle outward due to the } \\
\text { extreme compressive pressure generated axially on the wall }\end{array}$ \\
\hline $\begin{array}{c}\text { - Easy to construct it with different moderate capacities } \\
\text { considering the availability of the profiled sheets at the market } \\
\text { with a different light-gauge thickness }\end{array}$ & $\begin{array}{c}\text { - Generally, TSCW has less fire resistance compared with CWs } \\
\text { which has embedded plates, and that attributed to the TSCWs } \\
\text { configuration which expose the plated sheets to the external } \\
\text { factores directly }\end{array}$ \\
\hline \multicolumn{2}{|l|}{$\begin{array}{l}\text { Easy to apply an opening on it to generate a window and/or } \\
\qquad \text { a door }\end{array}$} \\
\hline - It can be assembled as a thin and lightweight & \\
\hline
\end{tabular}




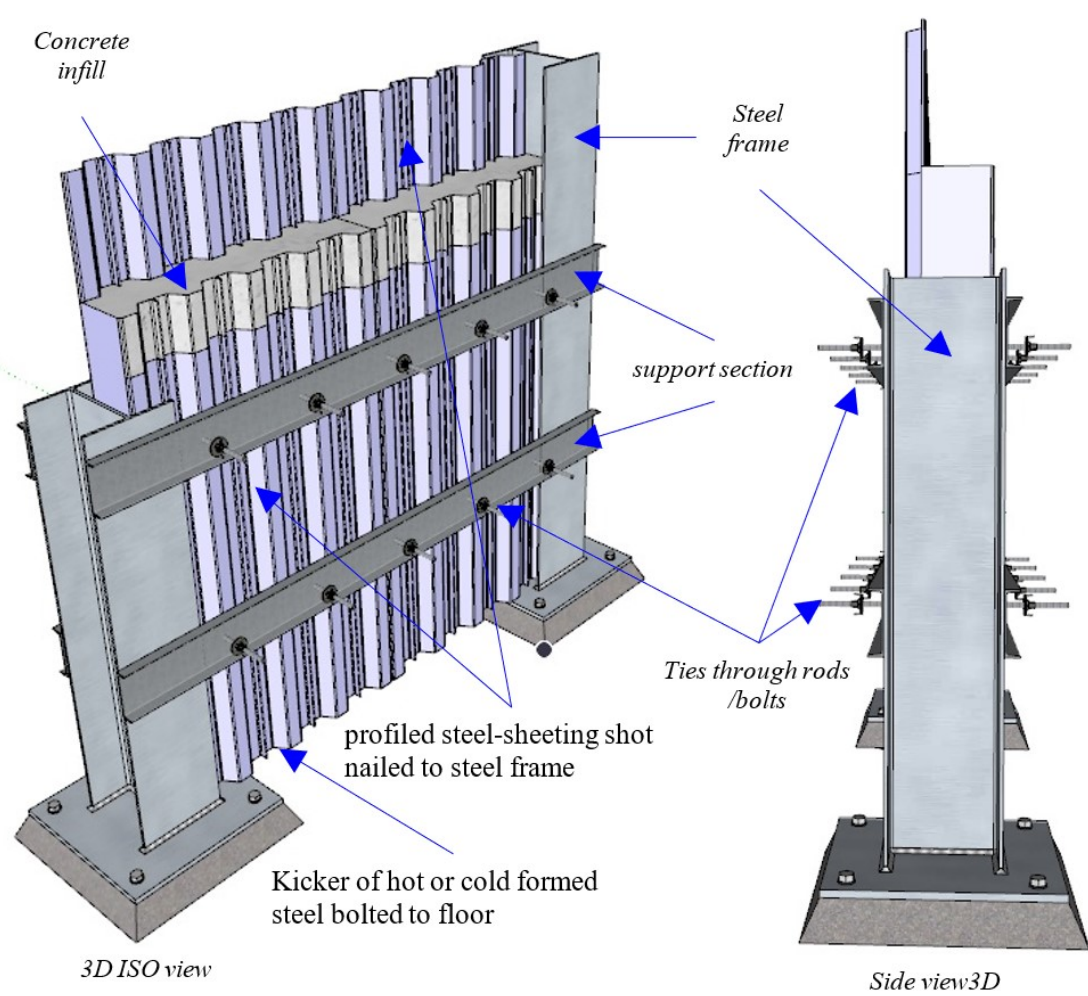

Figure 6. TPSCWs general concept

Table 2 - Categorized summary of previous TPSCWs case studies.

\begin{tabular}{|c|c|c|c|c|c|c|c|c|c|c|c|c|c|c|c|c|c|c|}
\hline \multirow[b]{2}{*}{ No. } & \multirow[b]{2}{*}{ The References } & \multicolumn{3}{|c|}{ Study type } & \multicolumn{6}{|c|}{ Loading type } & \multicolumn{4}{|c|}{ Filler type } & \multicolumn{4}{|c|}{ Interaction Type Concept } \\
\hline & & 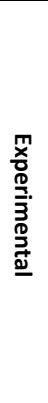 & $\begin{array}{l}\underline{z} \\
\mathbf{2} \\
3 \\
\underline{0} \\
\underline{\underline{3}} . \\
\underline{\underline{3}}\end{array}$ & $\begin{array}{l}\text { 罢 } \\
\text { 홀. } \\
\underline{\underline{3}}\end{array}$ & 吝. & 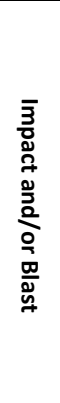 & 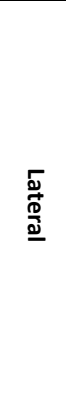 & $\underset{\substack{n \\
\bar{n}}}{2}$ & 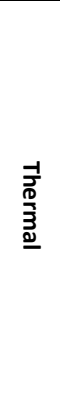 & $\begin{array}{l}\delta \\
\frac{\delta}{3} \\
\frac{5}{3} \\
\frac{0}{2}\end{array}$ & 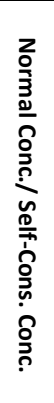 & 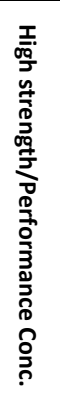 & 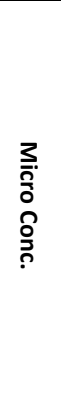 & 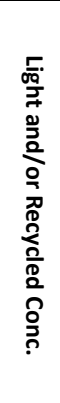 & 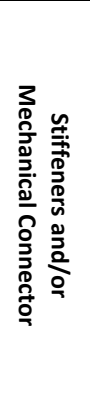 & 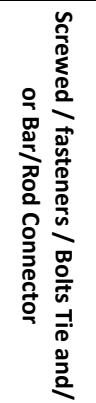 & 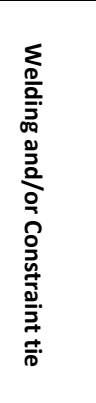 & 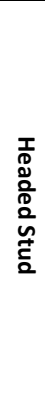 \\
\hline 1 & Rafiei et al. (2013) & & $\bullet$ & & & & $\bullet$ & & & & $\bullet$ & & & & & $\bullet$ & & \\
\hline 2 & $\begin{array}{l}\text { Hilo, Wan } \\
\text { Badaruzzaman, } \\
\text { et al. (2015) }\end{array}$ & $\bullet$ & & & $\bullet$ & & & & & & $\bullet$ & & & & & $\bullet$ & & \\
\hline 3 & Rafiei et al. (2015) & $\bullet$ & & & & & $\bullet$ & & & & $\bullet$ & & & & & • & & \\
\hline 4 & $\begin{array}{l}\text { Hossain and } \\
\text { Wright (2004) }\end{array}$ & $\bullet$ & & • & $\bullet$ & & & & & & $\bullet$ & & & & $\bullet$ & $\bullet$ & & \\
\hline 5 & $\begin{array}{l}\text { Hossain and } \\
\text { Wright (2005) }\end{array}$ & & $\bullet$ & & & & $\bullet$ & & & & $\bullet$ & & & & $\bullet$ & & & \\
\hline 6 & $\begin{array}{l}\text { Wright and } \\
\text { Gallocher (1995) }\end{array}$ & $\bullet$ & & & $\bullet$ & & & & & & & $\bullet$ & & & $\bullet$ & & & \\
\hline 7 & Wright (1998) & $\bullet$ & & & $\bullet$ & & & & & & $\bullet$ & & & & $\bullet$ & & & \\
\hline 8 & Hilo et al. (2015a) & & $\bullet$ & & $\bullet$ & & & & & & $\bullet$ & & & & - & & & \\
\hline 9 & Hilo et al. (2016) & & $\bullet$ & & $\bullet$ & & & & & & $\bullet$ & & & & $\bullet$ & & & \\
\hline 10 & Hilo et al. (2014) & & $\bullet$ & & $\bullet$ & & & & & & $\bullet$ & & & & & & & \\
\hline 11 & Rafiei et al. (2010) & & $\bullet$ & & & & $\bullet$ & & & & $\bullet$ & & & & & $\bullet$ & & \\
\hline 12 & $\begin{array}{l}\text { Prabha et al. } \\
\text { (2013) }\end{array}$ & $\bullet$ & & & $\bullet$ & & & & & & & & & $\bullet$ & & $\bullet$ & & • \\
\hline 13 & $\begin{array}{l}\text { Mydin and Wang } \\
\text { (2011) }\end{array}$ & $\bullet$ & & & $\bullet$ & & & & & & & & & $\bullet$ & & $\bullet$ & & \\
\hline 14 & $\begin{array}{l}\text { Hossain and } \\
\text { Wright (1998a) }\end{array}$ & $\bullet$ & & & $\bullet$ & & & & & & & & $\bullet$ & & & $\bullet$ & & \\
\hline
\end{tabular}


Table 2 - Continued...

\begin{tabular}{|c|c|c|c|c|c|c|c|c|c|c|c|c|c|c|c|c|c|c|}
\hline \multirow[b]{2}{*}{ No. } & \multirow[b]{2}{*}{ The References } & \multicolumn{3}{|c|}{ Study type } & \multicolumn{6}{|c|}{ Loading type } & \multicolumn{4}{|c|}{ Filler type } & \multicolumn{4}{|c|}{ Interaction Type Concept } \\
\hline & & 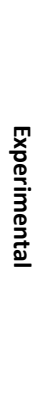 & 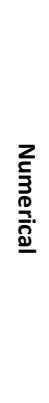 & 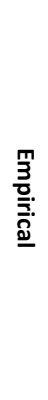 & 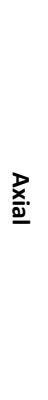 & 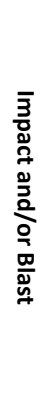 & 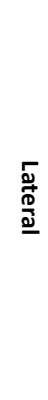 & হa & 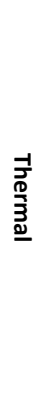 & $\begin{array}{l}\frac{2}{3} \\
\frac{0}{3} \\
\frac{0}{0} \\
\frac{1}{2}\end{array}$ & 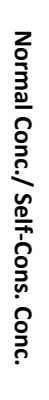 & 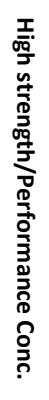 & 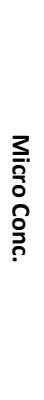 & 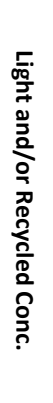 & 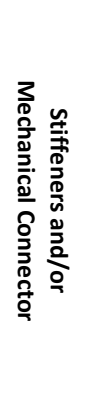 & 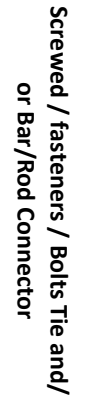 & 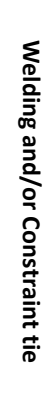 & 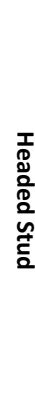 \\
\hline 15 & $\begin{array}{c}\text { Hossain and } \\
\text { Wright (1998) }\end{array}$ & & $\bullet$ & & $\bullet$ & & & & & & $\bullet$ & & & & & • & & \\
\hline 16 & $\begin{array}{c}\text { Bradford, } \\
\text { Wright, and Uy } \\
\text { (1998) }\end{array}$ & & & $\bullet$ & $\bullet$ & & & & & & $\bullet$ & & & & $\bullet$ & & & \\
\hline 17 & $\begin{array}{c}\text { Wright, Hossain, } \\
\text { and Gallocher } \\
\text { (1994) }\end{array}$ & $\bullet$ & $\bullet$ & & & & $\bullet$ & & & & $\bullet$ & & & & & $\bullet$ & & \\
\hline 18 & $\begin{array}{l}\text { Labibzadeh and } \\
\text { Hamidi (2019) }\end{array}$ & & $\bullet$ & & $\bullet$ & & & & & & $\bullet$ & & & & & • & & \\
\hline 19 & $\begin{array}{l}\text { Cao, Feng, and } \\
\text { Wu (2014) }\end{array}$ & $\bullet$ & & & & & & $\bullet$ & & & $\bullet$ & & & & & • & & \\
\hline 20 & $\begin{array}{l}\text { Hossain and } \\
\text { Wright (2005) }\end{array}$ & & $\bullet$ & & & & & $\bullet$ & & & $\bullet$ & & & & & $\bullet$ & & \\
\hline 21 & $\begin{array}{l}\text { Hossain and } \\
\text { Wright (2004) }\end{array}$ & $\bullet$ & & $\bullet$ & & & & $\bullet$ & & & $\bullet$ & & & & & • & & \\
\hline 22 & $\begin{array}{l}\text { Hossain et al. } \\
\qquad(2016)\end{array}$ & $\bullet$ & & & & & & $\bullet$ & & & $\bullet$ & & & & & & & \\
\hline 23 & $\begin{array}{l}\text { Edalati et al. } \\
\qquad(2014)\end{array}$ & & $\bullet$ & & & & $\bullet$ & & & & & & & & & & & \\
\hline 24 & $\begin{array}{c}\text { Rosario-Galanes } \\
\text { and Godoy } \\
(2014)\end{array}$ & & $\bullet$ & & & & $\bullet$ & & & & & & & & & - & & \\
\hline 25 & Taormina (2012) & $\bullet$ & & & & & & & $\bullet$ & & & $\bullet$ & & & & $\bullet$ & & \\
\hline 26 & $\begin{array}{l}\text { Wang et al. } \\
\text { (2014) }\end{array}$ & $\bullet$ & & & & & & & & $\bullet$ & & & & & & & & \\
\hline 27 & $\begin{array}{l}\text { Hossain and } \\
\text { Wright (2004) }\end{array}$ & $\bullet$ & & & & & & & & $\bullet$ & & & $\bullet$ & & & $\bullet$ & & \\
\hline 28 & $\begin{array}{l}\text { Hossain and } \\
\text { Wright (2004) }\end{array}$ & $\bullet$ & & $\bullet$ & & & & & & $\bullet$ & & & $\bullet$ & & & $\bullet$ & & \\
\hline 29 & $\begin{array}{l}\text { Hossain and } \\
\text { Wright (2004) }\end{array}$ & & $\bullet$ & & & & & & & $\bullet$ & & & $\bullet$ & & & $\bullet$ & & \\
\hline 30 & $\begin{array}{l}\text { Uy, Wright, and } \\
\text { Bradford (2001) }\end{array}$ & $\bullet$ & $\bullet$ & & & & & & & $\bullet$ & $\bullet$ & & & & & & & $\bullet$ \\
\hline 31 & $\begin{array}{l}\text { Hossain et al. } \\
\qquad(2016)\end{array}$ & $\bullet$ & & & & $\bullet$ & & & & & $\bullet$ & & & & $\bullet$ & & & \\
\hline 32 & $\begin{array}{l}\text { Rafiei et al. } \\
\text { (2017) }\end{array}$ & & $\bullet$ & & & $\bullet$ & & & & & $\bullet$ & & & & & $\bullet$ & & \\
\hline 33 & $\begin{array}{l}\text { Hossain (2000) } \\
\text { With-opening }\end{array}$ & $\bullet$ & & & $\bullet$ & & & & & & $\bullet$ & & & & $\bullet$ & $\bullet$ & & \\
\hline
\end{tabular}

Based on the data illustrated in Table 2, it can be seen that the vast majority of the conducted research work focused on investigating the structural behavior of TPSCWs infilled with either normal or self-consolidating concrete exposed to axial load program. A substantial lack of research work on the structural response of TPSCWs under impact, cyclic and thermal load influence is observed. This outcome is attributed to the effective TPSCWs trend of use in the construction projects as an axial bearing composite shear wall. To that end, a significant amount of studies adopted different types of connectors such as the screwed, fasteners bolts and/or rod connectors. Additionally, different types of infill concrete such as lightweight, recycled, mirco, and high-performance concrete were adopted in limited TPSCWs prior studies. 


\subsubsection{Axial Load Case Studies}

The earlier research that investigated the axial behavior of the TPSCWs system was conducted in 1995 by Wright and Gallocher Wright and Gallocher (1995). The study presented the TPSCWs as a development of the predominant composite flooring system characterized by ease of assembly. The results of four full-scale specimens tested under axial load indicated the high influence of the wall strength by the concrete-sheeting interface bond in addition to the equality of strain progression in both components (steel-concrete), which was difficult to achieve due to the level of the composite action provided in the specimens. Despite the unsuitability of the commercial decking used in the study in addition to the unsuitability of the composite level achieved, the wall system showed a predictable behavior but required further developments. Therefore, in 1998, Wright Wright (1998) investigated 13 new specimens of TPSCWs under axial load with several sheeting manufacturers and wall thickness. The results revealed the significant impact of the SSPs local buckling and the concrete profiled shape cross-section. Hence, the study proposed reduction factors to consider the coupling phenomenon after comparing the experimental results with those results obtained from the empirical formula exhibits in Eq. 1. It was proved that the longitudinal bending stiffness has a prime impact of the wall suitability by averting the early local buckling of the SSPs. Accordingly, further studies consider the SSPs slenderness was highly required.

$N=0.6 f_{c u} A_{c}+0.87 A_{s} p_{y}$

Figure 7 illustrates test No.13 under the compression of the axial load at eccentricity 0.05 times the wall width. A stiff bearing plate was used to apply the load, and a horizontal bar was installed along the wall with a stiff capping plate. Moreover, C-shape steel hooks were spot welded to PPS inner face to achieve a proper steel-concrete composite action, as depicted in Figure 8. Wright (1998)

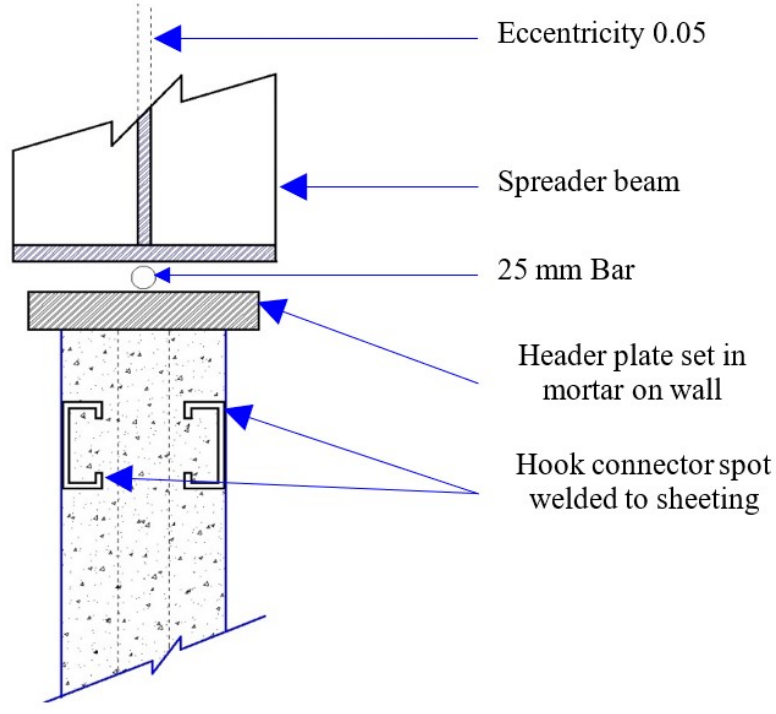

Figure 7. Eccentric load application detail adopted by Wright 1998

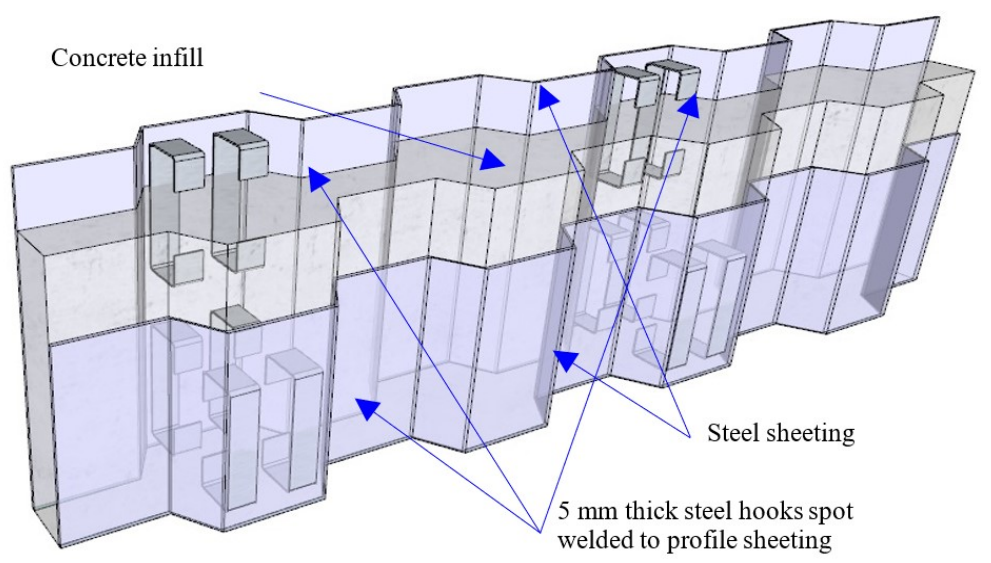

Figure 8. Concept of steel-concrete composite action through C-shape steel hook 
The prior researches of Wright Wright (1998) concentrated on the axial load. Therefore, on their seeking to further developments on the TPSCWs system, Wright and Hossain Hossain and Wright (1998, (1998) tested experimentally (1/6 scale), numerically, and analytically, the diagonal tensile strength of the profiled SSPs with and without micro-concrete cores. TPSCWs shear strength can be obtained from its equivalent plain cement board. The study used SSPs groups interconnected in the closures and in the middle by threaded rods (Figure 5-c) that passed through the spacers. Compared to a normal cement board, the plate's tension and the limits have changed due to the geometry of the profile. The research revealed a reduction factor for the design formula, considering the impact of the application of hysterical loading. It was observed that the FE modelling of the profile panels was adequate to predict the pre-cracking performance. Moreover, as a part of the big program of the work on the TPSCWs system, Wright et al. Bradford, Wright, and Uy (1998) developed a verified numerical analysis for the short-term and time-dependent TPSCWs system under compressive load. The analysis allows unequal eccentricity at both ends. The accurate analysis results in this study provided a deeper understanding of TPSCWs in long and short loading conditions. However, to adopt the TPSCWs system in practice, further fundamental research and feasibility studies were still required. Hence, Mydin and Wang Mydin and Wang (2011) tested 12 mini-scale samples of TPSCWs with a new concrete core, namely, lightweight foamed concrete (LFC) with $1000 \mathrm{~kg} / \mathrm{m}^{3}$ of density experimentally and analytically. The experiment focused on the failure mode and the peak load capacity with two different configurations, including open and close end, as shown in Figure 9. The results showed that the LFC is sufficient to prevent inward buckling and TPSCWs is adequate to be used in 4 floors residential building. A design equation is also proposed for the TPSCWs capacity stated in Eq. 2.

$N_{s}=0.63 A_{c} f_{c u}+b_{e f f} t f_{y}$

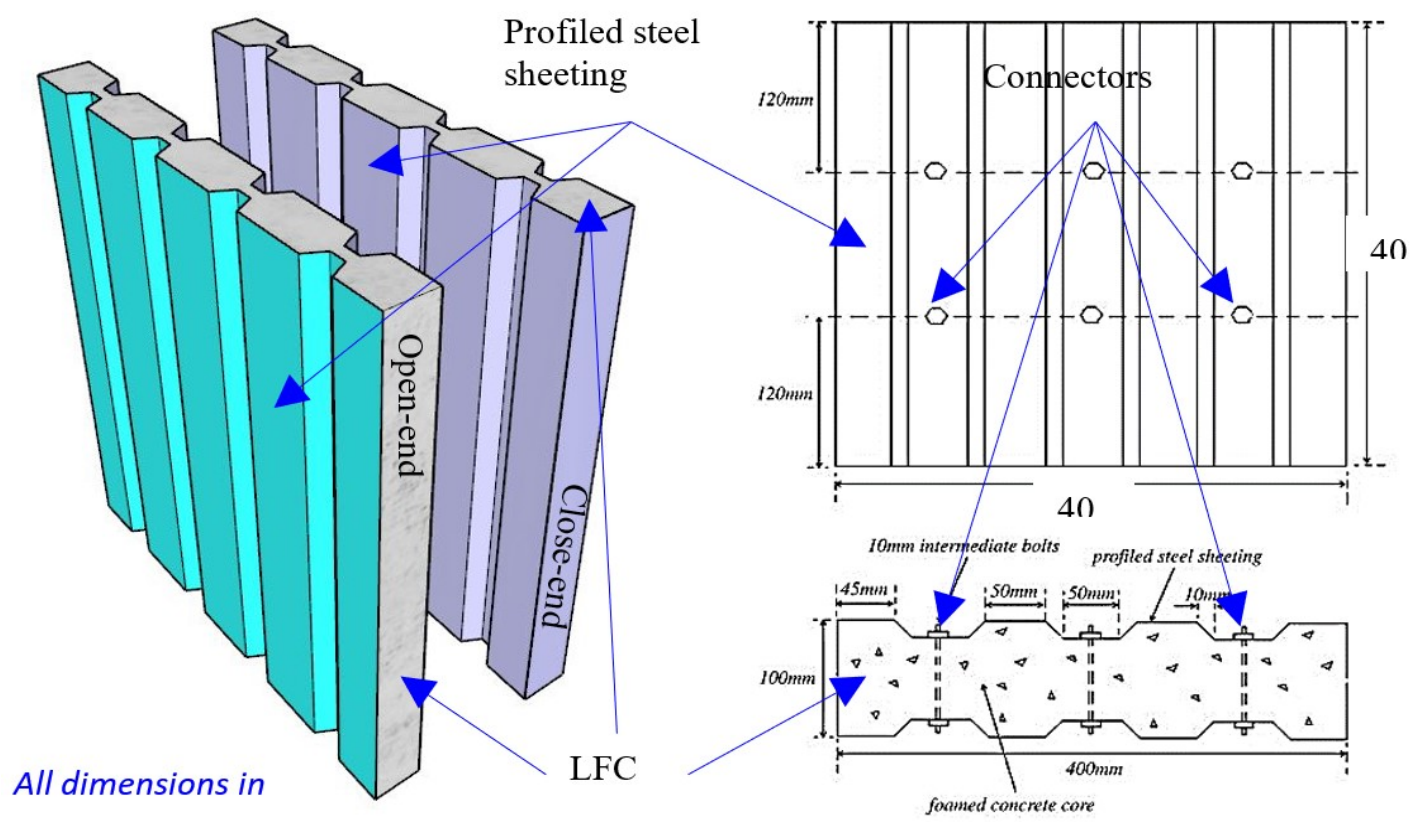

Figure 9. Details of the mini-scale specimens of Mydin

Similarly, the effect of confinement of profiled SSPs-LFC concrete on the axial capacity of TPSCWs was experimentally studied by Prabha et al. Prabha et al. (2013) using five mini-scale samples. The axial load was applied on the LFC panel only, and the end-status of the walls were considered to avoid early SSPs buckling. Through-bolts (Figure 5-b) were used to provide the SSPs-LFC composite action and achieve the desired confinement level, as shown in Figure 10. The results showed that the wall strength developed significantly by the confinement level, and the profiled SSPs improved the plain LFC panel strength by over $200 \%$. Despite the logical differences in the failures observed between the open and closed-end, the results obtained no notable difference in the capacities and that might be attributed to sampling fabrication imperfections. 


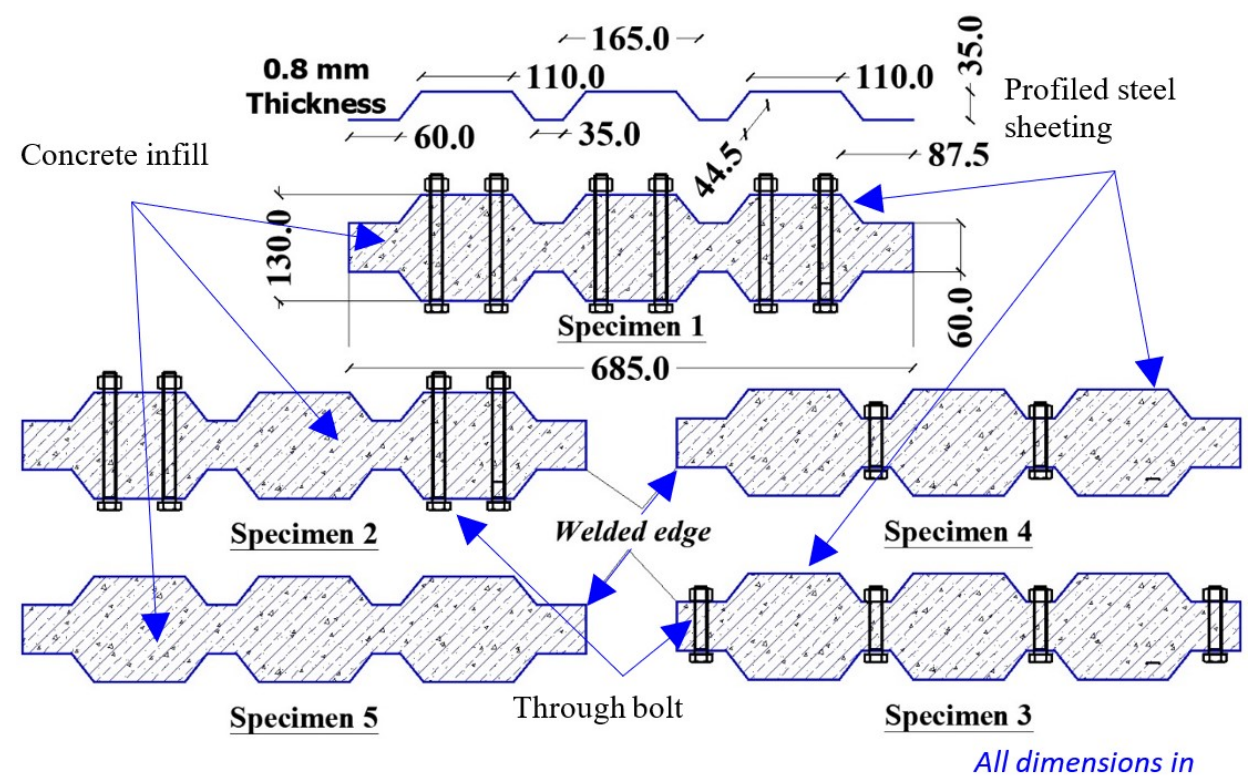

Figure 10. General configurations of specimen adopted by Prabha.

It can be noticed that the previously mentioned research efforts have focused on providing higher compressive strength of concrete and better SSPs-concrete confinement level and composite action to achieve higher TPSCWs capacity. These solutions were effective but limited. Therefore, a new suggestion was introduced and examined in several finite element (FE) studies of Hilo et al. (2014), Hilo, Hamidon, et al. (2015), Hilo et al. (2015a), and Hilo et al. (2016). The work program presented an embedded cold-form steel (ECFS) member as a strengthening development for the TPSCWs system, as the components shown in Figure 11. Further effects were also studied in this program, such as the profiled SSPs thickness, ECFS thickness, shape and number, and stiffening of the core of the ECFS. The FE simulation exhibited accurate results versus Wright et al. experimental results Wright (1998) and the results obtained from the prediction equation of the European standards (EC4) BEng and Park (1994) shown in Eq. 3.

$P_{E C 4}=A_{c} f_{C}^{\prime}+A_{s} f_{y}$

The results proved the efficiency of the proposed strengthening method. A couple of the ECFS improved the TPSCWs capacity by more than $30 \%$, whereas stiffening the ECFS increased up to $74 \%$ with $L$ and T shape of stiffeners. Comparing to $1.0 \mathrm{~mm}$ SSPs thickness, $0.8 \mathrm{~mm}$ was preferred due to the negligible difference in capacity.

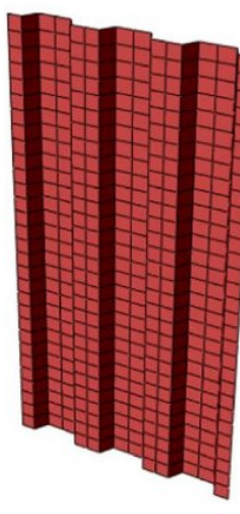

Profiled SSPs

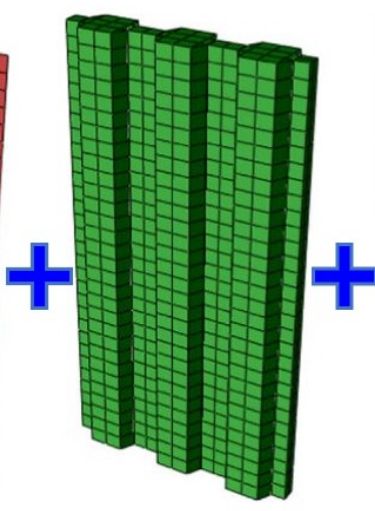

Concrete panel

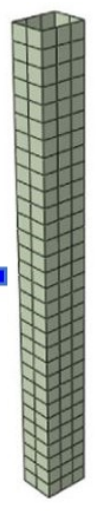

ECFS members

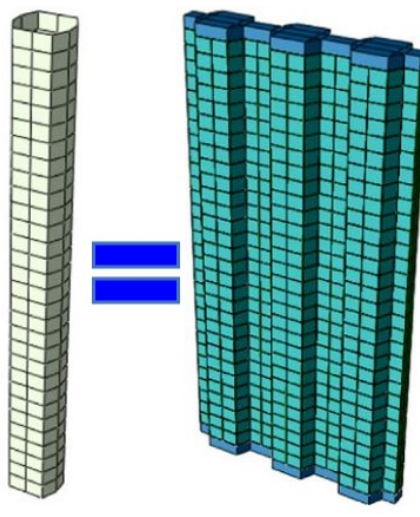

Full TPSCWs system

Figure 11. The main component of Hilo proposed wall

Similarly and most recently, Labib-Zadeh and Hamidi Labibzadeh and Hamidi (2019) presented a comparison study between capacities of the TPSCW system and the composite steel plate shear wall (CSPSW) system. To that end, 22 verified FE models of the TPSCWs system, includes the same concrete panel, SSPs thickness, fewer fasteners, and without 
reinforcement bars, were compared with CSPSWs type of walls. The comparison results proved TPSCWs could provide better loading capacity than that for CSPSW system.

\subsubsection{Cyclic Load Case Studies}

The TPSCWs system was investigated for the first time under cyclic load in 2004 by Hossain and Wright Hossain and Wright (2004). The study developed design guidelines for using the framed TPSCWs system in construction projects. The guideline equation was verified against experimental and theoretical findings. The study indicated that the TPSCWs is practical as a shear resisting element. The same authors proposed intermediate fasteners to provide composite action through a verified numerical study Hossain and Wright (2005). The number of intermediate bolts and the effect of the shear interaction was the key parameter. The results were used to describe how it influenced the ductility and strength of the proposed connectors.

On the other hand, Cao et al. Cao, Feng, and Wu (2014) investigated the influence of the TPSCW as a core of a reinforced concrete $(R C)$ frame. To that end, $1 / 3$ scale of One-bay, two-story samples were tested under cyclic load. The results demonstrate that the RC frames capacity developed by $225 \%$, and the stiffness increased by $108 \%$ with a notable enhancement in energy dissipation. More recently, Hossain Hossain et al. (2016) investigated the cyclic performance of the TPSCWs system (check Figure 12) with two different infill concrete, namely, self-consolidating concrete (SCC) and engineered cementitious composite (ECC), in addition to profiled SSPs with two varied yield strengths. The results showed higher ductility and less stiffness reduction for the specimens filled with ECC than the SCC specimens, while utilizing mild strength SSPs provided better ductility and energy absorption than high strength steel.

\subsubsection{Lateral Load Case Studies}

Certain studies investigated the response of TPSCWs under lateral loads, such as Hossain and Wright (Hossain and Wright (2005) and Wright, Hossain, and Gallocher (1994)), who simulated four FE models to study TPSCWs shear performance numerically through FE analysis with specific emphasis on steel-concrete interface representation, which permits either full or partial materials-interaction. To that end, non-linear joint elements or interfaces were proposed for steel-concrete interaction to simulate it partially in a way that allows steel-concrete in-plane slippage or out-of-plane separation to occur. The behavior of developed FE models showed a reasonable agreement with the experimental reference results. Therefore, the developed FE models were considered reliable to use. Similarly, Hossain and Wright (2005), Rafiei et al. (2010) and Rafiei et al. (2013) presented validated FE models to represent the behavior of unique TPSCWs under in-plane loading. The study investigated the influence of steel-concrete interaction parameters (steel strength, concrete grade, and an intermediate layer of joints) and material on the structural performance of the TPSCWs. To confirm the impact of the interaction type on TPSCWs performance, the research also explored the behavior of couple FE models using "surface constraints" and "contact surfaces" to accurately represent the performance of the TPSCWs. The observation also provided knowledge about the most appropriate distribution spacing of the interface connectors, as exhibited in Figure 12, to avert the shear buckling of SSPs before failure.

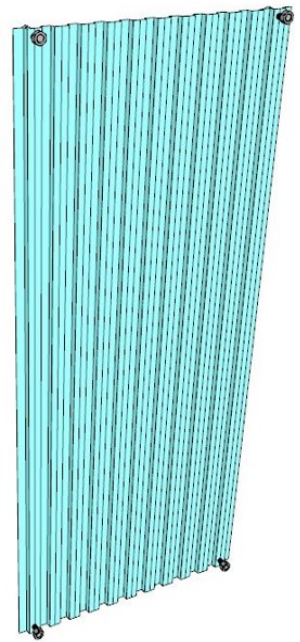

(a) Without constraint

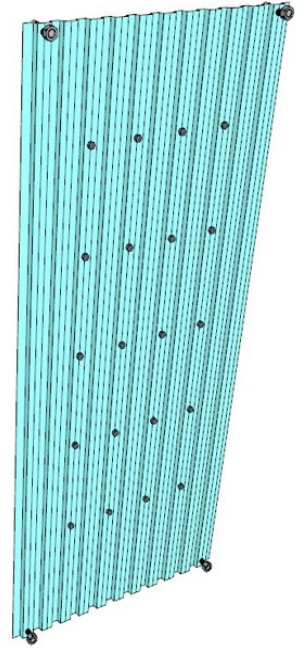

(b) 20 constraints

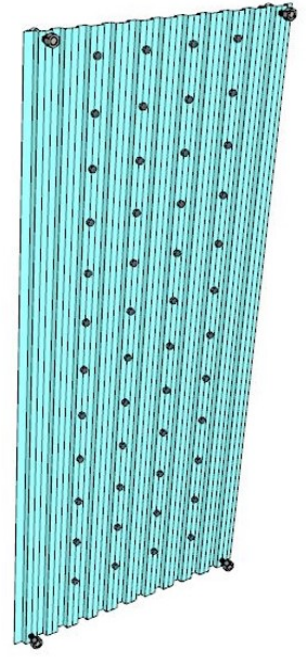

(c) 44 constraints

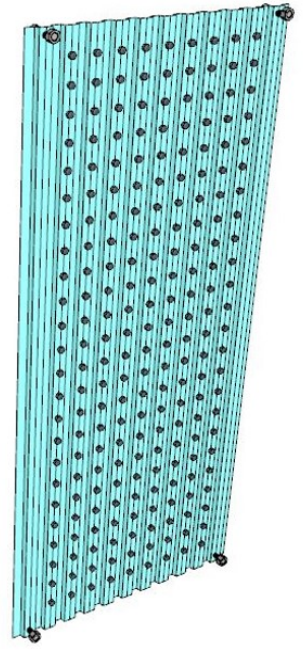

(d) 207 constraints

Figure 12. Tie constraints location of each wall side to mimic midway connections 
Additionally, Hossain and Wright (2005), and Rafiei et al. (2015) tested three samples of TPSCWs with $1622 \mathrm{~mm}$ $\times 720 \mathrm{~mm}(\mathrm{H} \times \mathrm{W})$ experimentally. The study used two SSPs yield strength values and two concrete infill types, namely SCC and ECC. Moreover, SSPs of specimens interacted with the core concrete via intermediate fasteners along the wall and were capable of averting the initial elastic buckling of the SSPs., as presented in Figure 13 . The results showed $79.5 \%$ higher energy absorption for the walls with ECC over SCC, in addition to higher deformation capacity and ultimate shear load. Also, higher ductility was observed by using mild strength of SSPs over the high SSPs strength. Accurate analytical models combining the strength of the SSPS and the concrete core to predict the shear resistance of TPSCWs were also derived in this study.

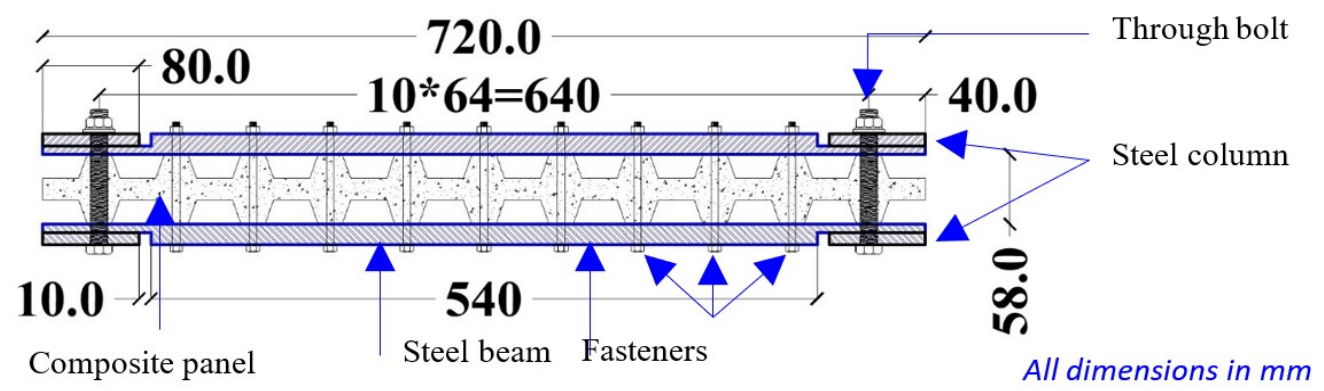

Figure 13. TPSCWs cross-section with connections and shear rig frame (in $\mathrm{mm}$ )

Another numerical study conducted by Edalati et al. Edalati et al. (2014) examined the behavior of TPSCWs under lateral pushover loads using FE method. The performance of the sinusoidal corrugated SSP wall was compared with trapezoidal corrugated SSP with constant dimensions. The results proved that trapezoidal plates' energy absorption, ductility, and peak bearing were higher than that for sinusoidal waves, with less steel material consumption. Similarly, using FE approach, R.Galanes, and Godoy Rosario-Galanes and Godoy (2014) developed an analytical model that can be utilized for fatigue analysis of the TPSCWs system. The study employed a documented data for the failures in screwed connections in roof and steel sheet cold-formed wall cladding systems during high wind periods. The study provided a validated analytical model that predicts fatigue life and failure mechanism with various connections and SSP thickness.

\subsubsection{Thermal Load Case Studies}

Only one experimental research in this field has been conducted by Taormina et al. Taormina (2012). The study highlighted the influence of non-traditional emerging high-performance concrete (HPC) on the TPSCWs behavior under axial and evaluated temperatures. Engineered cementitious composites (HCC) type of concrete, in addition to different temperatures values $\left(0^{\circ} \mathrm{C}, 300^{\circ} \mathrm{C}, 400^{\circ} \mathrm{C}\right.$, and $\left.500^{\circ} \mathrm{C}\right)$ were the variables of the study. The results were presented based on physical changes, residual capacity, stress-strain characteristics, load-deflection response, SSPs buckling, concrete cracking, and failure modes.

\subsubsection{Combined Load Case Studies}

The prior research also explored the response of TPSCWs under a combination of two or more different loads. In 2001, Uy et al. Uy, Wright, and Bradford (2001) conducted an extensive investigation on TPSCWs performance under bending and compression load combination, experimentally and numerically, as a part of the large program led by Wright. The results confirmed the influential role of local buckling on the wall strength and stiffness. Thus, a method that clarifies including the SSPs' local buckling influence for compression load and bending moments were proposed. In 2004, Wright and Hossain Hossain and Wright (2004) continued exploring the TPSCWs system's practicality under the combination of bending and shear deformation by testing a small-scale of TPSCWs samples fabricated from microconcrete and very thin SSPs (check Figure 14) along with analytical analysis. The experimental and numerical results were used to introduce Eq. 4 to calculate the modified shear capacity. Additionally, Hossain and Wright Hossain and Wright (2004) explored the potential of using the TPSCWs system as a shear-resistance element in buildings. High shear resistance was governed by ensuring an adequate SSPs-concrete interaction. The study also proposed design equations for the shear flexibility $\left(c_{c}\right)$, stiffness $\left(k_{c}\right)$, shear capacity $(V)$, and the ultimate shear resistance $\left(V_{w}\right)$, as shown in Eq. 4-6. The equations are shown to be safe to use when compared versus the experimental results.

$V_{w b}=\beta \varphi \sqrt{f_{c}^{\prime}} \cdot a\left[t_{e q c}+2 n \alpha t_{e q s}\right]$ 
$V=P \cos \emptyset_{d}$ and $\delta=\frac{\Delta}{\cos \emptyset_{d}}$

$C_{c}=\frac{1}{k_{c}}=\frac{2 b\left(1+V_{c}\right)}{E_{c} a t_{e q}}$

$V_{w}=72 \beta \frac{D_{x}^{1 / 4} D_{y}^{3 / 4} a}{b^{2}}+0.074 a t_{e q} f_{c u}=72 \beta \frac{D_{x}^{1 / 4} D_{y}^{3 / 4} a}{b^{2}}+\frac{f^{\prime}{ }_{c} f^{\prime}{ }_{t} a t_{e q}}{f^{\prime}{ }^{\prime}{ }^{+} f^{\prime}{ }_{t}}$

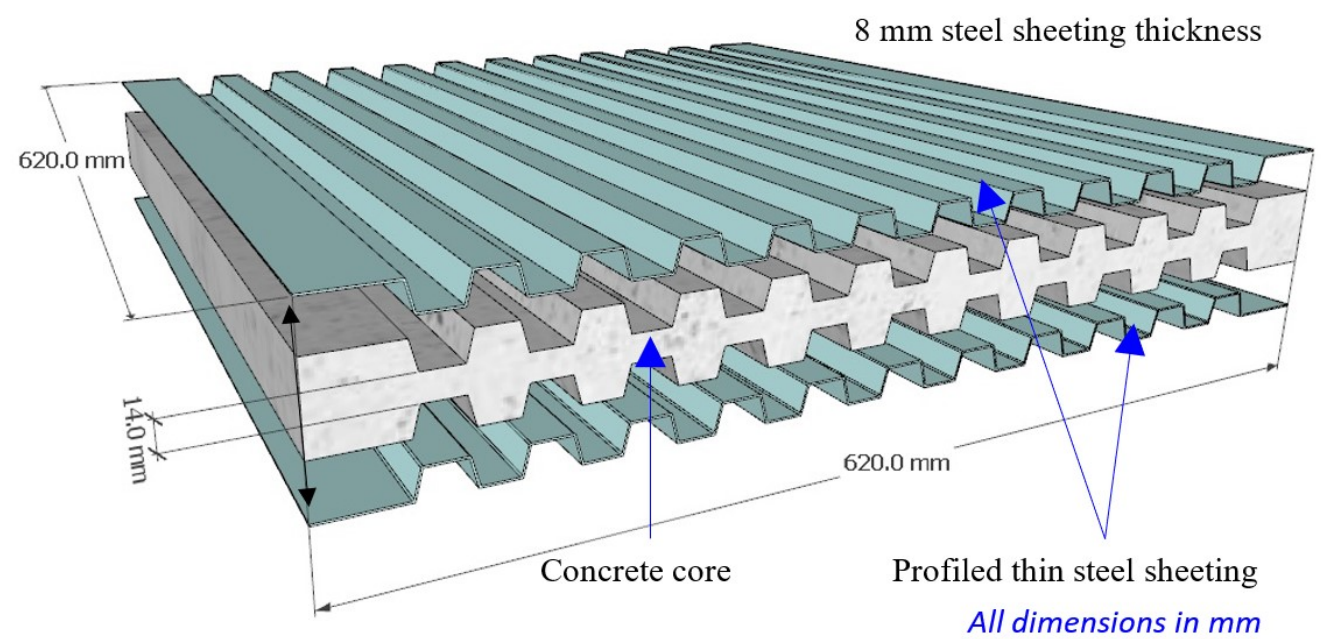

Figure 14. CW details suggested by Hossain and Wright

More recently, and due to the lack of related studies, Wang et al. Wang et al. (2014) studied the TPSCWs response under transversal pressure and vertical compression load using the numerical approach. Findings showed that the increment of the SSPs span or the transversal pressure would reduce the compression capacity. Moreover, based on the results, the cold-form thin-walled method is sufficient to be a reference solution for calculating the SSPs' capacity to resist the referred load types.

\subsubsection{Impact Load Case Studies}

The studies on the behavior of TPSCWs under impact loading were quite limited. In 2017, Hossain et al. Rafiei et al. (2017) experimentally examined the performance of TPSCWs system's under two phases of in-plane impact loading. In the first phase, the projectile impact energy was intentionally low to determine the dynamic wall characteristics. Whereas phase II, the maximum projectile speed used directly with high impact energy. The obtained results confirmed the suitability of TPSCWs to be used as an impact resistance element.

Additionally, Hossain et al. Hossain et al. (2016) developed FE models with accurately predicted results. Extensive parametric studies were also conducted to cover several key parameters not studied in the experimental tests. The proposed FE model is shown to be a suitable method to conduct further numerical investigations.

\subsubsection{Opening Effect Case Studies}

Only one study considered the effect of the opening on Hossain's TPSCW system Hossain (2000) and Hossain and Wright (2004d). Prior investigations considered the solid type of TPSCWs walls only. Therefore, this study investigated the axial compression response of TPSCWs as a building core wall with potential door/window openings, which could significantly affect wall behavior. To that end, eight models were assembled from different types of profiled SSPs tested to afford sufficient data on the influence of openings on load-drift curve, load capacity, stress-strain relationship, failure modes, and plate buckling, as shown in Figure 15. A hook and welded rod were used in the specimen's fabrication at both ends (top and bottom) of the TPSCWs to provide better steel-concrete interaction and more load transferring from the end top to the end bottom of the specimen. The pierced Spandek walls had a modification by adding a welded rod with a hook for strengthening purposes. The additional assembly performed as a lintel beam confine the concrete, support the opening boundary, and provide a proper connection between the sheeting plates. The non-pierced specimen has shown higher compression load capacity than the pierced specimen. The axial deformation in the pierced specimen 
was found greater than the non-pierced wall. Despite that Trimdek walls showed greater capacity than the Spandek walls, Spandek walls exhibited higher capacity regarding the net concrete area. Reduction factors were also proposed to modify the ultimate load formula from the British (BS8110) BS8110 (1985) and the Australian AS3600 2018 (2018) specifications to provide reasonable outcomes.

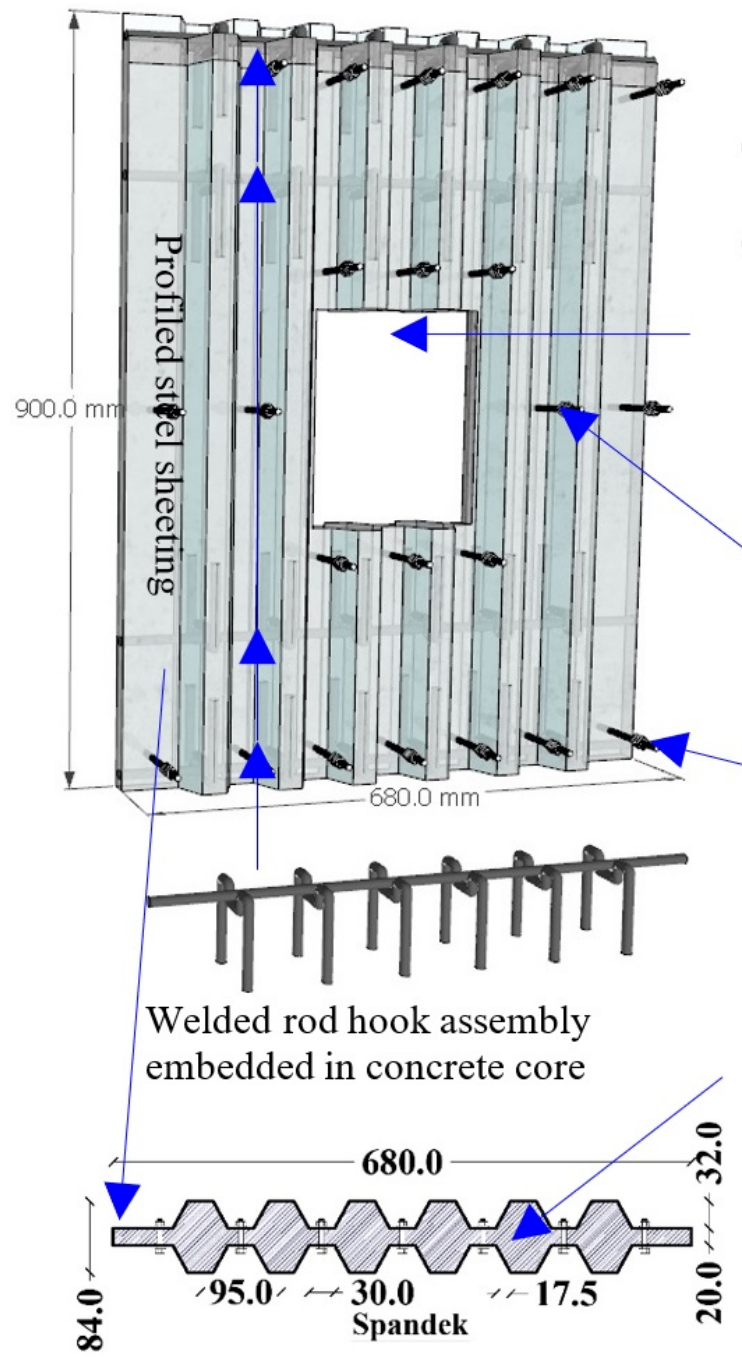

(b) Spandek pilot walls

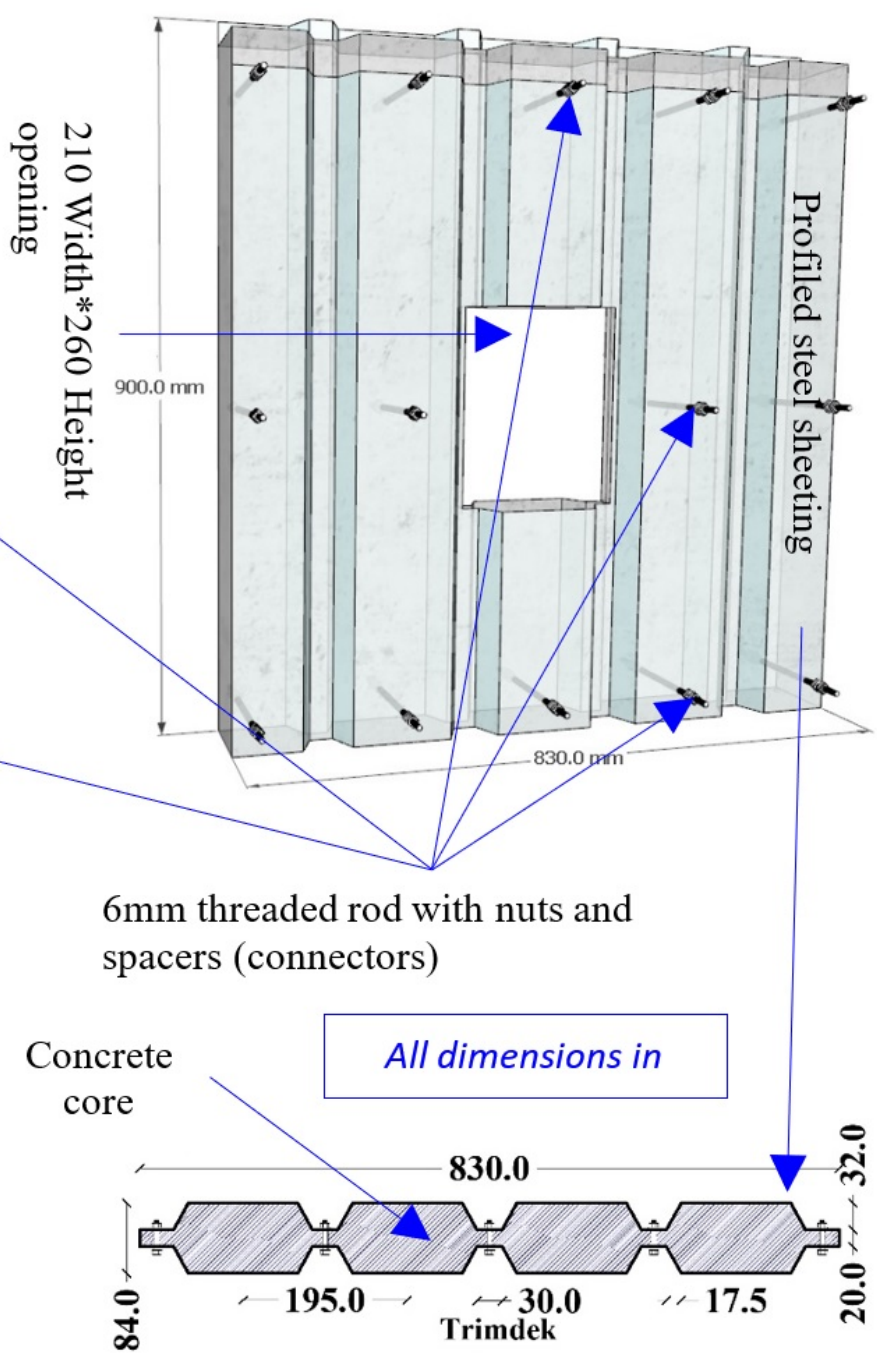

(a) Trimdek pilot walls

Figure 15. TPSCWs pilot tests with multi kinds of profiled SSPs

\subsubsection{Twin-Layer Flat Steel-Sheets Composite Walls System (TFSCW)}

The typical composition of the TFSCWs system is an external twin-layer of flat steel plate filled with concrete. The infill concrete is sandwiched between sheeting layers and interacts with these layers through mechanical connectors Zhang et al. (2014), as exhibited in Figure 16. Currently, TFSCWs have proven their efficiency as a main and backup shield wall in nuclear power plants Bruhl, Varma, and Johnson (2015a), considering the number of studies in this field. Several investigations found in the literature have studied a variety of TFSCWs usage. For instance, blast-resistant members in nuclear facilities, gas-retaining, and shelters in tunnels projects, high-rise buildings core wall and regular building bearing and retaining member Epackachi, Whittaker, and Huang (2015). Furthermore, Table 3 exhibits the pros and cons of the TFSCWs, and Table 4 exhibited a full characterization summary of these field studies. 
Table 3 - Advantages and disadvantages of TFSCW wall system

\section{TFSCW wall system}

\section{Advantages}

- Fast construction process compared with other CWs which required formwork especially for symmetrical high rias building

- Significantly function as a axial, lateral, cyclic, impact resistance wall

- It is moderately accepted in terms of construction cost as its do not required a formwork preparation

- Simple construction and implementation as earthquake resistance shear wall, blast resistance shield, nuclear plant protection shield

- It can be assembled under an industrial building system (IBM)

- Easy to construct it with diverse capacities considering the availability of the plate sheets at the market with a multi gauge thickness and yielding capacity

- Easy to apply an opening on it to generate a window and/or

$$
\text { a door }
$$

- It has a flat outside shape which makes it architecturally less challenging especially at open spaces

\section{Disadvantages}

- Relatively insufficient lightweight and low cost constructions

- Thin TFSCWs might requires self consolidating or high workability concrete to prevent the segregation phenomenon especially in a symmetrical core of high rias buildings which can be casted each four floors at one cast operation

- Compared with the embedded steel sheet CWs, TFSCWs are less thermal resistance as the double skin of steel sheet will be exposed directly to the thermal load

- As a cyclic and/or earthquick resistance member, TFSCW system mostly failed when the infilled concrete start spalling and crushing at the wall toe above the base line due to the extreme compressive pressure generated in these zones

- Generally, TSCW has less fire resistance compared with CWs which has embedded plates, and that attributed to the TSCWs configuration which expose the plated sheets to the external factores directly

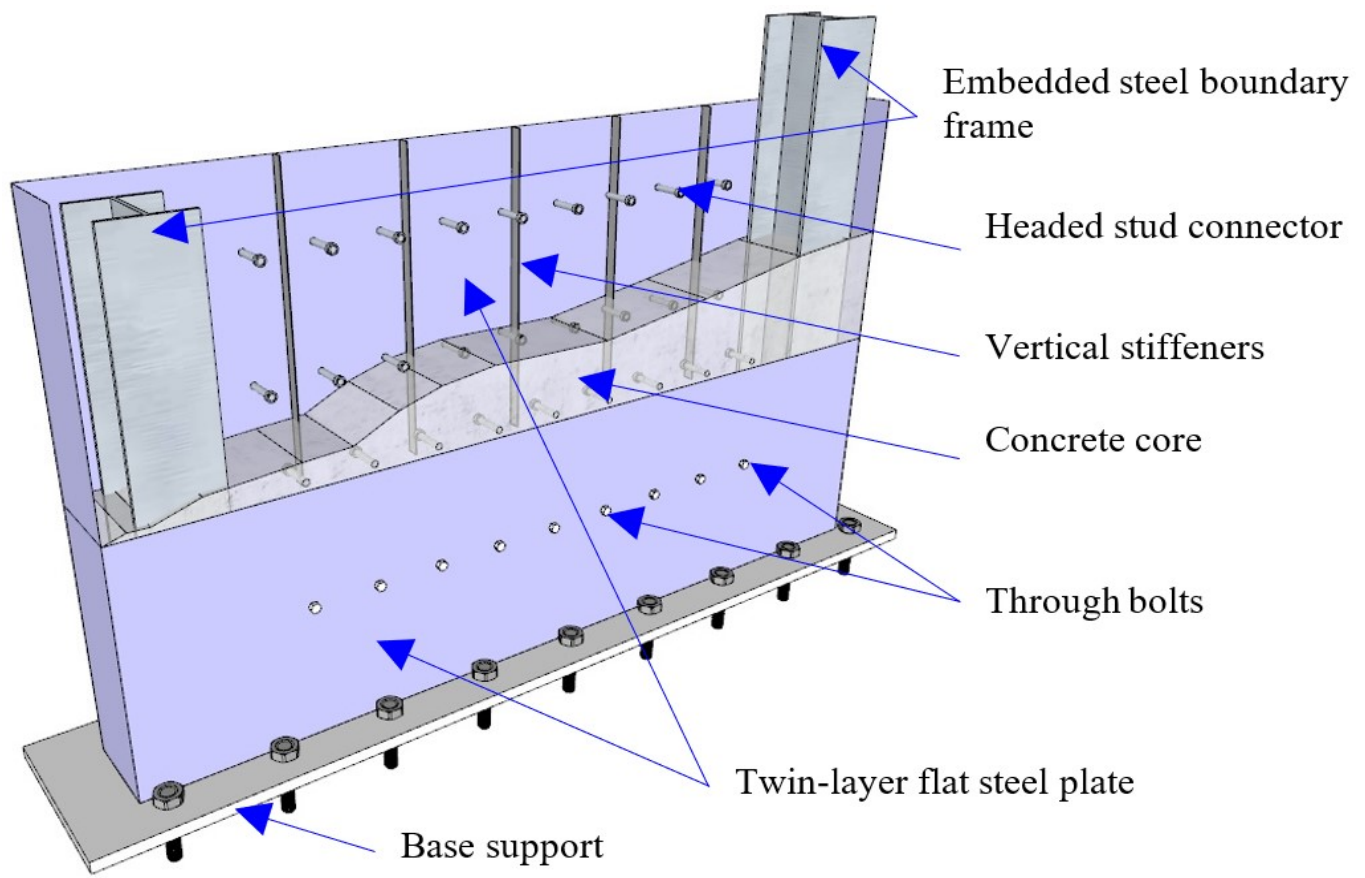

Figure 16. TFSCWs general concept 
Table 4 - Categorized summary of previous TFSCWs case studies.

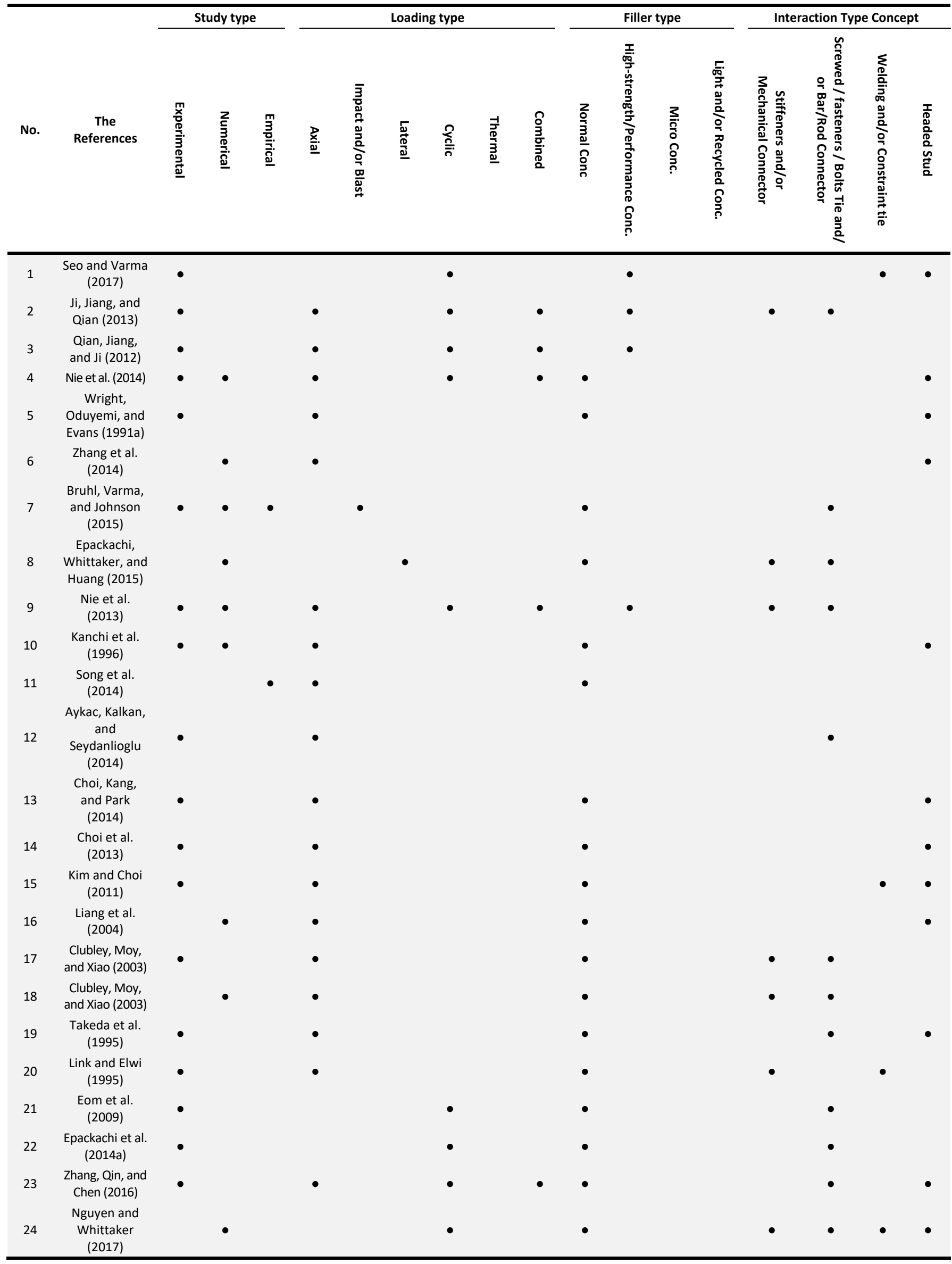


Table 4 - Continued...

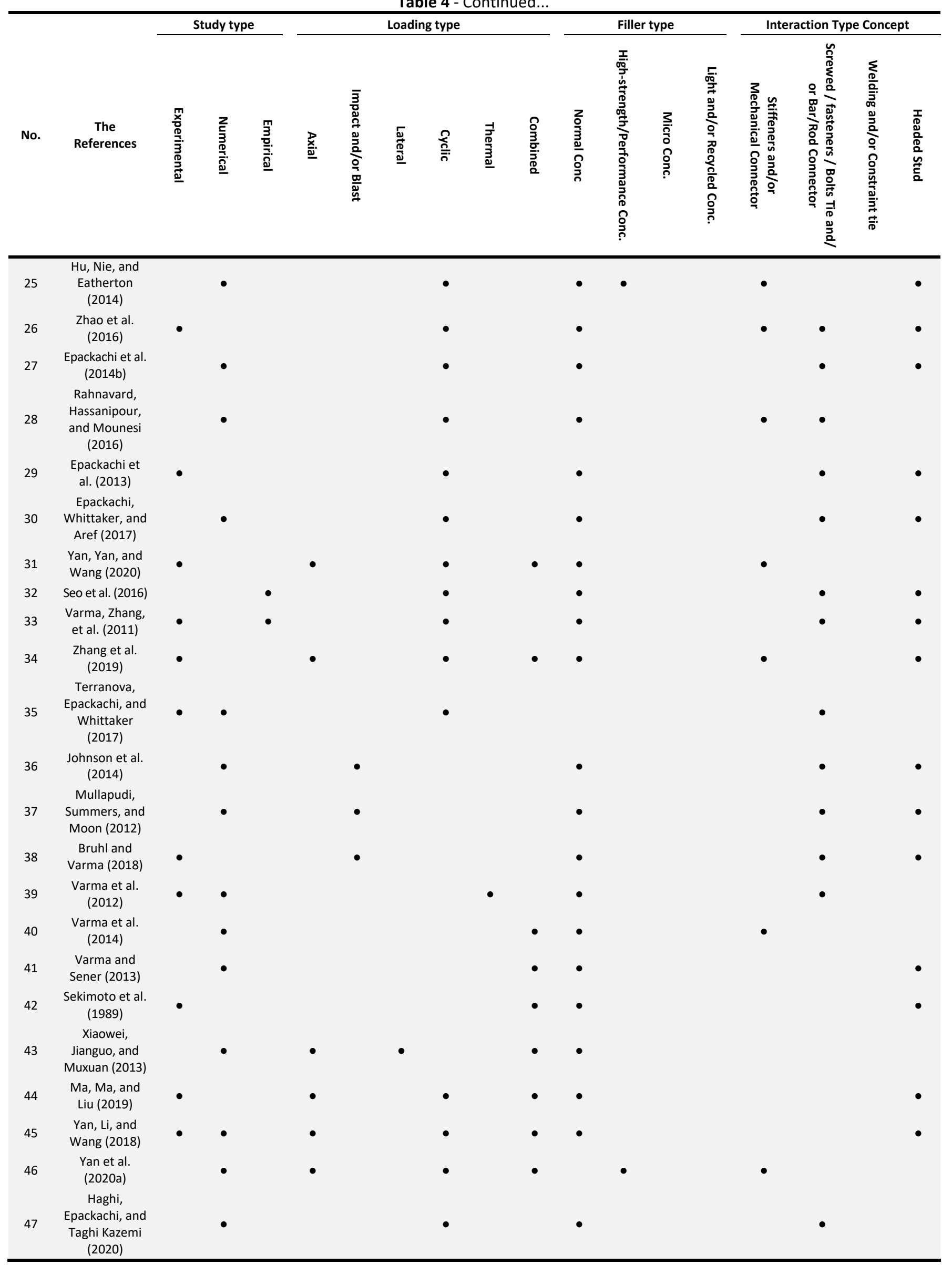


Based on the data demonstrated in Table 2, it can be seen that the prime number of the accomplished research work focused on examining the structural performance of TFSCWs infilled with normal concrete subjected to axial and cyclic load programs. This outcome is attributed to the effective TFSCWs applications in mid-rise and high-rise buildings as well as nuclear power plants projects, as an axial and/or lateral composite shear wall, and as a protection wall shield. To that purpose, many studies adopted several types of connectors, such as the headed studs and tie rods. The gaps of research work on this category of the composite shear wall are less compared with the category of TPSCWs. However, both Table 1 and 2 showed a significant gap in the empirical studies of both types of composite walls.

\subsubsection{Axial Load Case Studies}

Several studies were conducted in the literature to explore the axial behavior of twin-layer infilled concrete walls and/or elements. These studies began in the early 90s last century. One of the earliest studies in the field was conducted by Wright et al. Wright, Oduyemi, and Evans (1991a) on the behavior of full-scale double-skin composite (DSC) beam, column, and beam-column samples. Regardless of the significance of the shear connector spacing to avert the plate buckling, the study focused mainly on exploring the failure modes of 35 samples. The investigation demonstrated that the structural system response affords an acceptable and predictable construction element, therefore reliable to use. Accordingly, the system was adopted in Cardiff, UK, as a submerged tube tunnel Tomlinson et al. (1989), as illustrated in Figure 17. In efforts seeking a design method to predict the proposed system's strength, a sequel study developed a validated design method for the proposed system Wright, Oduyemi, and Evans (1991a). This study established the basis for many studies and applications of twin-layer filled concrete elements.

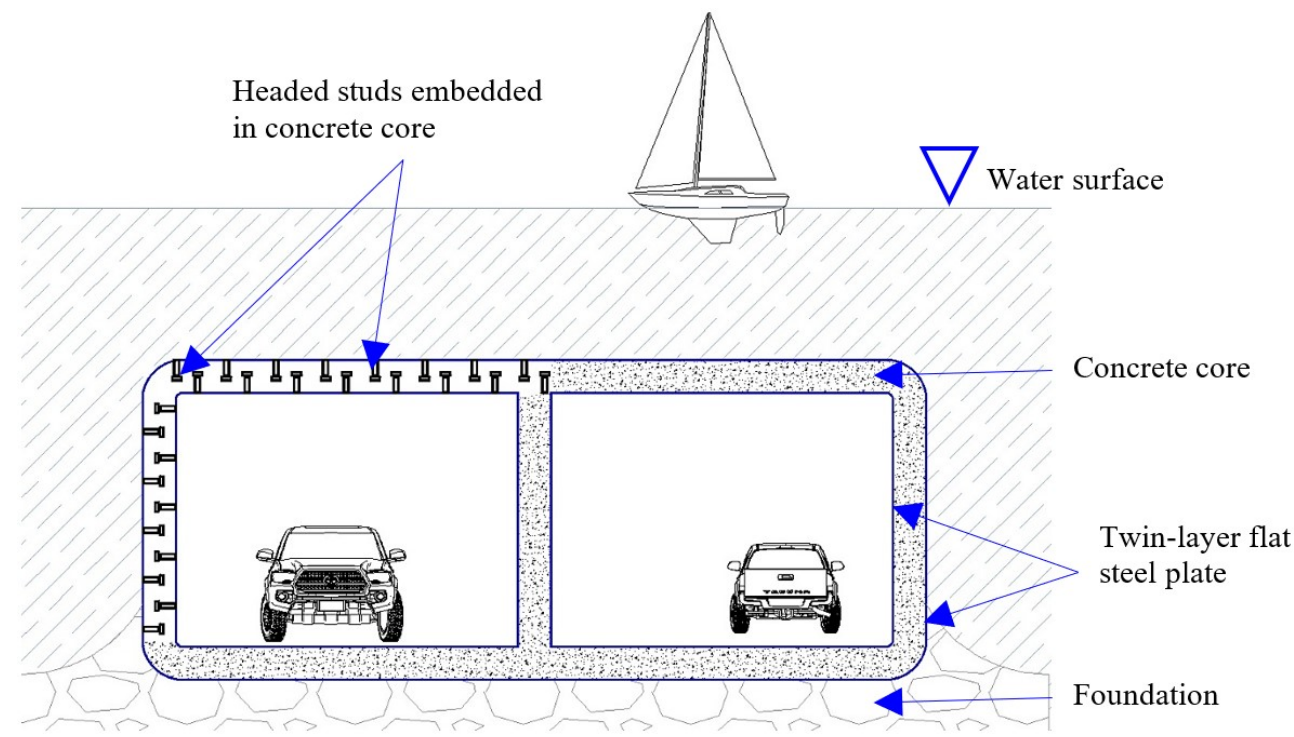

Figure 17. Twin-layer infill concrete element as a submerged tube tunnel.

A few years later, Link and Elwi Link and Elwi (1995) questioned the suitability of the traditional RC design method to design the CWs by that time, arguing the steel-concrete interaction dissimilarity in RC and CWs systems. Hence, the analysis results of eight validated FE wall models, subjected to transverse and longitudinal loading, were used to determine the proposed models' peak and post-peak capacity. Lagrangian multiplier gap elements represent the steelconcrete interface, whereas the steel was considered an elastic-plastic material. The analysis results showed a satisfied ductility since the residual strength of the models was sustained for large deflection. Also, stress redistribution in the wall proved to be essentially tied to the support diaphragm-bottom area (wall toe). The study suggested the bulkhead and amending the aspect ratio to overcome the failure observed in steel plate and infill concrete. This study considered a significant initiation in using the FE analysis in the field of twin-layer infilled concrete elements. In the same year, Takeda et al. (1995) conducted an experimental study to provide sufficient data on the mechanical characteristics of the TFSCWs system, which were unclarified then. Seven samples with the dimensions of $(1200 \times 1200 \times 200 \mathrm{~mm})$ infilled concrete were tested under axial in-plane loading with the parameters including SSPs slenderness ratio, number of inner partitions, and the availability of shear studs. The results indicated a stable load hysteresis envelopes up to $2 \times 10^{-3}$ shear strain. No strength reduction was observed after that due to steel plate confinement, which averts concrete separation. Simultaneously, large hysteresis loops were observed due to the SSPs in-plane shear mechanism. This study's results 
provided a significant understanding of the mechanical response of the TFSCWs system, even though the study did not clearly describe the limitation of the SSPs slenderness ratio and the behavior of the SSPs-partitions connection lanes.

On the opposite side, the high slenderness issues, SSPs spacing, and the SSPs' stress and the connector's surface were addressed extensively by Clubley et al. Clubley, Moy, and Xiao (2003, (2003) research. The study investigated the "Bi-Steel" system of TFSCWs experimentally and numerically. The proposed system includes transverse shear connectors welded to the SSPs' inner face to provide the required steel-concrete composite action. The study alleged that infill concrete exerted complex internal stress with the proposed connectors, influencing the TFSCWs system's shear response due to the confinement impact. The test results indicate that plate thickness and spacing, connectors spacing, and diameters influenced the shear strength and the behavior of the TFSCWs system significantly and should be considered in future design guidance.

Additionally, the thicker SSPs might fail in brittle, especially with few connectors. However, the SSPs sectional area improved the ductility effectively. The numerical results have a significant contribution in providing data that were unobtainable from the test. However, the models predicted a stiffer response during high-load levels. Generally, the study presented reliable data from the experimental test and accepted numerical analysis.

Another FE study conducted by Liang et al. Liang et al. (2004) explored the SSPs' local buckling that may occur between the shear-stud connectors during the axial load application. The study presented a relationship of local buckling interaction of steel sheeting with several boundary conditions, filling a concrete in-between couple of plate sheeting with a headed stud embedded in concrete at normal spacing as depicted in Figure 18. The nonlinear analysis was conducted to determine the strength of the post-local buckling interaction of steel plates under biaxial compression and shear. The analysis considered all of the steel sheeting initial effects, the shear stud nonlinear shear-slip response, and the material yielding. Accordingly, the FE analysis data was used to develop a design model for ultimate capacity and critical buckling to earn the ultimate stud distribution and maximum strength capacity of steel sheeting in TFSCWs. However, the study was limited to the FE method; further tests are required to prove the design model's efficiency.

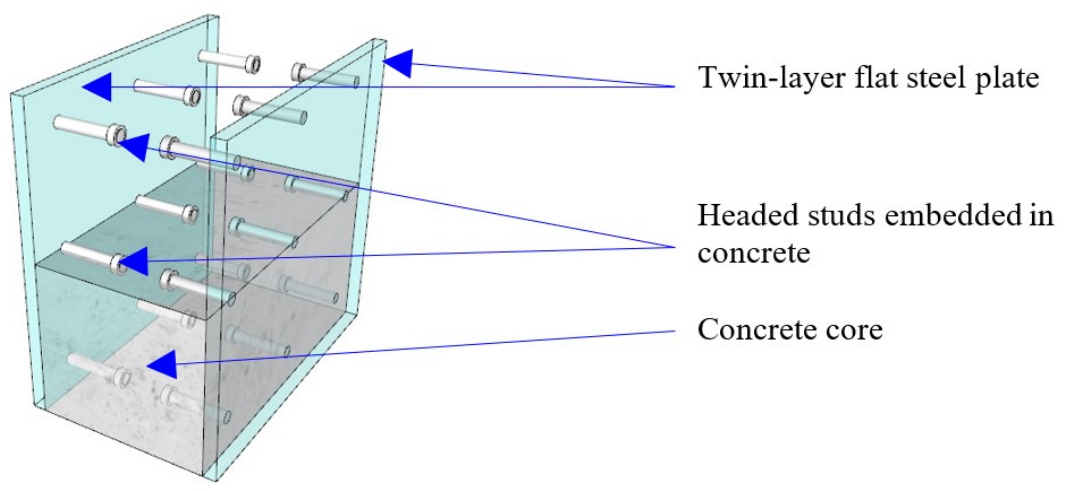

Figure 18. Common interaction concept used in TFSCWs system

Similarly, Kim and Choi (2011a) conducted tests to investigate the sandwich slabs-TFSCW element's connections behavior to understand force transfer between the TFSCW components better. The SSPs were welded to the base support, whereas studs with $13 \mathrm{~mm}$ diameter were distributed at $180 \mathrm{~mm}$ each on the SSPs to achieve the required composite action, besides the steelconcrete interface friction. The research observation indicated that shear strength at the interface is enhanced with the SSPs' presence regardless of the SSPs-concrete friction, which improves the shear capacity. The data obtained from the tests were employed to suggest an appropriate formula to design the connection strength, as shown in Eq. 8.

$V_{n}=A_{s p}+V_{\text {frsp }}=3 M_{y} / L_{w}+\emptyset \mu A_{s} F_{y}$

In the previous study, many inquiries regarding buckling patterns and the post-peak squash load value and strength/behavior of the headed studs remained to be addressed. Therefore, Choi et al. Choi et al. (2013) manage to address the former inquiries by testing six samples of TFSCWs considering the SSPs aspect ratio and yielding strength as key variables. The results showed that increasing the SSPs aspect ratio significantly influences the wall strength and energy absorption, especially if the stud's connectors were designed to prevent buckling potential before the SSPs yielding stage. However, a brittle failure in the SSPs might occur in case the stud's distribution was inappropriate. Moreover, the study proposed a design formula to predict the suggested wall capacity, as shown in Eq. 9.

$P_{n}=2 A_{p} F_{c r}+0.85 f_{c k} A_{c}$ 
Additionally, the infill concrete used in a former couple of studies was limited to the regular concrete. Therefore, a new concrete mixture, namely, eco-oriented cement concrete, includes red clay (Hwangtho) as a partial weight replacement of cement was suggested by Choi et al. Choi, Kang, and Park (2014) to be used as infill concrete. To that end, a group of six specimens of TFSCWs ( 3 with regular concrete and 3 with eco-oriented cement concrete) was tested under axial load to determine the TFSCWs compressive behavior with the eco-oriented cement concrete. The results showed that the strength reduction with specimens filled by eco-oriented cement concrete was restricted by increasing the B/t of the wall (the aspect ratio). The research was also discussed the TFSCW failure modes, SSPs buckling response, effective buckling length, and the SSPs buckling coefficient.

Again, the significance of connectors' suitability to the SSPs thickness was demonstrated by Aykac et al. Aykac, Kalkan, and Seydanlioglu (2014). The study investigated the influence of twin-layer perforated SSPs on the hollow brick infill wall under the diagonal compression load. The twelve tested samples results indicate that the strength, ductility, and energy dissipation are considerably improved with the proposed strengthening method. Moreover, thicker SSPs could improve the wall response if the connectors designed to provide a composite action meet the SSPs thickness. However, some key questions and notions are still undiscussed in the former work. For instance, the SSPs thickness's maximum limitation and the ratio of connectors distribution to SSPs thickness ( $\left.s / t_{\mathrm{SSP}}\right)$ are still unspecified. Therefore, another experimental and verified numerical study was conducted by Kanchi Kanchi et al. (1996) and Zhang et al. Zhang et al. (2014), addressed these inquiries intently. Their study investigated the influence of shear connectors design on the TFSCWs system's behavior and the suitable $s / t_{\text {ssp }}$ value that precludes the SSPs from buckling before yielding in compression. The study indicated that the SSPs must be non-slender during the axial compression load. To achieve that, the value of the SSPs slenderness $s / t_{\text {SSP }}$ should be calculated as follow: $s / t_{S S P}=1.0\left(E / F_{\mathrm{y}}\right)^{0.5}$. The study also proposed a formula for the partial composite action within the 75-90\% range if the connectors were designed accordingly.

Differently, a failure criterion model was generated by Song et al. Song et al. (2014), following the plastic limit analysis theory, to analyze the peak strength of TFSCWs under biaxial compression load. Two equations were proposed in this study to predict the TFSCWs compressive strength in $\mathrm{x}$ and $\mathrm{y}$-axis direction and the tensile strength of the same details expressed in Eq. 10 and 11 , respectively.

$f_{c x}=f_{c y}=(1+\Phi) f_{c}$

$f_{t x}=f_{t y}=\Phi f_{c}$

For evaluation purposes, the proposed model's analysis results were compared to former studies of Ozaki and Varma Ozaki et al. (2004); Varma, Malushte, et al. (2011). They obtained more accurate findings for the samples exerted to high compression force. Despite the limitation of the study on the theoretical side, it presented a reliable failure criterion model.

\subsubsection{Cyclic Load Case Studies}

In 2009, Eom Eom et al. (2009) explored the seismic performance of TFSCWs of couple configurations, rectangular and Tshape cross-sections (Figure 19). Tie bars with multi-distribution were used to provide composite action, reduce wall thickness, and enhance constructability. The primary failure occurred as a tensile fracture and SSPs local buckling. The observations showed that specimens with larger depth are less ductility. Generally, the ductility was governed by the failure progression at the wall base. Therefore, several base-strengthening methods were proposed in this study.

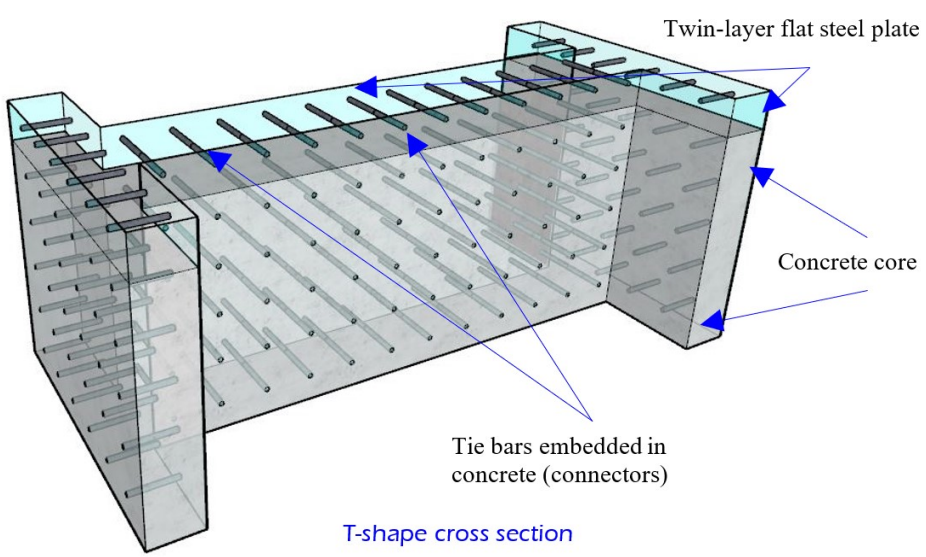

Figure 19. One of the TFSCW composition adopted by Eom 
In 2011, Varma et al. Varma, Zhang, et al. (2011) presented a simplified mechanistic for the in-plane complex shear behavior of TFSCWs, and a design formula for in-plane shear stiffness and capacity calculation (check Eq. 12-15) openingclosing the cracks in infill concrete during loading phases. An evaluation process was conducted to certify these equations' validity by using existing test data. The equations were further verified through testing a large-scale sample. The test results confirmed the theoretical behavior based on the equations below.

$K_{x y}^{u n c r}=G_{s} A_{s}+G_{c} A_{c}$

$S_{c t}=\frac{\sqrt[2]{f_{c}^{\prime}}}{1000}\left(\frac{E_{c} A_{c}+E_{s} A_{s}}{E_{c}}\right)$

$K_{x y}^{c r}=K_{s c}+K_{S}=\frac{1}{\frac{4}{0.7 E_{c} A_{c}}+\frac{2\left(1-v_{s}\right)}{E_{S} A_{S}}}+G_{S} A_{S}$

$S_{x y}^{Y}=V_{n}^{i n}=\frac{K_{s}+K_{s c}}{\sqrt{3 K_{S}^{2}+K_{s c}^{2}}} \times A_{s} F_{y}$

The majority of the literature on the TFSCWs system addressed using it in nuclear plants conducted on a small scale and focused on the pre-peak range of response. Therefore, Epackachi Epackachi et al. (2013) investigated four full-scale TFSCWs samples' cyclic response addressing the inelastic response range. The key parameters selected were the infill concrete thickness, studs, tie bars spacing, and reinforcement ratio. The results proved the influence of the SSPs slenderness ratio (range of 21-32) on the post-pea k response, where the pinching phenomenon was observed. Similarly, Epackachi Epackachi et al. (2014) developed numerical models using LS-DYNA software LS-DYNA (2012a, 2012b) to simulate the damage of the TFSCWs specimens accurately including, the damage on the infill concrete at wall toe and around the first row of the connectors, SSPs outward buckling, yielding and tearing near-wall baseline and the pinching phenomenon occurrences after peak-load stage Epackachi et al. (2014). Additionally, the study showed that the SSPs resisted over $75 \%$ of the baseline's total strength. The rate of post-peak decline was observed mainly related to the SSPs slenderness ratio. Also, the distance between the first row of connectors and the baseline significantly impacts the postpeak response.

Moreover, the numerical simulation proved the relationship between the initial stiffness and the foundation flexibility that must be considered during the models' simulation. Later, the analysis results of 98 models with several parameters were used to formulate prediction equations to predict the earthquake peak-strength for the TFCSWs system Epackachi, Whittaker, and Aref (2017), and the mechanics-based design equation of ultimate flexural capacity of the TFSCWs. It should be stated that ABAQUS could not simulate the cyclic behavior; therefore, LS-DYNA was an efficient alternative software that managed to overestimate the post-peak behavior of TFSCW. Later, Nguyen et al.Nguyen and Whittaker (2017) conducted a numerical simulation using ABAQUS software simulating Epackachi samples Epackachi et al. (2013). The overestimation in LS-DYNA models was attributed to the full bond assumed between the SSPs and the infill concrete. However, ABAQUS has varied types of interaction that can be used to overcome the overestimation issue. Moreover, the analysis results showed that the SSPs contribute between $20 \%$ and $70 \%$ of the shear strength of the TFSCWs based on the reinforcement ratio, SSPs slenderness ratio, displacement, and damage status. Additionally, the few rows of connectors above the baseline are preferred to be tie-rods where the greatest damage is expected. Part of this work program, Terranova et al. Terranova, Epackachi, and Whittaker (2017) used the LS-DYNA FE verified models of Epackachi Epackachi et al. (2014) to investigate the impact of off-plane load on the in-plane cyclic load. The analysis results showed that the off-plane load becomes more significant as the wall $\mathrm{H} / \mathrm{L}$ ratio increased. The study suggested a cyclic capacity reduction factor for ranges of $\mathrm{H} / \mathrm{L}$ ratios based on monotonic off-plane and in-plane cyclic loading.

Furthermore, Hu et al. Hu, Nie, and Eatherton (2014) presented a simplified formula for calculating the TFSCWs system's peak-curvature, as expressed in Eq. 16. The formula was established based on 6379 parametric models of developed analysis software built on a fiber section analysis approach. The adequacy of the software was formerly approved versus test results. The formula was also used to predict the drift ratios and the ductility of the TFSCWs. 
$n_{2}=\frac{N}{f_{y} A_{s}+f_{c 0} A_{c}}$

Similarly, Seo et al. Seo et al. (2016) implemented the mechanics-based model (MBM) to produce the fundamental force-shear strain $(V-\gamma)$ behavior of TFSCWs exhibits in Eq. 17.

$V_{n}^{M B M}=V_{n}=S_{x y}{ }^{Y} \frac{K_{s}+K_{s c}}{\sqrt{3 K^{2}{ }_{s}+K^{2} s c}} \times A_{s} F_{y}$

The MBM considers the infill concrete tensile cracks and the post-cracking orthotropic response of the TFCSWs during reverse cyclic load application. Moreover, the MBM behavior predictions were calibrated versus large-scale tests observations of 26 TFCSWs with a wide range of parameters conducted in Japan, S. Korea, and America. The experimental results of the 26 samples were compared with relevant predicted results from the available design code equations. In contrast, the MBM prediction results of TFSCWs showed mostly conservative outcomes, which were reliable with 0.95 strength reduction factors $(\varphi)$. Further experimental and numerical work conducted by Seo et al. Seo and Varma (2017) investigated the joint shear response and L-joints wall-to-wall corner capacity. The study focused on the force-shear strain and force-displacement response and the concrete damage in the joint area. Accordingly, the joint capacity and governing failure mode were established. The experimental and analytical outcomes were compared with the results obtained from ACl $349 \mathrm{ACl}$ (2006) equation to calculate the shear strength of RC beam-column joints, which showed a good agreement with shear strain ( $\gamma$ ) of 8.0. However, there was a lack of studies for TFSCWs structural collapse behavior due to cyclic load until it was investigated by Zhao et al. Zhao et al. (2016) through compiling prior experimental results of 32 samples of TFSCWs with several configurations. Accordingly, and based on the MBM, a calibrated and verified equations for stiffnesses and cyclic loads were derived, and the TFSCWs cyclic behavior was described.

In 2004, Astaneh-Asl Astaneh-Asl and Zhao (2004) presented an innovative system of composite walls with a special boundary-gap shown in Figure 20, aiming not to involve the concrete panel in shear strength of the CW with relatively small lateral drifts. Accordingly, Rahnavard et al. Rahnavard, Hassanipour, and Mounesi (2016) conducted a nonlinear validated numerical analysis on five new configurations using ABAQUS software Hibbitt, Karlsson, and Sorensen (2002), as illustrated in Figure 21. The results showed that the side of SSP achieved the best energy absorption. Also, the connector's distribution does not influence the lateral stiffness. However, reducing connectors spacing was shown to improve energy absorption. Moreover, increasing the concrete panel thickness reduced the SSP buckling.

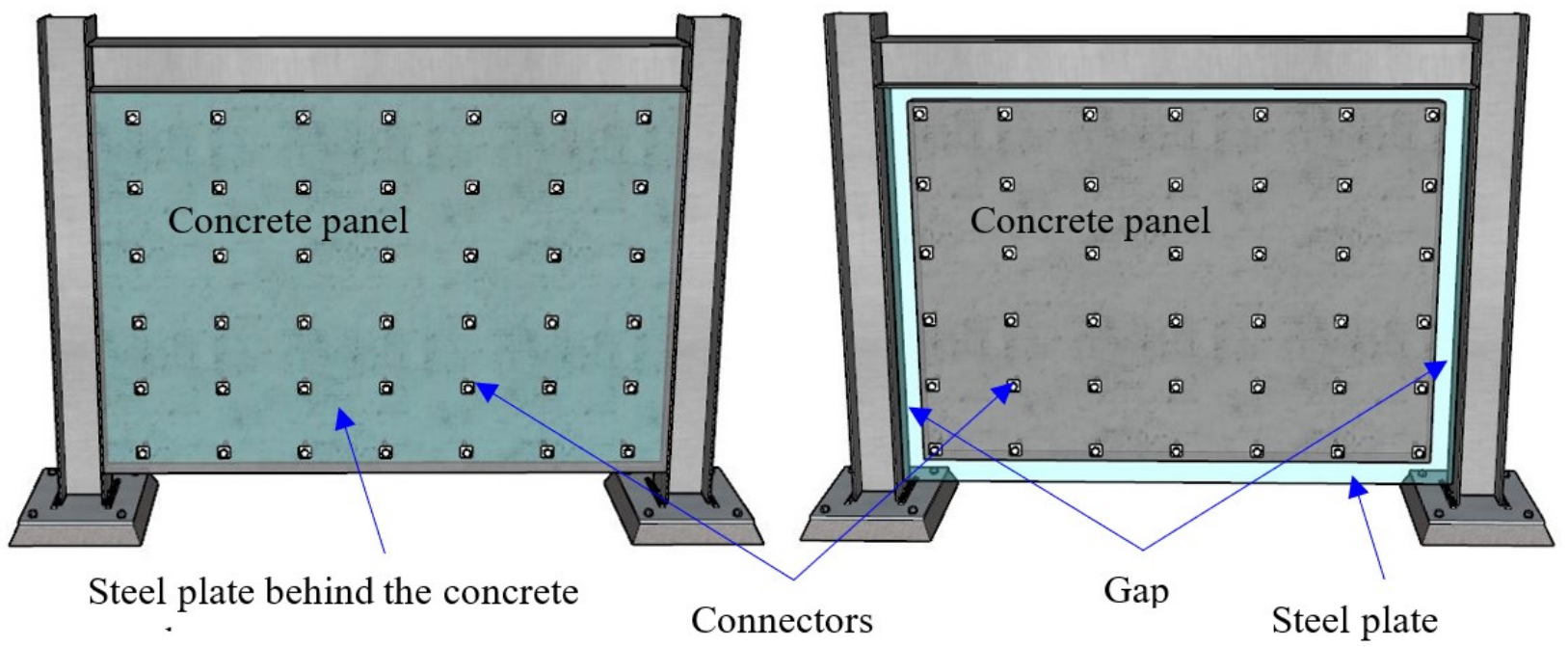

Figure 20. Composite shear wall systems concepts adopted by Astaneh-Asl 2004 


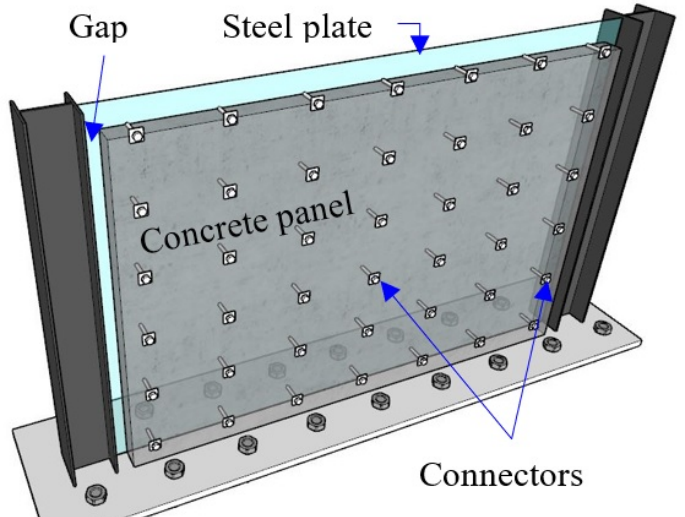

(a) Concrete with gap on one side
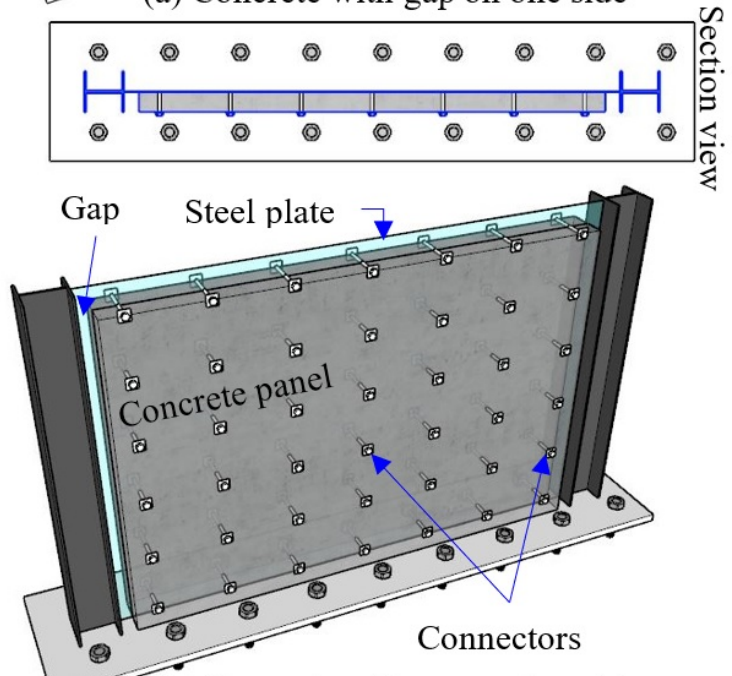

(c) Concrete with gap on two side

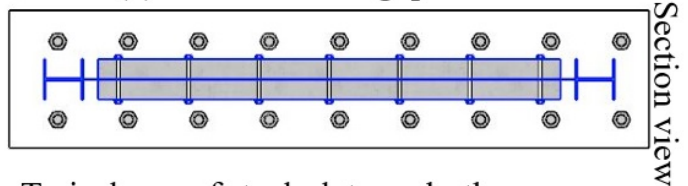

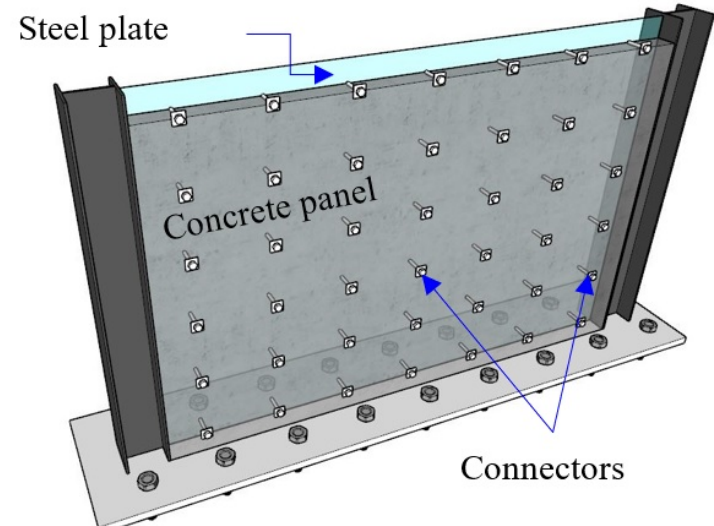

(b) Concrete on one side
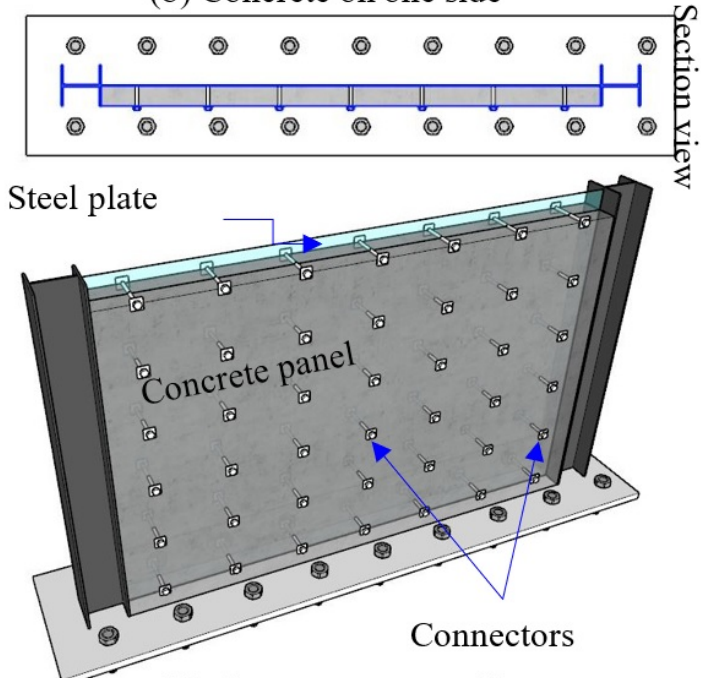

(d) Concrete on two side

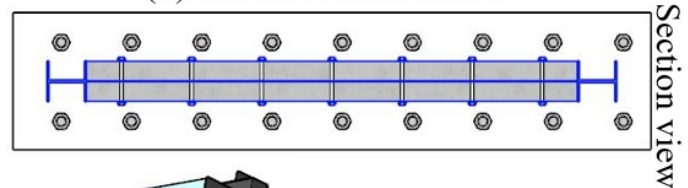

Twin-layer of steel plate on both

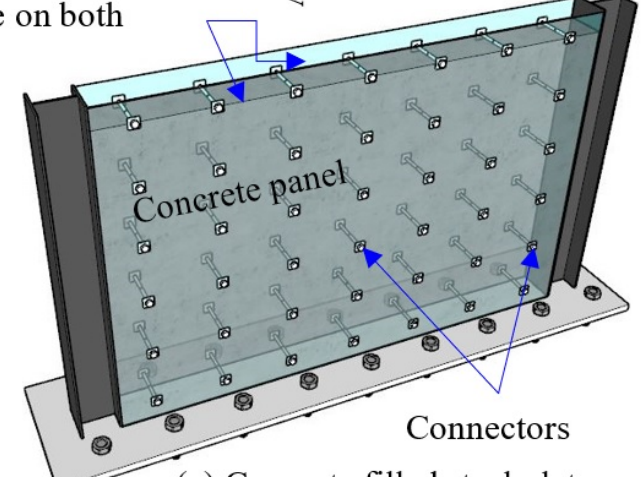

(e) Concrete filled steel plates

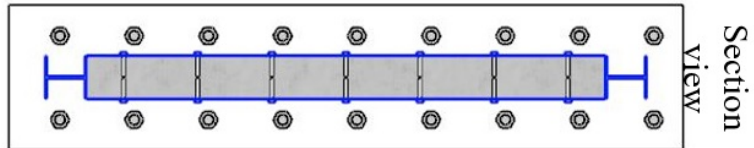

Figure 21. Composite shear wall systems concepts proposed by Rahnavard 2016

Recently, Epakachi et al. Haghi, Epackachi, and Taghi Kazemi (2020) investigated SC's seismic behavior robust fiberbased model using the PERFORM-3D program. The study provided several model details, such as material properties, boundary conditions, and element types. The numerical results were validated through 17 SC wall samples' available experimental data in the presence and absence of boundary elements. According to the results, this novel approach can 
accurately capture the global wall response. It can be used easily in numerical simulations of buildings and infrastructures in which TFSCWs are used.

\subsubsection{Lateral Load Case Studies}

Further studies conducted by Epakachi et al. Epackachi, Whittaker, and Huang (2015) as a part of the complete research program, addressed the monotonic force-displacement behavior of the TFSCWs system. To that end, a reliable simplified model was presented after validating it to the numerical and experimental results from the same working program. The proposed model helped conduct preliminary analysis for structures, including the TFSCWs system, efficiently and accurately.

\subsubsection{Impact Load Case Studies}

In 2012, Mullapudi et al. Mullapudi, Summers, and Moon (2012) evaluated the influence of various parameters on the TFSCWs response under impact load numerically. To achieve that, LS-DYNA LS-DYNA (2012a, 2012b) was used to develop 11 TFSCWs models using the Winfrith concrete constitutive model and the Riera force history method, which mimic the impact loads of aircraft. The results showed that thicker-plate in thinner-model observed less peakdeformation than a thicker concrete model. The study also proved the significance role of the tie bar in which the central loaded area of the models, mostly failed in complete shear with less tie bars. Generally, using LS-DYNA with an adequate material constitutive model showed substantial beneficiary as an analysis tool. Figure 22 exhibited a load application with varied time and uniform pressure.

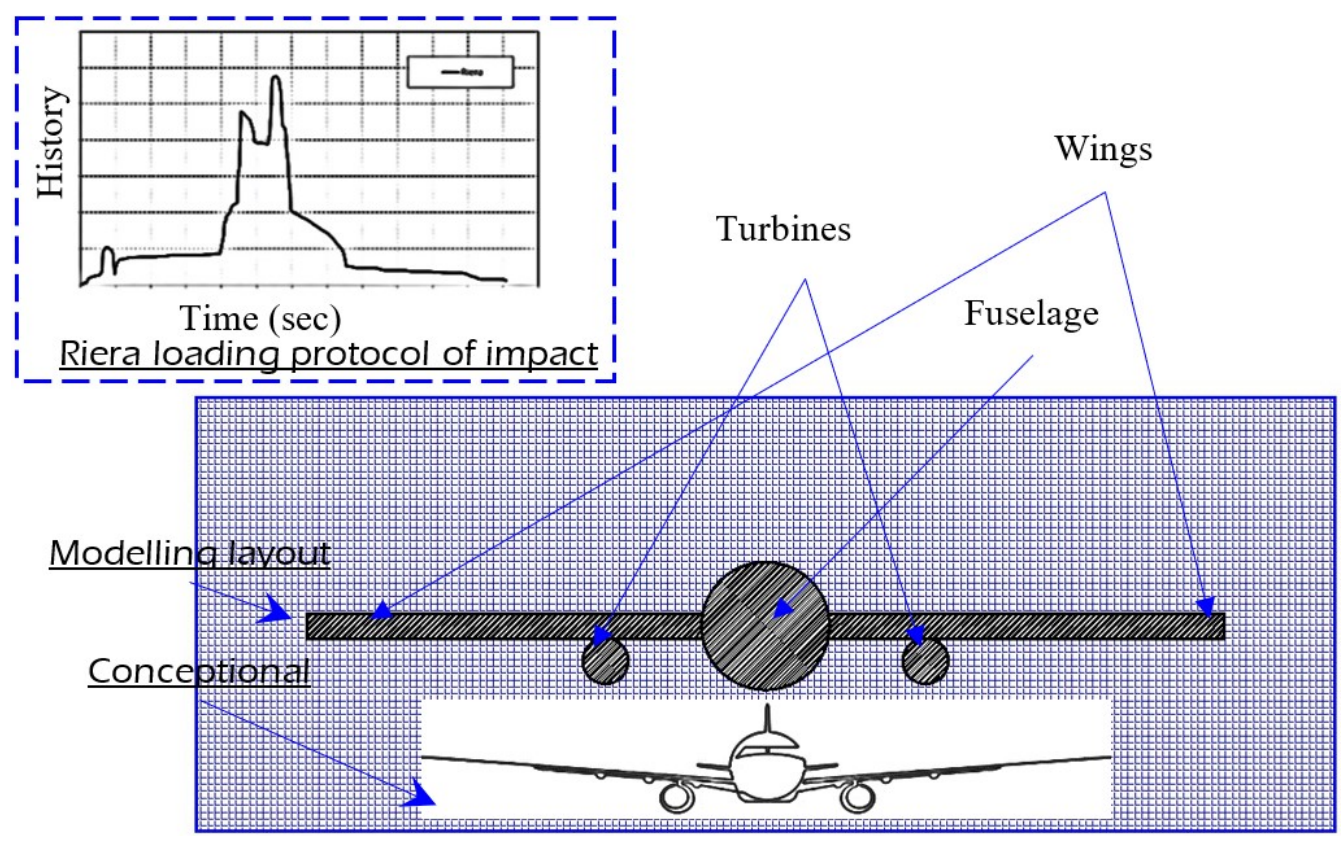

Figure 22. Load zone for Riera loading protocol with airplane key parts

Similarly, Bruhl et al. Johnson et al. (2014) investigated the TFSCWs impact response using LS-DYNA pseudo-static nonlinear solutions to develop a verified SDOF solution approach for TFSCWs. To that end, 19 models were analyzed under the impulse and demonstrated that the near-linear displacement hardening effect was exhibited as a load resistance function. The footprint size governs the load-deformation curve. The study proposed a design approach, including panel resistance function development, impact load representation as an equivalent SDOF system, and a panel response equilibrium equation solution. Further extensive investigations were conducted by Bruhl et al. Bruhl, Varma, and Johnson (2015) was by testing 130 samples of TFSCWs under missile impact experimentally. The study aimed to provide a three-step TFSCWs design method that can compute the minimum essential SSPs thickness to prevent missile perforation with $60 \mathrm{ft} / \mathrm{sec}$ and $750 \mathrm{ft} / \mathrm{sec}$ missile initial velocity. On that account, and based on the empirical equations and physics-based that consider the steel and concrete perforation separately beside their interaction, equation 18 was proposed as shown in Eq. 18. 
$V_{r}=\sqrt{\left\{\frac{1}{1+W_{C P} / W}\right\}\left(V_{o}^{2}-V_{P}^{2}\right)}$

The proposed equation showed reliable outcomes versus the experimental data. 3D-FE models were also developed and benchmarked versus the experimental test results to expand the database by conducting analytical parametric studies. Further checking for the design method's validity was conducted by comparing the FE predicted results with those calculated from the formula and shown well agreement. More recently, Bruhl and Varma Bruhl and Varma (2018) conducted an experimental test on mini scale TFSCWs exerted to short-duration uniform pressure to analyze 12 TFSCWs samples' blast response. Different parameters were included, such as steel plate strength and concrete reinforcement ratio in the test program. The results found that peak displacement was related inversely to SSPs' strength and flexural reinforcement ratio. Moreover, no concrete crushing was observed through the test, but some specimens showed flexural cracks through concrete panel depth. Flexural behavior governed the entire response, where no observation of shear failure was recorded at any specimens. Finally, the test findings were compared with the SDOF analytical model and obtained $10 \%$ greater than measured.

\subsubsection{Thermal Load Case Studies}

Seeking to provide a modeling recommendation for TFSCWs analysis and design under the influence of thermal load, in 2012, Varma et al. Varma et al. (2012) summarized findings from several work program types of research TFSCWs under various types of loadings. Experimental and analytical research indicated that additional concrete cracking and flexural stiffness reduction occurred with the accident thermal conditions. Accordingly, the study presented Eq. 19 to calculate the modified flexural stiffness $\left(\mathrm{El}_{\mathrm{eff}}\right.$ ) considering the accident thermal loading. Moreover, a formula to calculate the modified inplane shear stiffness $\left(\mathrm{K}_{\mathrm{xy}}{ }^{\mathrm{sec}}\right)$ in the presence of accident thermal loading was also proposed, as shown in Eq. 20.

$E I_{e f f}=\left(E_{S} I_{s}+\alpha E_{c} I_{c}\right)\left(1-\frac{\Delta T_{s}}{150 F}\right) \geq E_{s} I_{S}$

$K_{x y}{ }^{\text {sec }}=0.5(\bar{\rho})^{-0.42} G_{s} A_{s}$

\subsubsection{Combined Load Case Studies}

In 1989, Sekimoto et. al. Sekimoto et al. (1989) conducted one of the earlier studies in this field due to the high demand for a shorter construction period in nuclear facilities, one of TFSCWs system advantages. 1/10 scale samples were tested under a combination of axial and earthquake load. The findings showed superiority in the peak-load, ductility, and cyclic response. The study was limited on the experimental side. Therefore, a recommendation for further investigation to produce a rational design method was stated in the study. Accordingly, in 2013, Varma et al. Varma and Sener (2013) developed verified numerical models for the entire containment internal structure (CIS) of the nuclear reactor using ABAQUS FE-software. The 3D model of the CIS provided a deeper understanding of TFSCWs behavior as a full structure. Further data, including the lateral deformation ductility and energy absorption, were also reported in addition to several recommendations for modeling such cases were also provided. Several studies on the TFSCWs system conducted in Japan and S.Korea, especially nuclear power plant usage, were unfortunately unreachable in that era. However, in 2012, Qian et al. Qian, Jiang, and Ji (2012) presented new TFSCWs compositions by embedding fully baseanchored steel tubes at the wall boundary elements to improve the TFSCWs seismic behavior, as shown in Figure 23. Thus, a group of specimens was tested under a high axial load combined with a lateral cyclic load. The results proved the advantage of the TFSCWs over the RC wall in terms of strength. The deformation ability, which is inclined to increase the embedded steel tube and CFST, declined with the applied axial load increment. Additionally, larger deformation and energy absorption showed to be related to improving the boundary elements. In contrast, the SSPs sectional area showed a slight effect on the deformation capacity Ji, Jiang, and Qian (2013). Theoretically, the study developed formulas to calculate the wall capacity accurately as expressed in Eq. 21-24.

$$
\begin{aligned}
& N=N_{c}-N_{s w}+N_{c f s t}-A_{a} f_{a} \\
& M_{p}=0.5 N_{c}\left(h_{w}-x\right)+A_{s} f_{y}\left(h_{w}-2 a_{s}\right)+N_{C F S T}\left(0.5 h_{w}-a_{a}\right)+A_{a} f_{a}\left(0.5 h_{w}-a_{a}\right)+N_{s w} d \\
& N_{c}=\alpha f_{c} b_{w} x
\end{aligned}
$$




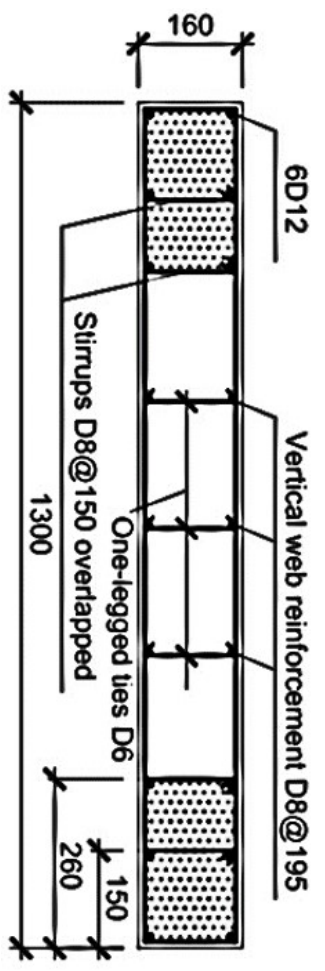

(a) SW1

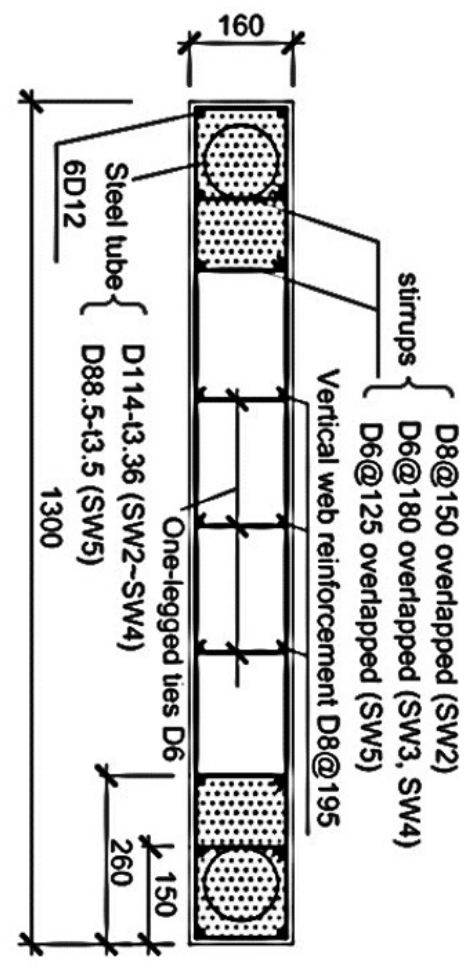

(b) SW2 through SW5

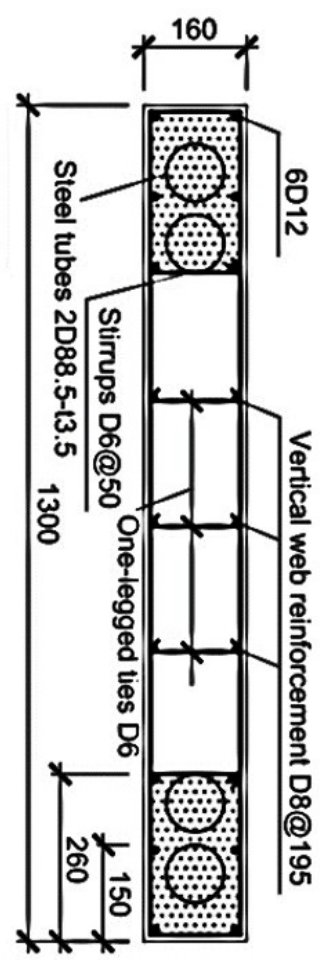

(c) SW6

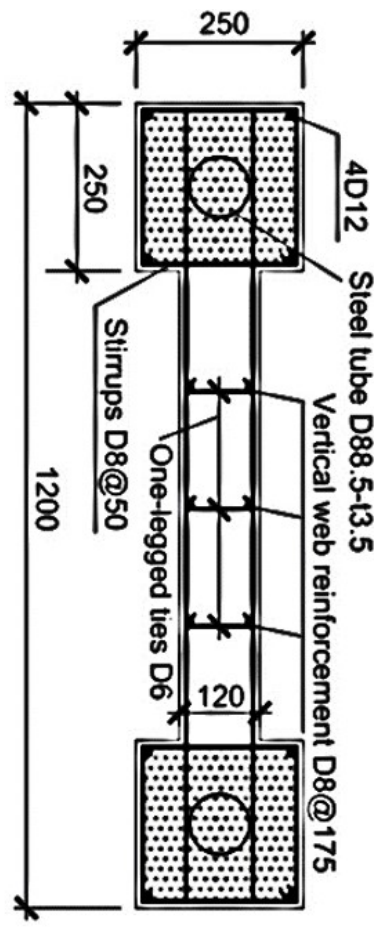

(d) SW7

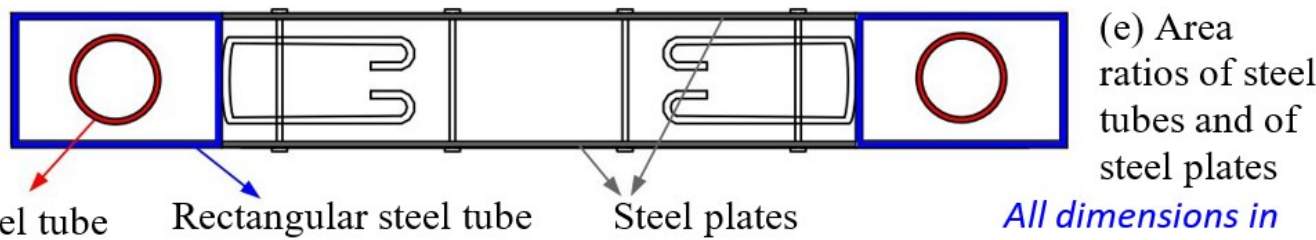

Figure 23. Samples sections configuration adopted by Qian et al. Qian, Jiang, and Ji (2012)

More recently, an experimental test on 14 specimens was conducted by Yan et al. Yan, Li, and Wang (2018) adopting a similar steel tube concept embedded in the boundary frame, seeking more ductile behavior of the TFSCWs system in high-rise buildings with the stud's connectors overlapping configuration. Higher studs' overlapping is shown to be improving the wall strength and energy absorption capacity. Moreover, significant improvement was obtained by embedding the steel tube in the boundary frame on the peak strength, ductility, and energy absorption.

Another experimental investigation addressed the effect of axial load on a unique TFSCWs system's hysteresis behavior, namely, bundled-lipped channel-concrete (BLC-C) system conducted by Zhang et al. Zhang, Qin, and Chen (2016). The test program included seven full-scale specimens of TFSCWs fabricated with different bundled lipped channels configurations and infilled concrete. Again, results proved the significance of the axial load ratio on the cyclic wall capacity and the reduction of strength and stiffness. Also, a huge influence on the boundary elements was observed on the seismic wall response. This study's significant finding was that more plentiful hysteresis loops were obtained with smaller crosssectional lipped channels. Another study by Ma et al. Ma, Ma, and Liu (2019) experimentally and numerically, and Wang et al. Zhang et al. (2019) experimentally on 15 TFSCWs samples. Wang showed that changing the number of channels and the wall thickness showed a major improvement on the wall ductility but no influence on the wall shear strength. Figure 24 shows the specimens configurations adopted in this study. Generally, several configurations in the shear walls' literature addressed the brittle behavior of concrete, such as the walls compositions exhibits in Figure 25. However, the partitions configuration shown to use the orthotropic post-peak behavior of concrete better. 


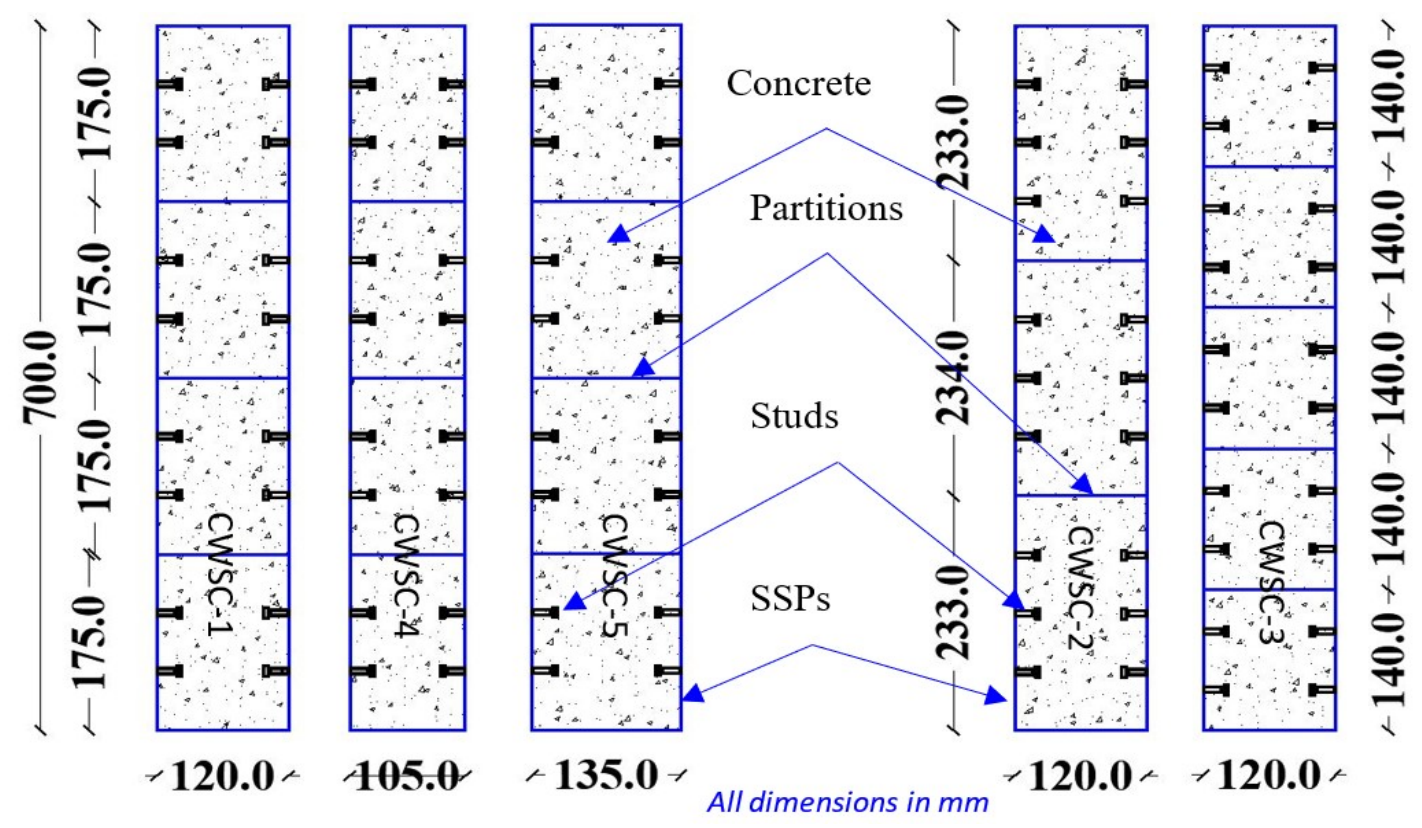

Figure 24. Details of Wang specimens

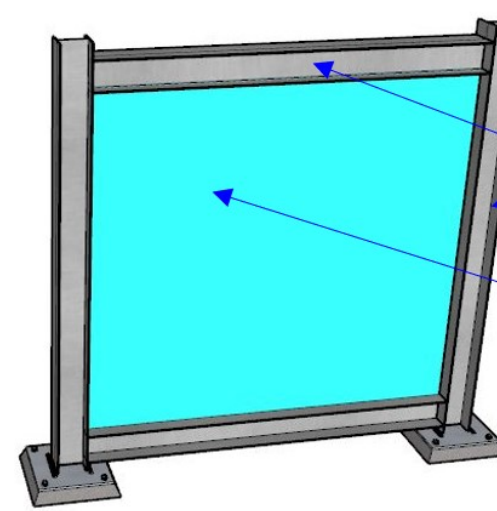

(a) Steel plate shear wall

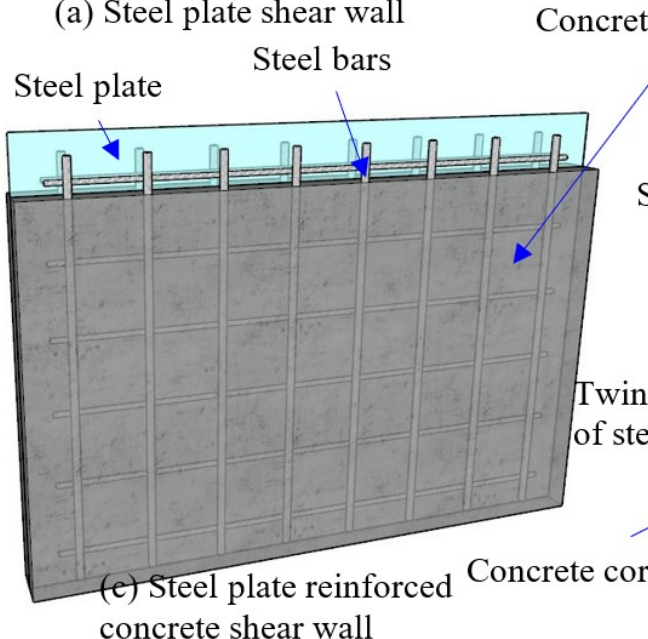

concrete shear wall

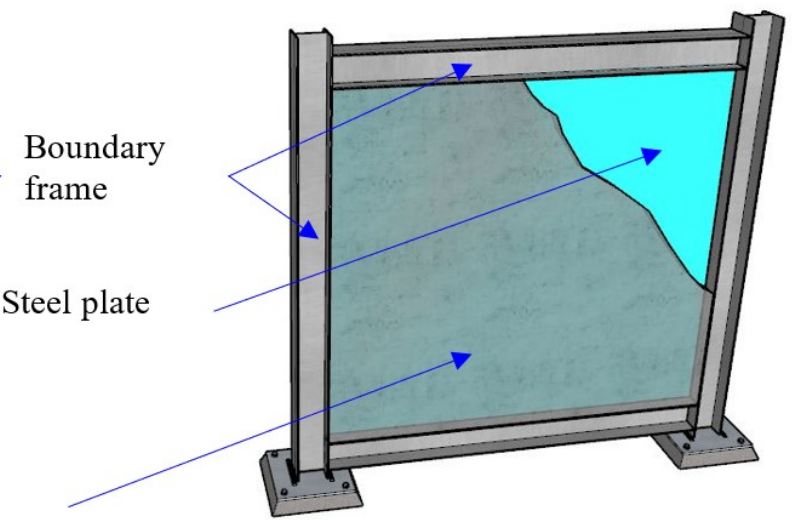

(b) Composite steel plate shear wall

Steel bars

Tie rods

Shear studs

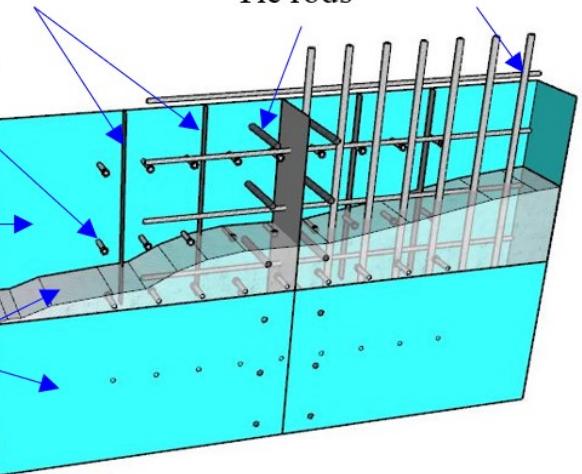

(d) TFSCW system

Figure 25. Compositions of different shear walls

Similarly, Nie et al. Nie et al. (2013) proposed a new composition of the TFSCWs system exhibits in Figure 26 to provide a high ductile core wall required in skyscraper buildings. Therefore, the study used high-strength concrete with a reasonable wall aspect ratio and adequately arranged batten SSPs. To that end, 12 samples were tested under high axial and reverse cyclic lateral load. Due to the efficient connectors and the adopted wall aspect ratio, the steel-concrete worked compatibly; 
thereby, the SSPs showed no buckling sign. Good energy dissipation and deformation capacity were gained from the tested samples, indicating that the combination of high-strength concrete with the proposed system can behave effectively. Based on the analysis results, a calculation approach with satisfactory prediction was presented, as expressed in Eq. 25. Additionally, to investigate the proposed system's effective stiffness, Nie et al. Nie et al. (2014) used the plane combination truss model (PCTM), verified with the test results, which implements the fixed angle truss model theory. Accordingly, formulas calculating the effective stiffness were derived, as expressed in Eq. 26 and 27, respectively. Moreover, further numerical investigation using MSC.Marc (2005r2) software addressed several parametric studies that did not include the experimental test, especially the axial load ratio's influence, and the SSPs slenderness ratio was conducted Xiaowei, Jianguo, and Muxuan (2013). Results showed that increasing the axial force minimizes the wall's cyclic capacity significantly, and the slippage phenomenon occurred where the concrete cracks at the tension side of the wall-base.

$n_{d}=1.25 N /\left(f_{c} A_{c} / 1.4+f_{y} A_{s} / 1.11\right)$

$\Delta_{v, h}=\Delta_{c} / \sin \emptyset_{c}+\Delta_{s}$

$K_{e, v}=V /\left(\emptyset_{\text {total }} \times H\right)$

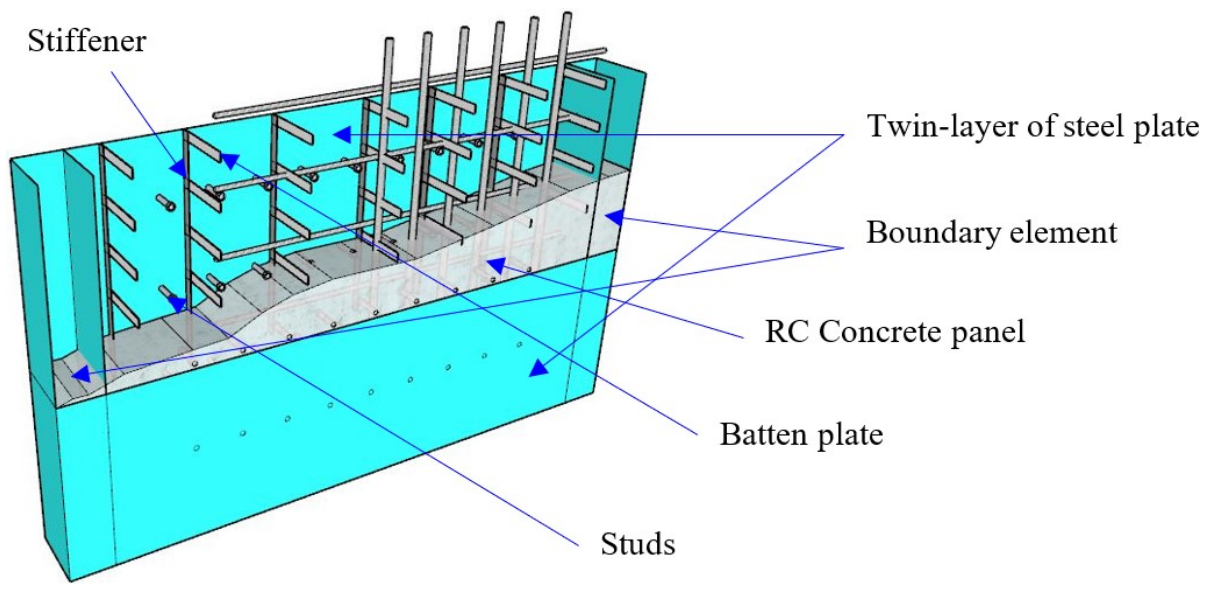

Figure 26. TFSCWs composition of Nie

Similarly, Varma et al. Varma et al. (2014) presented a verified MBM and numerical FE model to predict the actual behavior of the TFSCWs system exerted to combinations of in-plane forces and moments. Seeking the adequacy in design, effects such as concrete spalling, post-crashing orthotropic response, SSPs yielding were included. Hence, both models predicted TFSCWs behavior conservatively. The models were used to explore the effects of several in-plane forces and their combinations on the TFSCWs' response. Later, the results were implemented to develop a conservative interaction surface (Sp1-Sp2), which is significantly important in the prediction adequacy of the TFSCWs model under and combinations of in-plane loads.

In 2020, Yan et al. Yan, Yan, and Wang (2020) presented another study that investigated the cyclic response of TFSCWs under the influence of axial load. The study tested five full-scale samples with J-hook shear connectors and filled steel tubes as boundary frame members, as shown in Figure 27-a. The five samples were failed by flexural failure during the test. Test results also indicated that increasing the J-hook spacing could diminish the seismic wall response through early buckling in the SSPs and reduce the wall's initial stiffness. Therefore, further investigations addressing the J-hook distribution are required. Again, this study proved that increasing the axial load shear would decline the deformation capacity, ductility, and energy absorption. Also, it would aggravate the stiffness deterioration and strength retrogression. However, lateral peak shear resistance and initial stiffness showed an improvement in increasing the axial load share. Theoretical validated models were also proposed but with $28 \%$ underestimation. Therefore, further work was conducted by Yan et al. Yan et al. (2020a) numerically by developing a FE model validated versus 11 tested samples, as illustrated in Figure 27-b. Several parameters were studied numerically did not include in the experimental test. Based on the FE results, the underestimation ratio on the theoretical models achieved $11 \%$, thereby proving its efficiency. Increasing the J-hook spacing and the concrete $f_{c}^{\prime}$ affected the ultimate cyclic capacity by only $10 \%$. However, increasing the SSPs thickness from 3 to $7.5 \mathrm{~mm}$ led to improve of the ultimate cyclic capacity by $20 \%$, whereas adopting similar thickness 
increment in the steel tubes in edge columns enhanced the ultimate cyclic capacity by $60 \%$, which proved the essential role of boundary frame steel tube on improving the ultimate cyclic capacity.
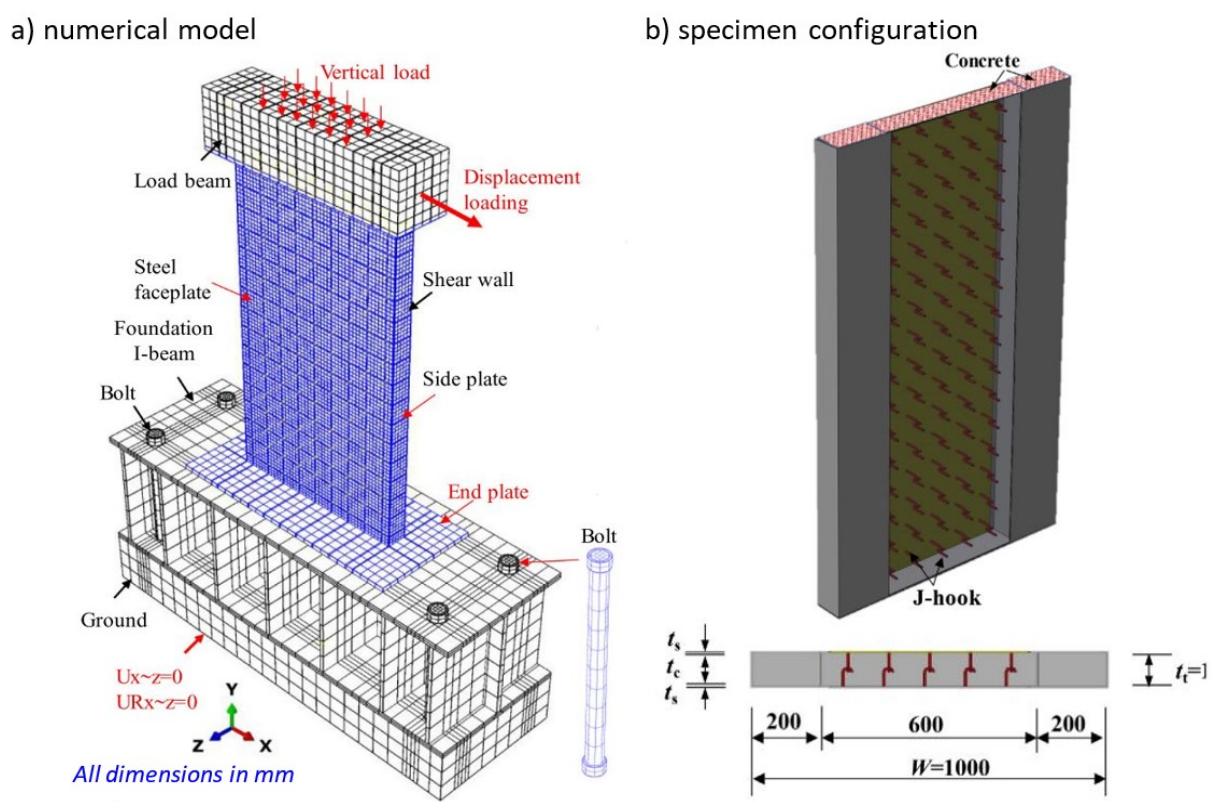

Figure 27. Component and details of Yan samples and models Yan et al. (2020a)

\section{Discussions}

A comprehensive and systematic review of 80 research works from the current knowledge in the literature on the TSCWs system for the last three decades has been conducted in this paper. This section extensively discussed the presented researches in terms of the type of studies (experimental numerical and/or empirical investigations), loading conditions, properties of infill material, and interaction concept between the steel sheet layers and the concrete. Out of the 80 references indexed in this review, 33 studied the behavior of TPSCWs, 47 assessed the performance of TFSCWs, in addition to other studies considered literature cases of CWs in general, as illustrated in Figure 28. The great majority of the previous studies were carried out experimentally and numerically, compared to empirical studies. This research attention might be attributed to a large number of the novel configuration and the special arrangement of components' combinations in the field of composite walls, which are required a comprehensive investigation for each new wall system, independently to provide a full wall's assessment. It should also be noted that most of the studies simultaneously utilized more than one investigating approach, such as experimental and numerical. However, there is still a critical need for more theoretical and analytical studies to enrich the designing part's fundamental knowledge, which is required to estimate several outputs such as load capacity, dissipated energy, and stiffness.

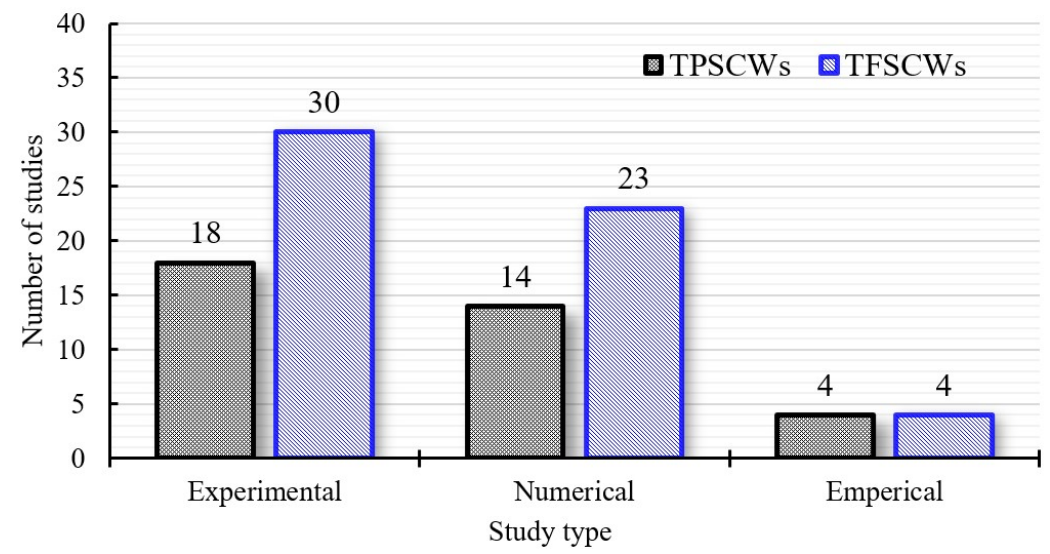

Figure 28. Statistics of different types of TSCW previous studies 


\subsection{Interaction Concepts}

Generally, the TSCW system requires a good interaction between the layers of steel sheet and the infill concrete to achieve the best composite performance. The steel tensile ability and the concrete compression capacity shall be merged by using mechanical connectors. A Shear connector is an addendum projection and/or partly made of steel, provided on the surface of plates, profiles section, and bridge girder to provide the desired shear distribution between the member interacted parts (i.e., steel-concrete walls). Several concepts of steel concrete interaction were used in the previous studies, for instance, internal stiffeners headed studs, fasteners, bolts, and mechanical shapes connectors. Figure 29 and Figure 30 present some common interaction concepts used for both sheeting shapes, besides the number of studies that have addressed these interaction concepts in prior research.

A few shapes of stiffeners and mechanical connectors were implemented in the literature to reduce the twin-layer steel plate outward local buckling and provide an adequate stress distribution and load-transfer between steel and concrete (i.e., Figure 29 (c), (d) and (f)), and therefore provide the required composite action. Furthermore, most of the previous studies focused on using the stiffeners internally (embedded in the infill concrete) rather than externally. This research observation could be because utilizing internal stiffeners helps provide a couple of improvements: stiffening the plates and securing the steel-concrete composite action. Additionally, internally stiffening the twin-layer of plates is more architecturally appropriate since the stiffeners are hidden inside the wall's core; accordingly, there will be no indoors-space disturbing. However, in certain cases, the external stiffeners are urgently needed, such as the construction strengthening process and structures reinforcing that mostly required due to miscalculation during the structural-design process, as well as to compensate for any potential failure that might occur due to overloading, earthquakes, changing the nature of construction usage, or averting any possible defects. Consequently, and due to the significant role of strengthening via external stiffeners, further research work has to be conducted about that matter.

In general, and for both types of TSCW systems, the through bolts, fasteners, and tie rods are illustrated in Figure 29 (b), (e) and (g) subfigures, respectively, which confined both twin-layer faces of the walls symmetrically, to achieve a significant performance in improving their behavior under different types of loading conditions, especially the axial compression, the cyclic and the combination of both types of loading. Additionally, the use of bolts, fasteners, and tie rods method can significantly reduce the off-plane failure mode by restricting the SSPs' buckling and simultaneously providing better confinement for the concrete than the other connector, which improves the concrete strength significantly. However, achieving the wall's ultimate performance depends on the number, type, and size of the through bolts and their distribution in the wall panels, which may be considered during the structural design stage.

Despite the lack of studies on the shear studs in TPSCWs, the available investigations on the TFSCWs are extensive. That can be attributed to the fact that shear studs are highly efficient in providing the composite action in the walls that subjected to seismic or lateral cyclic loading. It should be noted that TFSCWs are mostly used as core shear walls in high-rise buildings to resist the axial and lateral cyclic loads. However, despite the studies paucity that has examined shear studs in TPSCWs, this system was implemented in some structures as bearing and retaining walls. Therefore, further investigations in this area are required to be conducted.

Generally, the through-through types of interaction methods, such as bolts, rods, and fasteners interaction, were found to be the most efficient concept for the TPSCWs system to provide the best composite behavior and distribute the load between materials effectively. In contrast, the review findings showed that vertical stiffeners are highly preferred in bearing walls to resist compression forces. It was also found that bolts, fasteners, tie rods, and headed steel studs are the most efficient connectors in TFSCW systems. Furthermore, combining concepts is significantly useful in improving wall strength and reducing the wall section, thereby providing extra indoor space. For instance, the combination of longitudinal stiffeners headed studs and bolts is undoubtedly recommended to develop the bearing capacity, cyclic response, and provide an adequate steel-concrete interaction.

The diagonal stiffener concept is significantly efficient in terms of strength, energy absorption and ductility, for different shear wall types, whether installed internally (performed and/or sold plate/profile) or externally (solid plate or rod) Ramin and Fereidoonfar (2015). This review shows that no study has investigated the diagonal stiffening method onto TFSCW systems yet. Therefore, this study suggested implementing the diagonal stiffening concept to enhance lateral cyclic capacity and ductility and provide a novel concept of steel-concrete composite connectors for the TFSCWs system. 


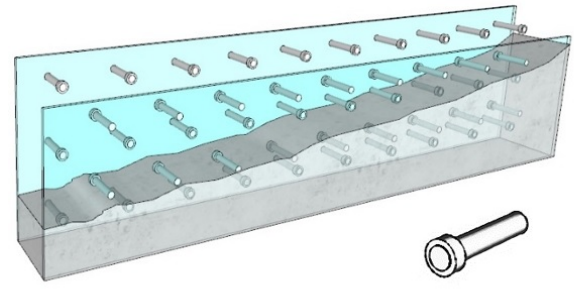

(a) Headed studs

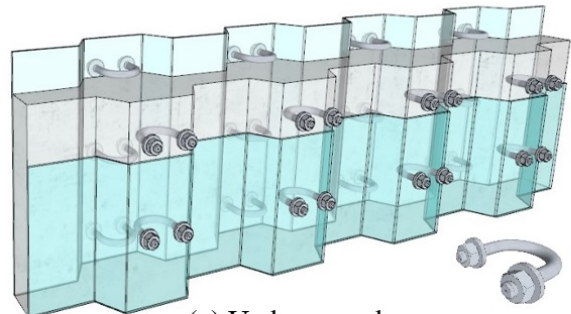

(c) U-shape anchors

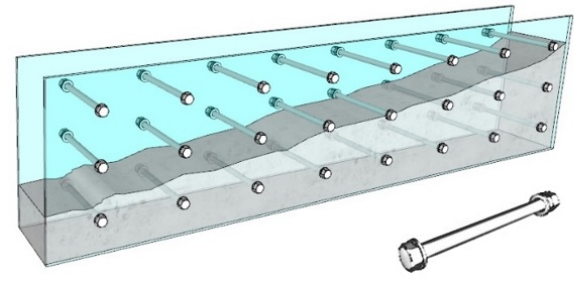

(e) Through bolts

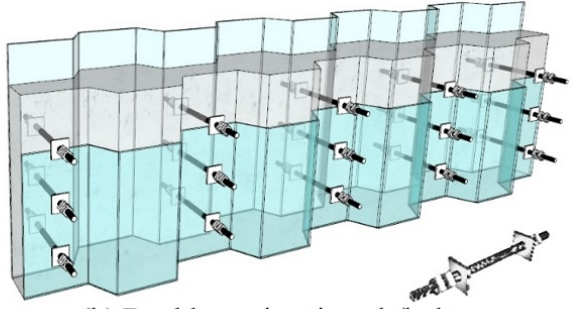

(b) Double arming tie rods/bolts

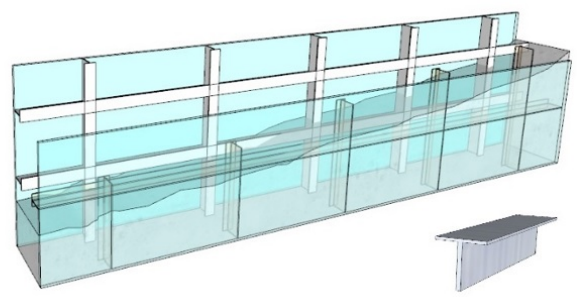

(d) T-shape internal stiffeners

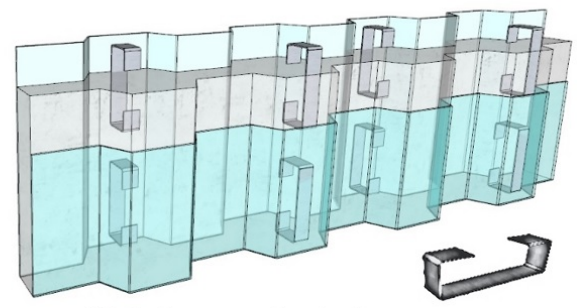

(f) C-shape mechanical connectors

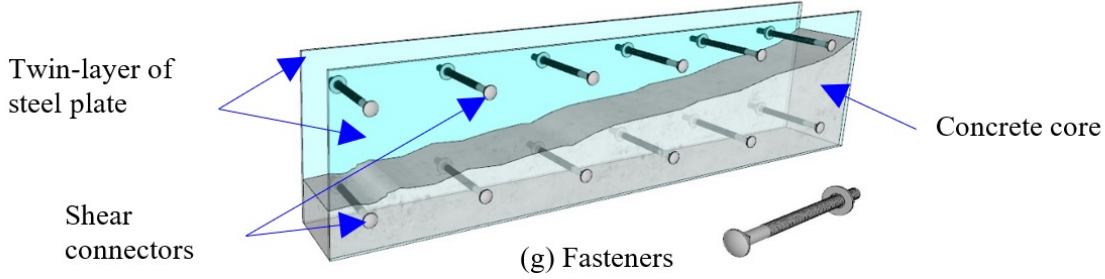

Figure 29. The common interaction concept used in prior research

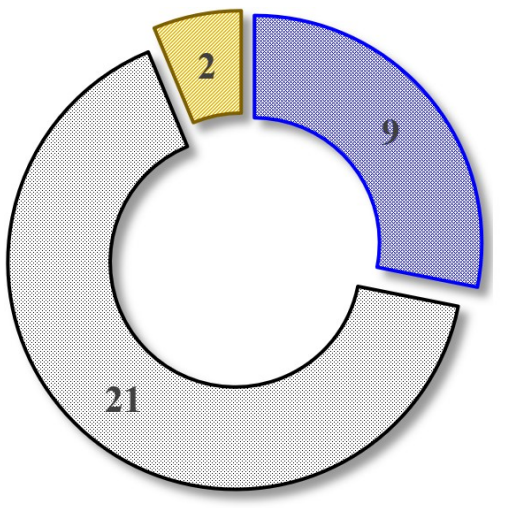

— Stiffeners and/or Mechanical Connectors

由 Screwed / fasteners / Bolts Tie and/or Bar / Rod Connectors

口Headed Shear-Studs

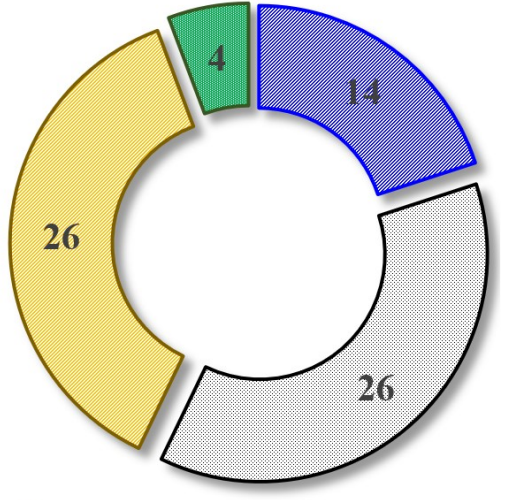

Q Stiffeners and/or Mechanical Connectors

■Screwed / fasteners / Bolts Tie and/or Bar / Rod Connectors

Headed Shear-Studs

口Welding and/or Constraint tie
(a) TPSCWs
(b) TFSCWs

Figure 30. Number of different types of interaction concepts in TSCW prior studies 


\subsection{Infill Concrete}

The systematic review has also classified the infill concrete type available in the past literature. It was found that only limited types of concrete have been used as an infill core in the TSCWs system. For instance, only normal selfconsolidation, high strength, micro, and lightweight-recycled concrete were utilized. As presented in Figure 31, most previous studies for both types of TSCWs were conducted using normal and self-consolidation concrete, which attributed to the availability of this type of concrete and the ease of producing it. However, many concrete types are useful, efficient, and available as infill materials, for instance, high-density concrete, air-entrained concrete, polymer concrete, and ecofriendly green concrete.

This review shows a lack of studies considering using these types of concrete referred to above as infill material. Moreover, no studies have investigated the impact of engineered cementitious composites as infill materials for both wall systems, despite the advantages of this type of concrete Sahmaran et al. (2009). Furthermore, no studies have examined the effects of waste materials such as crushed recycled concrete and/or plastic as infill material. Based on that, and to meet the global push toward a green environment, this review recommends using waste-recycled concrete as infill material should receive more research attention in coming studies.

Moreover, despite the high deformability of the expanded polystyrene (EPS) lightweight concrete Carbonari et al. (2012), a very limited number of studies have considered lightweight concrete as inf

ill material in composite walls systems. Therefore, future research should investigate the combination of lightweight and CWs systems deeply.

Despite the potential role of high-strength concrete in improving the TPSCWs as a bearing wall, this type of infill concrete did not involve a sufficient number of studies, giving that only couple of studies in the literature were found to discuss this issue. Hence, extra research work is needed to provide a better understanding of this area.

In general, and according to these findings, this review is highly suggested investigating the performance of TFSCWs with engineered cementitious composite as filler material under different types of loads to gain a clear understanding and thorough information about this ductile material since this type of wall are frequently used as a cyclic load resistance member, where the ductile materials mostly preferred. However, it was found that engineered cementitious composite was used only once as infill material among prior investigations for the TPSCWs system.

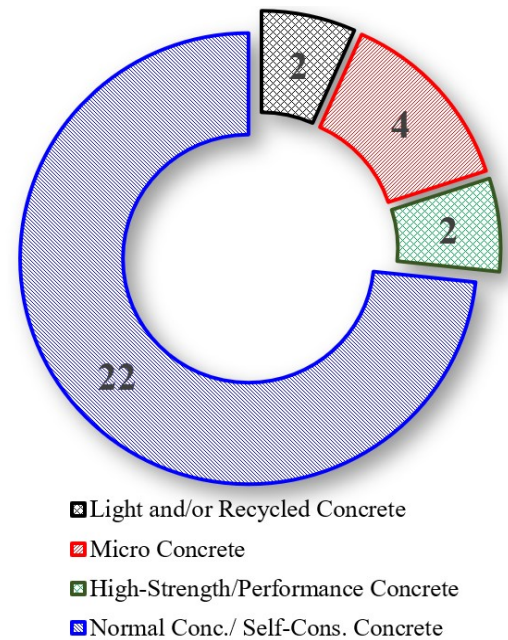

(a) TPSCWs

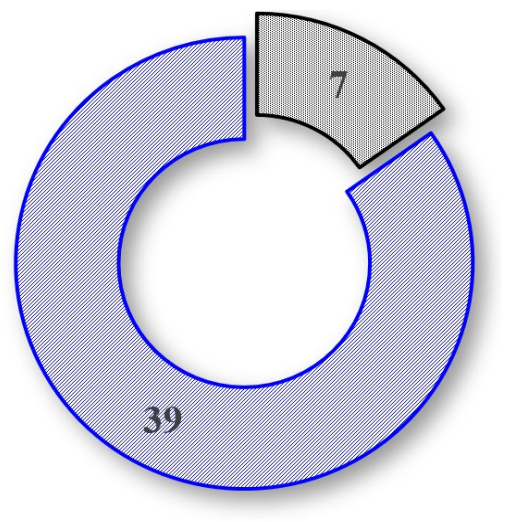

图High-Strength/Performance Concrete ఐNormal Conc./ Self-Cons. Concrete

(b) TFSCWs

Figure 31. Number of different types of infill concrete in TSCW prior studies

\subsection{Applied Loading}

The TSCWs system has been tested under several types of loading. For instance, axial, lateral, cyclic, thermal, impact, and combined loading conditions were utilized. Therefore, it was considered in the review taxonomy illustrated earlier in Figure 3. Figure 32 provides the number of studies on each loading form and each TSCW type categorized in this paper. 


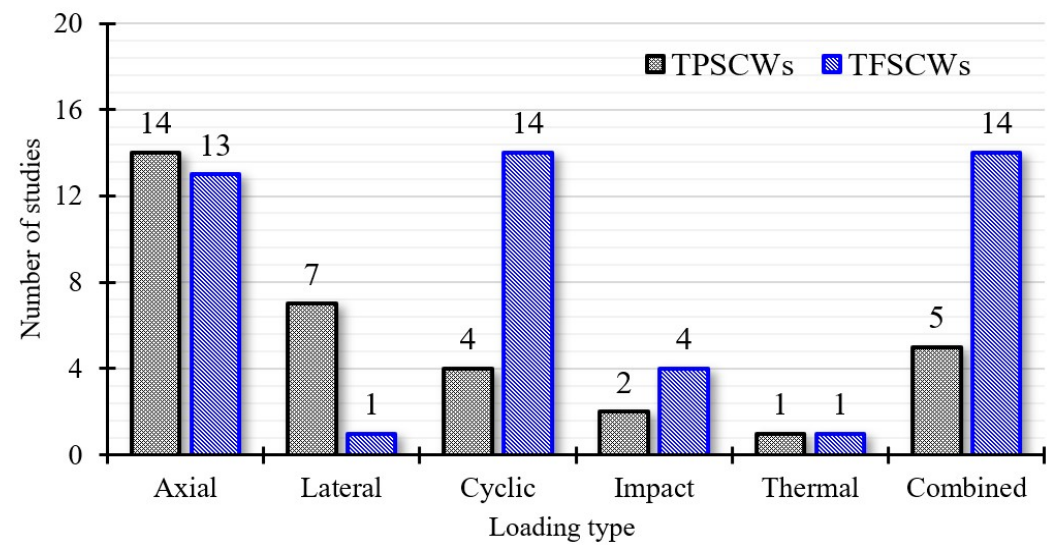

Figure 32. Statistics of previous studies of TSCW under the impact of different loadings

\subsubsection{TPSCWs}

Various investigations have considered the structural performance of TSCWs under different load types (i.e., axial, lateral, cyclic, thermal, impact, and combined loads) to report a comprehensive description of the efficiency of this $\mathrm{CW}$ type as a major element in structural bodies as a bearing and retaining member. According to this review, 14 studies considered the behavior of TPSCWs under axial load, 7 investigated the behavior of TPSCWs under lateral load, 4 analyzed the behavior of TPSCWs under cyclic load, 2 investigated the behavior of TPSCWs under impact load, 1 assessed the behavior of TPSCWs under thermal load, and 5 studies examined the behavior of TPSCWs under combined load, as shown in Figure 32.

However, major gaps and a lack of studies are observed in this review. For instance, limited studies have examined the influence of impact loading on TPSCW structural response, which is essential for understanding TPSCW performance and its efficiency in ensuring safety in facilities that require a high level of protection, such as nuclear facilities military bases.

The influence of explosion, impact, and thermal loading on TPSCWs were not taken adequately into account. Therefore, these fields have to be further investigated to provide sufficient data and deeper understanding for structural engineers to design structures sufficiently able to resist blast and thermal load. Accordingly, many future investigations are required to conduct to provide appropriate and thorough information about TPSCWs behavior.

\subsubsection{TFSCWs}

In brief, TFSCWs is one of the most efficient CWs systems and an effective alternative option to conventional RC and SPSW walls for the safety of nuclear facilities, military bases, high-rise buildings' core, and even regular structures, and that attributed to their load resistance capacity, durability, economical cost, and structural efficiency. This system was investigated with a multi-design configuration and subjected to different loading types (i.e., axial, lateral, cyclic, thermal, impact, and combined loads). In general, the findings in prior research observed that the TFSCWs could resist loading effectively with high ductility, which makes it a recommended option in the above-referred types of structures.

This review found that 13 studies considered TFSCW behavior under axial loads, 14 studied TFSCW behavior under cyclic loads, 1 investigated TFSCW behavior under lateral loads, 4 assessed TFSCW behavior under impact loads, only 1 analyzed TFSCW behavior under thermal loads, and 14 investigated TFSCW behavior under combined loads, as indicated in Figure 32.

However, this review paper has spotted a lack of studies and significant gaps in this field, for instance, the lack of investigations in the lateral and thermal loading on TFSCW structural behavior, as this topic is investigated by two studies only, which provides insufficient information on the wall behavior under these types of loading. Also, no studies have considered the behavior of this TSCW system under eccentric loading. Therefore, this study recommends that future studies consider the effects of eccentric, lateral, and thermal loads on TFSCWs' structural behavior to provide a deep understanding of TFSCWs and prove their efficiency under these types of loadings.

\subsection{Effect of openings}

Openings are an inevitable requirement for architects, mechanical, and structural designers in framed structures that consider TSCWs in their constructions. Studies had investigated the effects of openings on the structural performance of TSCWs insufficiently. To date, the influence of rectangular openings on TPSCW structural performance has been investigated 
by only one study Hossain (2000). Additionally, the impact of openings on the TFSCW structural response has not been investigated by any studies; briefly, there is only one opening case study for TPSCWs and none for TFSCWs.

Various gaps have been observed in the literature, mainly regarding the impacts of openings on the structural behavior of TSCWs system studies. Openings in the shear wall are typically desired for architectural purposes, structural aims and/or crossing multiple utilities, which might negatively affect the wall behavior. The effects of several shapes (circular, rectangular, square, trapezoidal, and triangular), sizes, and openings on the structural performance of TSCWs should be examined in the next studies. The application of openings results in negative side effects in similar walls and requires particular solutions. Hence, a strengthening technique and/or stiffening mechanism (embedded or external parts) and the interaction concept between the sheet plate and infill materials for the TSCWs system with opening must be considered in design criteria. This type of study is highly recommended; future researches should investigate the effects of multiple shapes, sizes, and locations of openings on TSCW behavior under varied types of loadings mentioned in this study, as well as to determine the most proper, sufficient, and practical solutions that can rectify the implications of openings on TSCW behavior.

\section{Conclusions}

A systematic review of the current state of the art of extensive investigations in the literature on TSCWs was conducted in this paper. The type of study (experimental, numerical and analytical), the forms of steel-plate sheets (flat or profiled plate), the applied load (axial, cyclic, lateral, impact, thermal, or combined loads), and the infill concrete type were used for classification propose new taxonomy of the current knowledge of TSCWs. Each investigation was discussed and summarized separately in paragraph form, including the studies' parameters, findings, discussion, and conclusions. Classifications and summaries of the data collected in the past 25 years are reported in Tables 2 and 4 . These tables include filler materials, composite interaction concepts, and study types (analytical studies, experimental research, and numerical investigations).

In previous decades, studies have been extensively conducted on the structural behavior of TSCWs. To understand the behavior of TSCWs, researchers have performed experiments and proposed analytical solutions. Several FE simulation programs were used to develop numerical models, such as LUSAS, ABAQUS, LS-DYNA, ANSYS, and MSC Marc, to further investigate the effects of other TSCW parameters that probably have not been tested experimentally for reasons of high cost. In general, the current review study shows that the implementation of FE simulations in this field is useful for predicting accurate TSCW behavior. The FE results have proven to be relatively consistent with the existing experimental data. Several analytical solutions have been developed and applied in numerous studies, such as steel sheet yielding theory, three-step method theory, modified compression field theory, lower bound theory, fixed angle theory, and yield line theory. The developed solutions are appropriate for predicting the shear capacity of TSCWs with different design configurations and under various types of loads, with accurate results relative to existing experimental data. The design codes (i.e., EC4, ACl, AISC, British, Australian, and Chinese standards) adopted multi analytical solutions, and the implementations are suitable for use; however, the solutions are considered overly conservative.

This review clearly and extensively describes the behavior of two types of TSCWs. However, several studies, gaps, and suggestions are proposed for future research. An insufficient number of studies have considered strengthening TSCWs with multiple shapes and sizes of embedded steel sections and/or members. Furthermore, very limited studies have investigated the effects of openings on TSCW behavior, which is commonly architecturally, mechanically, and/or structurally required. Studies on the connections between the TSCWs and composite floor systems (i.e., PSSDB systems) are lacking. Due to research limitations in the referred field, thorough studies must be carried out to investigate eccentric and thermal loading on TSCW behavior.

\subsection{Summary of conclusion}

A comprehensive systematic review focused on the TSCWs system research work during the prior 25 years was conducted to highlight the significant outcomes and gaps in the TSCWs system research field. The summary of the findings is listed in the following points

- The twin-layer composite panel system comprises double outside skin of steel sheets infilled with a certain filler material such as concrete. The core concrete interacts with the outsider steel sheets layers through shear connectors.

- $\quad$ The TSCWs system is categorized into two types of CWs based on the twin-layer steel sheet form, TFSCWs which include a twin-layer of flat steel sheet, and TPSCWs, which contain a twin-layer of profiled steel sheets. 
- $\quad$ Both types of TSCWs systems, TFSCWs and TPSCWs, have been used efficiently in different types of constructions as axial, lateral, cyclic, and impact resistance member

- $\quad$ One of the most significant applications of the TSCWs system as a shear wall in vertical buildings such as skyscrapers and was attributed to the properties provided by the TSCWs system, such as strength, rigidity, and energy absorption.

- $\quad$ The conducted research work in the TSCWs system field during the past 25 years investigated the structural behavior of the relevant member experimentally, numerically, and empirically.

- The structural response of TSCWs was investigated under different types of loading, including axial, cyclic, impact, thermal, lateral, and combined of more than one load.

- $\quad$ TPSCWs system was mainly implemented as an axial load-bearing wall due to the profiled shape of the twin-layer of steel sheets, which significantly improve the wall-bearing capacity by delaying the local buckling.

- $\quad$ TFSCWs system was majorly used as a lateral and cyclic loading due to the effective diagonal tensile resistance field provided by the flat twin-layer of steel sheet during any lateral movement. Not only but also as bearing core walls in vertical high-rise buildings simultaneously. Furthermore, in recent years, a research group in the USA focused mainly on investigating the structural response of the TFSCWs as a core wall shield in nuclear power plants. It showed reliable and effective blast resistance properties.

- $\quad$ TPSCWs system requires substantial additional research work to comprehend the structural behavior of TPSCWs under the cyclic, impact, and thermal loading in a better way as the literature review demonstrated a crucial lack of knowledge in this field.

- Most of the conducted research on the TPSCWs system used bolts and/or fasteners to provide the composite action between the twin-layer of steel sheets and the concrete. An alternative, practical, fast, and effective method providing steel-concrete interaction is highly required.

- $\quad$ As a prime bearing wall, TPSCWs require further investigation with the high-strength concrete as a filler material. This type of concrete delays the crushing and spalling phenomenon, the predominant failures significantly, thereby improving the wall bearing capacity sufficiently.

- $\quad$ Both types of TSCWs systems, TFSCWs and TPSCWs, can be fabricated under the Industrial Building System, which substantially saving construction time. Furthermore, openings such as doors and windows can be applied in both TSCWs systems, which provides an important architecture option.

- $\quad$ The empirical studies on both types of TSCWs systems, TFSCWs and TPSCWs were the less among the collected studies in this field, and that was attributed to the diversity of these walls configuration and details. Due to that, and considering that empirical studies require a significant amount of accurate and precise data on a specific wall configuration, this review observed fewer empirical studies conducted in this field.

- $\quad$ Failure mode in TSCWs system exposed to cyclic loading initiate to occur as spalling and crushing the concrete-toe of the wall, while under axial load start to obseve in twin-layer of steel plate as outward local bucking.

\subsection{Recommendations for future work}

- $\quad$ Due to the obvious lack of studies on the TFSCWs and TPSCWs system under numerous types of loading indicated in Table 3 and 4, this study suggests investigating the behavior of the TFSCWs and TPSCWs system under the impact, blast, and thermal loading. It should be noted that the TFSCW has the advantage of being used as a resistant shield at highly sensitive locations such as nuclear power plants, army and military bases.

- The boundary frame is playing a significant role in the overall shear capacity of frame shear walls. Recent frame structures used several structural members (beams and columns), such as a concrete-filled tube. Due to the related desired characteristics of these members, it can be used as a boundary frame for the TFSCWs and TPSCWs system. Therefore, investigating the effect of different types and combinations of boundary frames on the structural behavior of the TFSCWs and TPSCWs system is highly recommended.

- $\quad$ Carbon fiber reinforced polymer (CFRP) is an extremely lightweight tensile resistant material that has several implementations in improving the structural members' capacity. Since the SSP layers of the TFSCWs and TPSCWs system have experienced high tensile and local buckling forces, investigating the effect of the CFRP wrapping scheme on the strengthening response of the TFSCWs TPSCWs system is required. 
- Different types of concrete named Engineered Cementitious Composite (ECC) have high ductility, tensile force resistance, long life cycle, and high compressive strength than ordinary concrete. These characteristics could be highly useful for infill material in shear walls. Hence, investigating the cyclic behavior of engineered cementitious composite concrete-filled TFSCWs and TPSCWs systems is remarkably recommended

- Generally, the prior studies focused on strengthening the composite walls by mostly internal stiffeners scheme, which was for architectural reasons and to prevent any disturbance in the indoor space. However, the external stiffeners could be significantly needed, especially for strengthening purposes after the construction stage. Therefore, investigating the TFSCWs and TPSCWs system's strengthening behavior with external stiffeners is vastly required to be explored.

- Different shapes of openings, such as square and rectangular, are similarly required to open doors and windows in buildings. Therefore, the effect of different shapes of openings on the structural behavior of the TFSCWs and TPSCWs system is required for further investigations.

- In order to obtain more accurate results, the structural behavior of the TFSCWs and TPSCWs system infilled with different lightweight concrete compressive strengths is required to be examined experimentally

- Researchers need to put more effort into implementing recycled materials such as recycled aggregates and recycled plastic in future research work. These materials can be extracted from classified rabish and demolished constructions, respectively. The purpose of using the referred materials is to preserve the natural resources and following the global orientation toward the green environment.

\section{Acknowledgments}

The writers gratefully acknowledge the support of this research by Universiti Kebangsaan Malaysia (UKM) and the Fundamental Research Grant Scheme, Ministry of Education, Malaysia under Grant code: FRGS/1/2018/TK01/UKM/02/1.

Author contribuitions: Conceptualization, Investigation and Writing - original draft, Mustafa M. Ali; Supervision and Writing - review \& editing, S.A. Osman and Al Zand AW; Data curation and Visualization, Faesal Alatshana, Salam J. Hilo and M.Y.M. Yatim

Editor: Marcílio Alves

\section{References}

2018, AS 3600. (2018). Concrete Structure. Standard Australia / Concrete Institute of Australia

$\mathrm{ACl}, 349$ Committee. 2006. Code requirements for nuclear safety-related concrete structures (aci 349 m-06) and commentary. In American Concrete Institute, Farmington Hills.

Astaneh-Asl, Abolhassan, and Qiuhong Zhao. (2004). Cyclic Behavior of Traditional and Innovative Composite Shear Walls. Journal of Structural Engineering 130 (2):271-284.

Aykac, Sabahattin, Ilker Kalkan, and Mahmut Seydanlioglu. (2014). Strengthening of hollow brick infill walls with perforated steel plates. Earthquakes and Structures 6 (2):181-199.

BEng, Stephen Hicks, and Silwood Park. 1994. EN 1994-Eurocode 4: Design of composite steel and concrete structures: Report of e Steel Construction Institute, Berkshire, UK.

Bradford, Mark Andrew, HD Wright, and B Uy. (1998). Short and Long Term Behaviour of Axially Loaded Composite Profiled Walls. Proceedings of the Institution of Civil Engineers-Structures and Buildings 128 (1):26-37.

Bruhl, Amit H. Varma, and William H Johnson. (2015). Design of composite SC walls to prevent perforation from missile impact. International Journal of Impact Engineering 75:75-87).

Bruhl, Jakob C, and Amit H Varma. (2018). Experimental Evaluation of Steel-Plate Composite Walls Subject to Blast Loads. Journal of Structural Engineering 144 (9):04018155. 
Bruhl, Jakob C., Amit H. Varma, and William H. Johnson. (2015a). Design of composite SC walls to prevent perforation from missile impact. International Journal of Impact Engineering 75:75-87.

BS8110. 1985. Standards Institute Structural use of Concrete British,. In Code of practice for design and construction,. Part 1,.

Cao, Pingzhou, Ningning Feng, and Kai Wu. (2014). Experimental study on infilled frames strengthened by profiled steel sheet bracing. Steel and Composite Structures 17 (6):777-790.

Carbonari, G., S. H. P. Cavalaro, M. M. Cansario, and A. Aguado. (2012). Flexural behaviour of light-weight sandwich panels composed by concrete and EPS. Construction and Building Materials 35:792-799.

Choi, Byong-Jeong, Cheol-Kyu Kang, and Ho-Young Park. (2014). Strength and behavior of steel plate-concrete wall structures using ordinary and eco-oriented cement concrete under axial compression. Thin-Walled Structures 84:313-324.

Choi, Byong-Jeong, Won-Ki Kim, Woo-Bum Kim, and Cheol-Kyu Kang. (2013). Compressive performance with variation of yield strength and width-thickness ratio for steel plate-concrete wall structures. Steel and Composite Structures 14 (5):473-491.

Clubley, Simon K, Stuart SJ Moy, and Robert Y Xiao. (2003). Shear strength of steel-concrete-steel composite panels. Part Itesting and numerical modelling. Journal of Constructional Steel Research 59 (6):781-794.

Clubley, Simon K, Stuart SJ Moy, and Robert Y Xiao. (2003). Shear strength of steel-concrete-steel composite panels. Part IIdetailed numerical modelling of performance. Journal of Constructional Steel Research 59 (6):795-808.

Dean, R Gordon, Ted J Canon, and Chris D Poland. 1977. Unusual structural aspects of HC Moffit Hospital. Paper read at Proceedings of the 46th Annual Convention, SEAOC, Coronado, CA.

Edalati, SA, Y Yadollahi, I Pakar, A Emadi, and M Bayat. (2014). Numerical study on the performance of corrugated steel shear walls. Wind and Structures 19 (4):405-420.

Eom, Tae-Sung, Hong-Gun Park, Cheol-Ho Lee, Jin-Ho Kim, and In-Hwa Chang. (2009). Behavior of Double Skin Composite Wall Subjected to In-Plane Cyclic Loading. Journal of Structural Engineering 135 (10):1239-1249.

Epackachi, Siamak, Nam H Nguyen, Efe G Kurt, Andrew S Whittaker, and Amit H. Varma. 2013. An experimental study of the in-plane response of steel-concrete composite walls. Paper read at Structural Mechanics in Reactor Technology Conference (SMiRT-22), San Francisco, California, USA.

Epackachi, Siamak, Nam H. Nguyen, Efe G. Kurt, Andrew S. Whittaker, and Amit H. Varma. (2014a). In-Plane Seismic Behavior of Rectangular Steel-Plate Composite Wall Piers. Journal of Structural Engineering 141 (7):04014176-04014176.

Epackachi, Siamak, Nam H. Nguyen, Efe G. Kurt, Andrew S. Whittaker, and Amit H. Varma. (2014b). Numerical and Experimental Investigation of the In-Plane Behavior of Rectangular Steel-Plate Composite Walls. (1989):2478-2487.

Epackachi, Siamak, Andrew S Whittaker, and Yin Nan Huang. (2015). Analytical modeling of rectangular SC wall panels. Journal of Constructional Steel Research 105:49-59.

Epackachi, Siamak, Andrew S. Whittaker, and Amjad Aref. (2017). Seismic analysis and design of steel-plate concrete composite shear wall piers. Engineering Structures 133 (January):105-123.

Fukumoto, T., B. Kato, K. Sato, K. Toyama labse Report, and Undefined. (1987). Concrete filled steel bearing walls. IABSE Symposium, Paris-Versailles.

Haghi, Nakisa, Siamak Epackachi, and Mohammad Taghi Kazemi. (2020). Macro modeling of steel-concrete composite shear walls. Structures 23 (October 2019):383-406.

Hibbitt, Karlsson, and Sorensen. 2002. Abaqus/CAE User's Manual: Hibbitt, Karlsson \& Sorensen, Incorporated.

Hilo, Salam J., W. H. Wan Badaruzzaman, S. A. Osman, and Ahmed W. Al-zand. (2016). Structural behavior of composite wall systems strengthened with embedded cold-formed steel tube. Thin Walled Structures 98:607-616.

Hilo, Salam Jasim, Wan Hamidon Wan Badaruzzaman, Siti Aminah Osman, and Ahmed W Al Zand. (2014). Effect of Rectangular Cold-Formed Steel on the Behavior of Double-Skinned Profiled Steel Sheet In-Filled With Concrete under Axial Load. Int. J. Adv. Agric. Environ. Eng. 1.

Hilo, Salam Jasim, Wan Hamidon, Wan Badaruzzaman, S. A. Osman, and Ahmed W. Al Zand. (2015). Axial Load Behavior of. Composite Wall Strengthened with an Embedded Octagon Cold-Formed Steel. 437-441. 
Hilo, Salam, Wan Hamidon Wan Badaruzzaman, Siti Aminah Osman, and Ahmed W Al Zand. (2015a). Axial Load Behavior of Acomposite Wall Strengthened with an Embedded Octagon Cold-Formed Steel. Paper read at Applied Mechanics and Materials .

Hossain, Shahryar Rafiei, Mohamed Lachemi, and Kamran Behdinan. (2016). Finite element modeling of impact shear resistance of double skin composite wall. Thin-Walled Structures 107:101-118.

Hossain, Shahryar Rafiei, Mohamed Lachemi, and Kamran Behdinan. (2016). Structural performance of profiled composite wall under in-plane cyclic loading. Engineering Structures 110:88-104.

Hossain, K. M. A., and H. D. Wright. 1998a. Shear interaction between sheeting and concrete in profiled composite construction, 1998a.

Hossain, K. M. Anwar. (2000). Axial load behaviour of pierced profiled composite walls. The Institution of Professional Engineers New Zealand:1-7.

Hossain, K. M. Anwar, and H. D. Wright. (2004d). Performance of double skin-profiled composite shear walls - experiments and design equations. Canadian Journal of Civil Engineering 31 (2):204-217.

Hossain, KM Anwar. (2000). Axial load behaviour of pierced profiled composite walls. In IPENZ Conference, . New Zealand,. Hossain, KM Anwar, and HD Wright. (1998). Performance of profiled concrete shear panels. Journal of Structural Engineering $124(4): 368-381$.

Hossain, KM Anwar, and HD Wright. (1998). Shear interaction between sheeting and concrete in profiled composite construction. Paper read at Proceedings of the Australasian Structural Engineering Conference, Auckland.

Hossain, KM Anwar, and HD Wright. (2004b). Behaviour of composite walls under monotonic and cyclic shear loading. Structural Engineering and Mechanics 17 (1):69-85.

Hossain, KM Anwar, and HD Wright. (2004). Design aspects of double skin profiled composite framed shearwalls in construction and service stages. Structural Journal 101 (1):94-102.

Hossain, KM Anwar, and HD Wright. (2004a). Experimental and theoretical behaviour of composite walling under in-plane shear. Journal of Constructional Steel Research 60 (1):59-83.

Hossain, KM Anwar, and HD Wright. (2004c). Flexural and shear behaviour of profiled double skin composite elements. Steel and Composite Structures 4 (2):113-132.

Hossain, KM Anwar, and HD Wright. (2004d). Performance of double skin-profiled composite shear walls-experiments and design equations. Canadian Journal of civil engineering 31 (2):204-217.

Hossain, KM Anwar, and HD Wright. (2005). Finite element modelling of the shear behaviour of profiled composite walls incorporating steel-concrete interaction. Structural Engineering and Mechanics 21 (6):659-676.

Hossain, KM Anwar, and HD Wright. 2005. Steel-Concrete Interaction in Double Skin Profiled Composite Walls: Development of Finite Element Model. In 33rd Annual General Conference of the Canadian Society for Civil Engineering. Toronto, Ontario, Canada,: 2005b, pp. 1-9.

Hu, Hong-Song, Jian-Guo Nie, and Matthew R Eatherton. (2014). Deformation capacity of concrete-filled steel plate composite shear walls. Journal of Constructional Steel Research 103:148-158.

Ji, Xiaodong, Feiming Jiang, and Jiaru Qian. (2013). Seismic behavior of steel tube-double steel plate-concrete composite walls: experimental tests. Journal of Constructional Steel Research 86:17-30.

Johnson, William H, Jakob C. Bruhl, Damon G Reigles, Jie Li, and Amit H. Varma. 2014. Missile Impact on SC Walls: Global Response. Paper read at Structures Congress 2014.

Kanchi, Masaki, T Kitano, R Sugawara, and K Hirakawa. 1996. Experimental study on a concrete filled steel structure Part. 2 Compressive Tests (1). Paper read at Summary of technical papers of annual meeting, architectural institute of Japan, Structures.

Kim, Woo Bum, and Byong Jeong Choi. (2011a). Shear strength of connections between open and closed steel-concrete composite sandwich structures. Steel and Composite Structures 11 (2):169-181.

Labibzadeh, Mojtaba, and Reza Hamidi. (2019). A Comparison Between Shear Capacities of Two Composite Shear Walls: DSCSWs and CSPSWs. Structural Engineering International 29 (2):276-281. 
Liang, Qing Quan, Brian Uy, HD Wright, and Mark A. Bradford. (2004). Local Buckling of Steel Plates in Double Skin Composite Panels under Biaxial Compression and Shear. Journal of Structural Engineering 130 (3):443-451.

Link, RA, and AE Elwi. (1995). Composite concrete-steel plate walls: analysis and behavior. Journal of Structural Engineering $121(2): 260-271$.

LS-DYNA. 2012a. Keyword User's Manual,Volume I, in, Livermore Software Technology Corporation (LSTC),, Livermore, CA, USA.

LS-DYNA. 2012b. Keyword User's Manual, Volume II, in, Livermore Software Technology Corporation (LSTC),, Livermore, CA, USA

Ma, Kaize, Yudong Ma, and Boquan Liu. (2019). Quasistatic Cyclic Tests and Finite Element Analysis of Low-Aspect Ratio Double Steel Concrete Composite Walls. Advances in Civil Engineering 2019.

Mullapudi, TRS, Paul Summers, and II-Hwan Moon. 2012. Impact analysis of steel plated concrete wall. Paper read at Structures Congress 2012.

Mydin, Md Azree Othuman, and YC Wang. (2011). Structural performance of lightweight steel-foamed concrete-steel composite walling system under compression. Thin-Walled Structures 49 (1):66-76.

Nguyen, Nam H, and Andrew S Whittaker. (2017). Numerical modelling of steel-plate concrete composite shear walls. Engineering Structures 150:1-11.

Nie, Jian-Guo, Hong-Song Hu, Jian-Sheng Fan, Mu-Xuan Tao, Sheng-Yong Li, and Fu-Jun Liu. (2013). Experimental study on seismic behavior of high-strength concrete filled double-steel-plate composite walls. Journal of Constructional Steel Research 88:206-219.

Nie, Jian-Guo, Xiao-Wei Ma, Mu-Xuan Tao, Jian-Sheng Fan, and Fan-Min Bu. (2014). Effective stiffness of composite shear wall with double plates and filled concrete. Journal of Constructional Steel Research 99:140-148.

Ozaki, Masahiko, Shodo Akita, Hiroshi Osuga, Tatsuo Nakayama, and Naoyuki Adachi. (2004). Study on steel plate reinforced concrete panels subjected to cyclic in-plane shear. Nuclear Engineering and Design 228 (1-3):225-244.

Petkune, Natalja, Ted Donchev, Homayoun Hadavinia, Mukesh Limbachiya, and David Wertheim. (2016). Performance of pristine and retrofitted hybrid steel/fibre reinforced polymer composite shear walls. Construction and Building Materials 117:198-208.

Prabha, P, V Marimuthu, M Saravanan, GS Palani, N Lakshmanan, and R Senthil. (2013). Effect of confinement on steel-concrete composite light-weight load-bearing wall panels under compression. Journal of Constructional Steel Research 81:11-19.

Qian, Jiaru, Zao Jiang, and Xiaodong Ji. (2012). Behavior of steel tube-reinforced concrete composite walls subjected to high axial force and cyclic loading. Engineering Structures 36:173-184.

Rafiei, Shahryar, KM Anwar Hossain, Mohamed Lachemi, and Kamran Behdinan. 2010. Shear buckling of profiled steel sheets under in-plane monotonic loadings. Paper read at Proceedings of CSCE 2nd international structures specialty conference, Winnipeg, Manitoba.

Rafiei, Shahryar, KM Anwar Hossain, Mohamed Lachemi, and Kamran Behdinan. (2015). Profiled sandwich composite wall with high performance concrete subjected to monotonic shear. Journal of Constructional Steel Research 107:124-136.

Rafiei, Shahryar, KM Anwar Hossain, Mohamed Lachemi, and Kamran Behdinan. (2017). Impact shear resistance of double skin profiled composite wall. Engineering Structures 140:267-285.

Rafiei, Shahryar, KM Anwar Hossain, Mohamed Lachemi, Kamran Behdinan, and MS Anwar. (2013). Finite element modeling of double skin profiled composite shear wall system under in-plane loadings. Engineering Structures 56:46-57.

Rahnavard, Rohola, Akbar Hassanipour, and Ali Mounesi. (2016). Numerical study on important parameters of composite steel-concrete shear walls. Journal of Constructional Steel Research 121:441-456.

Ramin, Keyvan, and Mitra Fereidoonfar. (2015). Finite Element Modeling and Nonlinear Analysis for Seismic Assessment of Off-Diagonal Steel Braced RC Frame. International Journal of Concrete Structures and Materials 9 (1):89-118.

Rosario-Galanes, Osvaldo, and Luis A. Godoy. (2014). Modeling of wind-induced fatigue of cold-formed steel sheet panels. Structural Engineering and Mechanics 49 (2):237-259.

Sahmaran, Mustafa, Mohamed Lachemi, KM Anwar Hossain, Ravi Ranade, and Victor C. Li. (2009). Influence of aggregate type and size on ductility and mechanical properties of engineered cementitious composites. ACI Materials Journal 106 (3):308-316. 
Sekimoto, Hiroshi Akiyama Hisashi, Mamoru Tanaka, Kunio Inoue, Masaaki Fukihara, and Yutaka Okuda. (1989). 1/10th scale model test of inner concrete structure composed of concrete filled steel bearing wall.

Seo, Jungil, and Amit H. Varma. (2017). Behavior and design of steel-plate composite wall-to-wall corner or L-joints. Nuclear Engineering and Design 323:317-328.

Seo, Jungil, Amit H. Varma, Kadir Sener, and Deniz Ayhan. (2016). Steel-plate composite (SC) walls: In-plane shear behavior, database, and design. Journal of Constructional Steel Research 119 (January 2011):202-215.

Song, Xiaobing, Meng Chu, Honghui Ge, and Hailin Wang. 2014. A Failure Criterion for Steel-Concrete Composite Walls. In Sustainable Development of Critical Infrastructure.

Takeda, T, T Yamaguchi, T Nakayama, Kz Akiyama, and Yz Kato. (1995). Experimental study on shear characteristics of a concrete filled steel plate wall.

Taormina, K.M.A.H. A. 2012. Behaviour of profiled composite walling system under elevated temperatures. In Annual Conference of the Canadian Society for Civil Engineering Leadership in Sustainable Infrastructure, Canada, edited by CSCE.

Terranova, B, Siamak Epackachi, and AS Whittaker. 2017. Effect of out-of-plane loading on the in-plane response of SC wall piers. Paper read at Proceedings, 16th World Conference on Earthquake Engineering.

Tomlinson, M. J., A. Tomlinson, M. Li Chapman, A. D. Jefferson, and HD Wright. 1989. Shell composite construction for shallow draft immersed tube tunnels.

Uy, Brian, HD Wright, and MA Bradford. (2001). Combined axial and flexural strength of profiled composite walls. Proceedings of the Institution of Civil Engineers-Structures and Buildings 146 (2):129-139.

Varma, Amit H, Sanjeev R Malushte, Kadir C Sener, and Zhichao Lai. (2014). Steel-plate composite (SC) walls for safety related nuclear facilities: Design for in-plane forces and out-of-plane moments. Nuclear Engineering and Design 269:240-249.

Varma, Amit H., Sanjeev R. Malushte, Kadir C. Sener, and Zhichao Lai. (2011). Steel-plate composite (SC) walls for safety related nuclear facilities: Design for in-plane and out-of-plane demands. Transactions, SMiRT 21, 6-11 November, 2011, New Delhi, India 269 (c):240-249.

Varma, Amit H., SR Malushte, KC Sener, and PN Booth. 2012. Analysis recommendations for steel-composite (SC) walls of safety-related nuclear facilities. Paper read at Structures Congress 2012.

Varma, Amit H., and Kadir Sener. (2013). Lateral Load Behavior of a Containment Internal Structure.

Varma, Amit H., Kai Zhang, Hoseok Chi, Peter Booth, and Tod Baker. 2011. In-plane shear behavior of SC composite walls: theory vs. experiment. Paper read at Proceedings of the 21st IASMiRT Conference (SMiRT 21).

Wang, Dengfeng, Yongfu Yu, Licheng Pan, and Haijin Dai. (2014). Study of Load Bearing Capacity of Profiled Steel Sheet Wall Subjected to Combined Bending and Vertical Compression in Electrostatic Precipitator. The Open Mechanical Engineering Journal 8 (1).

Wright, H. D., T. O. S. Oduyemi, and H. R. Evans. (1991a). The experimental behaviour of double skin composite elements. Journal of Constructional Steel Research 19 (2):97-110.

Wright, HD. (1998). The Axial Load Behaviour of Composite Walling. Journal of Constructional Steel Research 45 (3):353-375.

Wright, HD, and Gallocher. (1995). The behaviour of composite walling under construction and service loading. Journal of Constructional Steel Research 35 (3):257-273

Wright, HD, KM Anwar Hossain, and Stewart Gallocher. 1994. Composite walls as shear elements in tall structures. Paper read at Structures Congress XII.

Wright, HD, T. O. S. Oduyemi, and H. R. Evans. (1991). The design of double skin composite elements. Journal of Constructional Steel Research 19 (2):111-132.

Wu, Yun-tian, Dao-yang Kang, and Yeong-Bin Yang. (2016). Seismic performance of steel and concrete composite shear walls with embedded steel truss for use in high-rise buildings. Engineering Structures 125:39-53.

Xiaowei, Ma, Nie Jianguo, and Tao Muxuan. (2013). Nonlinear Finite-Element Analysis of Double-Skin Steel-Concrete Composite Shear Wall Structures. International Journal of Engineering and Technology 5 (6):648-652. 
Yan, Jia-Bao, Zhong-Xian Li, and Tao Wang. (2018). Seismic behaviour of double skin composite shear walls with overlapped headed studs. Construction and Building Materials 191:590-607.

Yan, Jia Bao, Hui Ning Guan, Yan Yan Yan, and Tao Wang. (2020a). Numerical and parametric studies on SCS sandwich walls subjected to in-plane shear. Journal of Constructional Steel Research 169:106011-106011.

Yan, Jia Bao, Yan Yan Yan, and Tao Wang. (2020). Cyclic tests on novel steel-concrete-steel sandwich shear walls with boundary CFST columns. Journal of Constructional Steel Research 164:105760-105760.

Zhang, Kai, Amit H Varma, Sanjeev R Malushte, and Stewart Gallocher. (2014). Effect of shear connectors on local buckling and composite action in steel concrete composite walls. Nuclear Engineering and Design 269:231-239.

Zhang, Wenyuan, Ke Wang, Yong Chen, and Yukun Ding. (2019). Experimental study on the seismic behaviour of composite shear walls with stiffened steel plates and infilled concrete. Thin-Walled Structures 144:106279.

Zhang, Xiaomeng, Ying Qin, and Zhihua Chen. (2016). Experimental seismic behavior of innovative composite shear walls. Journal of Constructional Steel Research 116:218-232.

Zhao, Weiyi, Quanquan Guo, Zeyu Huang, Li Tan, Jun Chen, and Yinghua Ye. (2016). Hysteretic model for steel-concrete composite shear walls subjected to in-plane cyclic loading. Engineering Structures 106:461-470.

\section{Notations}

Fy Yield strength of steel

K Strength coefficient

N Axial compression force

$f_{t x}$ TFSCW tension yield stress

$f_{c x}$ TFSCW compression yield stress

$f_{\text {ty }}$ Steel plate (SP) tension yield stress

$f_{c y} \mathrm{SP}$ compression yield stress

$\mathrm{H}$ Length of the wall

$\Delta c$ Shortening of concrete strut

$\Delta s$ Elongation of SP in horizontal direction

$\varphi c$ The drift angle

$\varepsilon_{\mathrm{cp}}$ Strain at the compression edge

$\mathrm{M}_{\mathrm{m}}$ Maximum bending moment

$\mathrm{F}_{\mathrm{co}}$ Concrete compressive strength

n Axial force ratio

$f^{\prime}{ }_{c}$ Concrete compressive strength

$f_{p}$ Yield strength of SP

$f_{a}$ Yield strength of steel tube

$A_{p}$ Area of steel plate

$A_{a}$ Area of steel tube

$\mathrm{P}_{\mathrm{n}}$ Nominal compressive strength

$A_{c}$ Area of core concrete

$\mathrm{El}_{\text {eff }}$ Effective flexural stiffness

$I_{s}$ Moment of inertia

$E_{s}$ Steel modules of elasticity

A Reduction factor

$\checkmark$ max Maximum shear strain

$\tau$ max Maximum shear stress

$P_{E C 4}$ Ultimate axial load for Euro Code

$A_{s}$ Area of steel materials

$b$ Width of SP

$t$ Thickness of SP

$\alpha$ Adjusting coefficient 
$\rho$ Adjusting coefficient

$N_{s}$ Ultimate axial load

$f_{c u}$ Concrete compressive strength

$b_{\text {eff }}$ Effective width of the TPSCW

$P$ The diagonal force

$\triangle$ Diagonal deformation

$\checkmark$ Panel shear force

$\delta$ Shear displacement

$\mathrm{El}_{\text {cr-tr }}$ Cracked-transform flexural stiffens

$f^{\prime}{ }_{c}$ Cylinder tensile strength of concrete

$f_{c u}^{\prime}$ Cube tensile strength of concrete

$f^{\prime}{ }_{t}$ Splitting tensile strength of concrete

$D_{x}$ Orthotropic constants for the PSS

$D_{y}$ Orthotropic constants for the PSS

$\beta$ Co-efficient ranging (1.00-1.72)

$N$ Modular ratio

$\varphi$ Factor can be taken from $\mathrm{ACl}$ code

$t_{e q c}$ Effective width of the concrete

$t_{e q s}$ Equivalent thickness of steel skins

$f_{y}^{e}$ Flexural resistance of the SP

$\gamma$ Interaction factor

$\mathrm{M}_{\mathrm{o}}$ Flexural strength at the wall bottom

$\mathrm{N}_{\mathrm{c}}$ Axial compressive force

$\mathrm{N}_{\text {CFST }}$ Reaction forces in compression

$\mathrm{N}_{\text {sw }}$ Reaction forces in tension

$\mathrm{L}_{\mathrm{w}}$ Factor (PSS thickness $\times 4$ )

$\mu$ Friction coefficient 